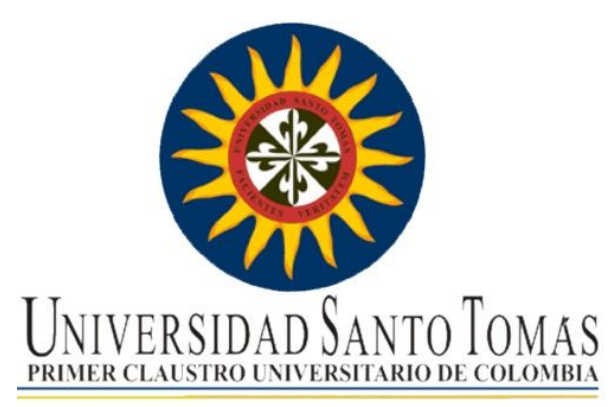

\title{
¿EXISTEN SALARIOS DE EFICIENCIA EN EL SECTOR BANANERO DE URABÁ - COLOMBIA?
}

\author{
Diana Patricia Gutiérrez Mejía \\ Víctor Hugo Nauzán Ceballos
}

\author{
Universidad Santo Tomás \\ Maestría en Ciencias Económicas \\ Bogotá D.C., Colombia \\ 2015
}




\title{
¿EXISTEN SALARIOS DE EFICIENCIA EN EL SECTOR BANANERO DE URABÁ - COLOMBIA?
}

\author{
Diana Patricia Gutiérrez Mejía \\ Víctor Hugo Nauzán Ceballos
}

Tesis presentada como requisito parcial para optar al título de:

Magíster en Ciencias Económicas

Director (a): Doctor Gustavo Díaz

Universidad Santo Tomás

Facultad de Economía. Maestría en Ciencias Económicas

Bogotá, D.C. Colombia

2015 


\section{Resumen}

Esta investigación pretende determinar la existencia de salarios de eficiencia en el sector bananero de Urabá mediante un modelo probit, basado en las teorías de salarios de eficiencia de Shapiro -Stiglitz y otros autores como Bulkley y Myles. Para esto se realizó una prueba piloto mediante un trabajo de campo, aplicando una encuesta en algunos trabajadores del sector que permitieron observar y medir el impacto que tiene la productividad de cada trabajador en los salarios recibidos los cuales se pueden considera eficientes.

Palabras Clave: Sector Bananero, Salarios de Eficiencia, Salario Mínimo, Sindicatos, Productividad, Bienestar 


\section{Contenido}

Pág.

Resumen $\mathrm{vi}$

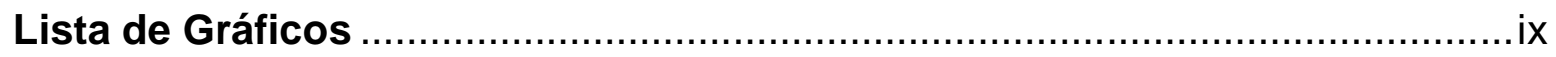

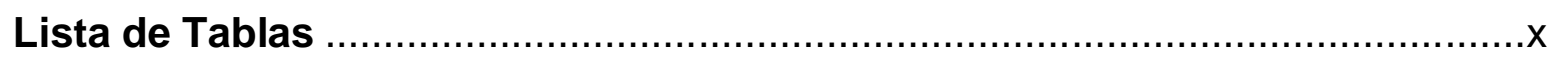

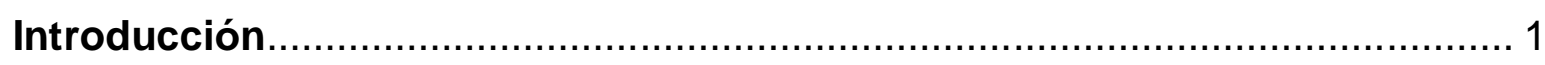

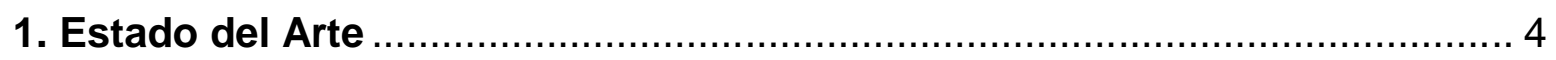

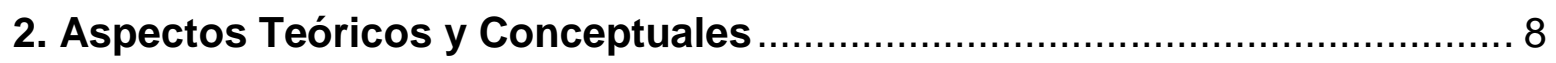

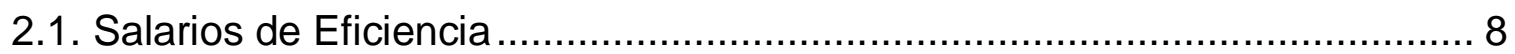

3. Determinación de los Salarios de Eficiencia en el Sector Bananero de Urabá

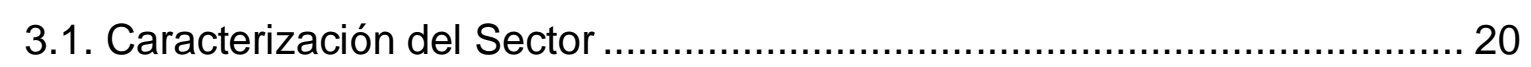

3.1.1. La Agroindustria En Colombia .................................................... 20

3.1.2. Agroindustria Bananera En Colombia.................................................. 22

3.1.3. Sector Bananero Zona de Urabá ...................................................... 29

3.1.4. Estructura Salarial Urabá ................................................................ 33

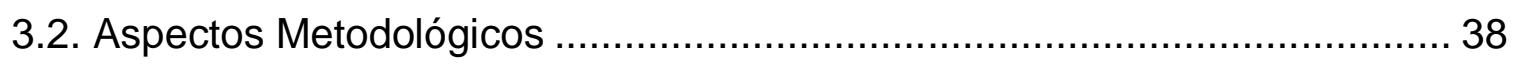

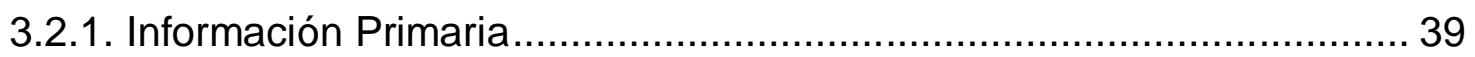

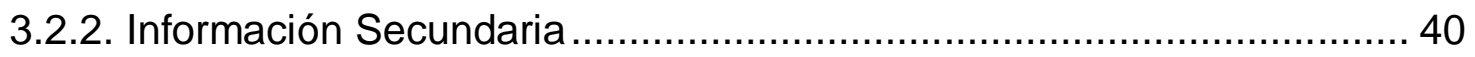

3.3. Modelo Probit en la Determinación de los Salarios de Eficiencia................ 41

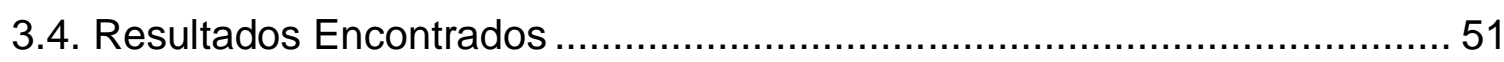

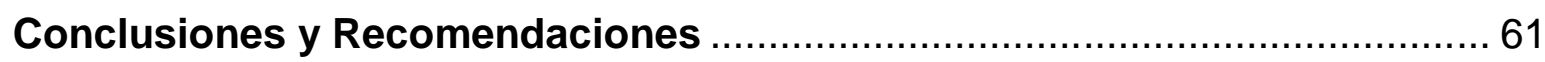

Anexo 1. Cambios Legales en el Salario Mínimo en Colombia ..................... 65

Anexo 2. Salario Mínimo Legal en Colombia ................................................. 66

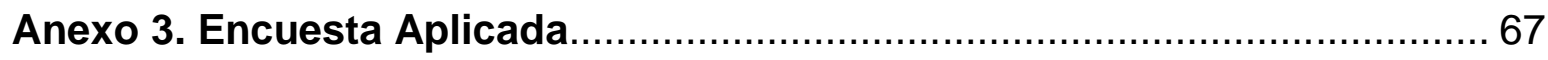

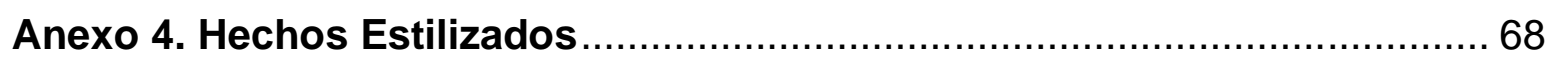

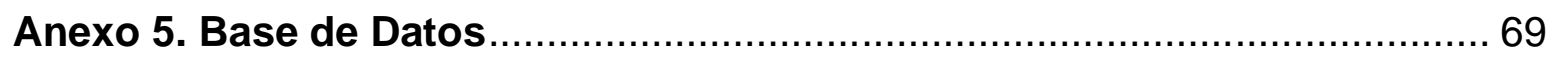

Anexo 6. Variables Explicativas Modelo Logit y Probit ............................... 71

Anexo 7. Modelo Probit Propuesto (Efectos Marginales) ............................ 72

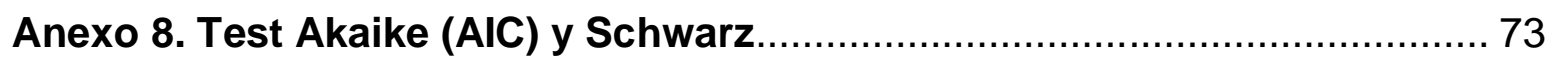

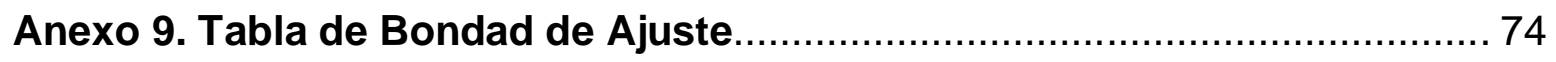




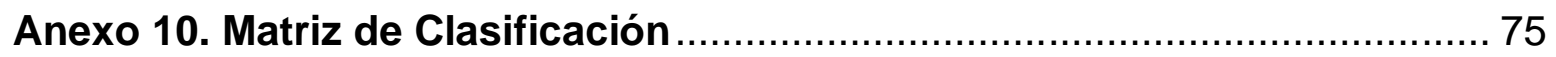

Anexo 11. Curva ROC (Receiver Operating Characteristic) ...................... 76

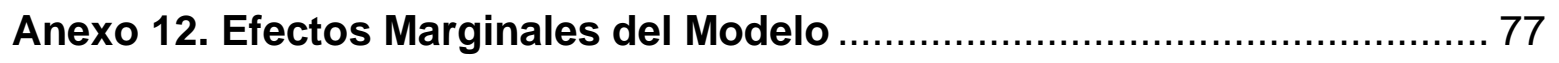

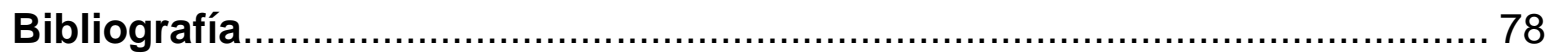




\section{Lista de Gráficos}

Pág.

Gráfico 1: participación de la agricultura en el PIB y el empleo en América Latina (1990 - 2012) 17

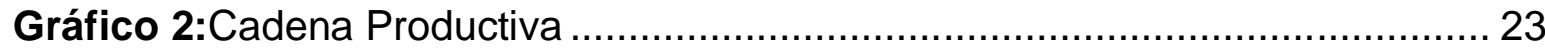

Gráfico 3: Zona Bananera de Santa Marta......................................................... 24

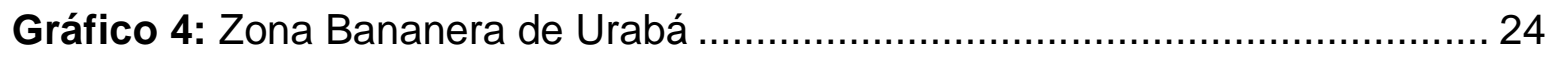

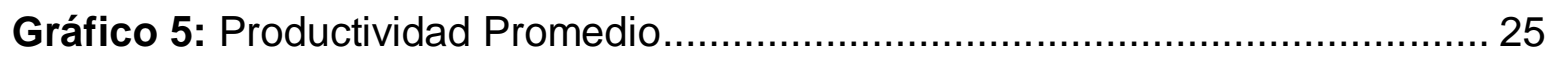

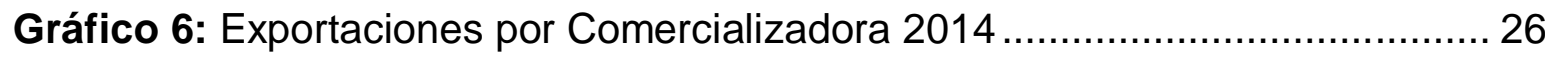

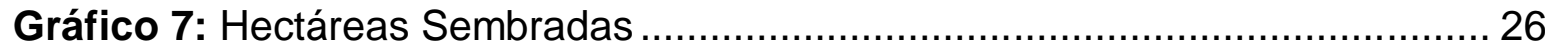

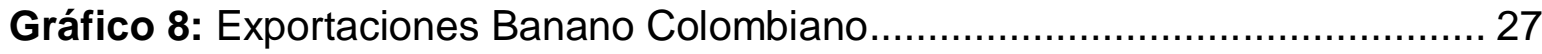

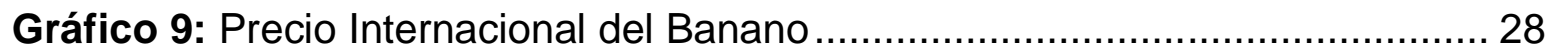

Gráfico 10:Distribución Geográfica Empresas Bananeras Urabá ....................... 30

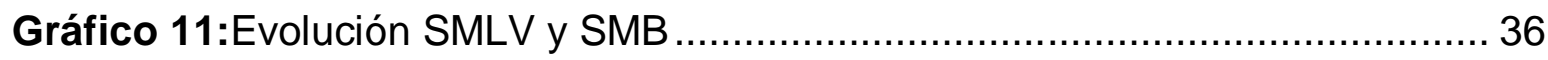

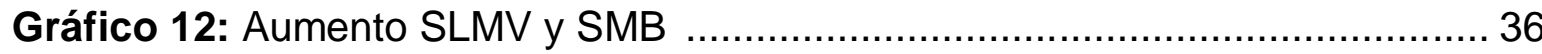




\section{Lista de Tablas}

Pág.

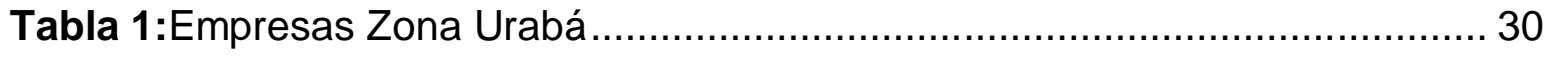

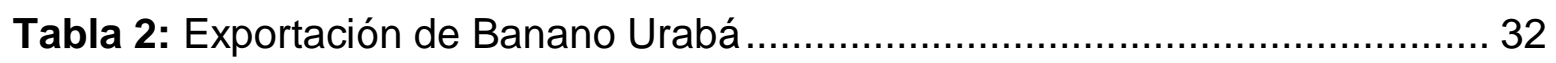

Tabla 3:Exportación de Banano Urabá por Puerto de Destino ............................ 33

Tabla 4:Salario Mínimo Legal Vs. Salario Mínimo Sector Bananero Urabá........... 35

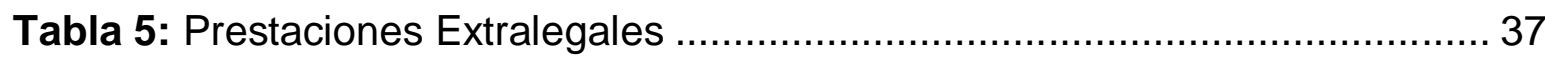

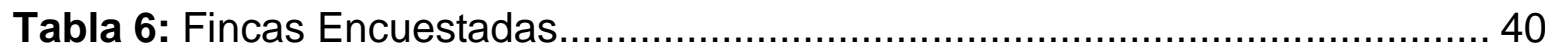

Tabla 7:Relación Modelo Probit y Logit .......................................................... 43

Tabla 8:Primer Modelo Probit Propuesto ........................................................ 51

Tabla 9:Modelo Probit Propuesto ........................................................................ 53

Tabla 10. Comparativo Modelo Propuesto...................................................... 56

Tabla 11. Estimación Probabilidad de Salario de eficiencia ............................... 57 


\section{INTRODUCCIÓN}

La teoría de los salarios de eficiencia presenta el desempleo involuntario como resultado de rigideces salariales (Romer, 2006), aun así, se considera que los salarios de eficiencia tienen un efecto positivo en el bienestar del trabajador y por ende éste es más productivo aumentando los beneficios de la empresa. Este tipo de salarios son comunes en la parte industrial en países desarrollados, dónde la demanda es alta en comparación con algunos países emergentes.

Los salarios de eficiencia en sectores rurales, según la literatura, son inexistentes, esto se presenta en los países de América Latina dónde su economía se basa principalmente en el sector primario (Villar, Ramírez \& Malagón, 2013), no obstante, en la agroindustria del banano Colombiano se ha dado un fenómeno particular de organización donde según sus dirigentes los salarios permiten mejorar sustancialmente el bienestar del trabajador y su familia lo que ha generado controversia debido a la mala percepción que se tiene del salario en el sector rural; por esta razón es preciso preguntar si ¿Es posible avalar salarios de eficiencia en el sector Bananero Urabá - Colombia dada su organización sindicalista y el hecho de que se considera la productividad como una de las principales variables que lo afectan?

Esta investigación tiene como objetivo general Analizar si los salarios de eficiencia existen en el sector Bananero en Colombia y si estos dependen de la productividad de los trabajadores. De aquí que el alcance de este trabajo abarca la recolección de datos de campo en una muestra de 9 fincas bananeras de las 334 presentes en la zona de Urabá - Colombia con el objetivo principal de determinar si los salarios de eficiencia se dan en el sector bananero en esta área del país partiendo del análisis 
de las variables que determinan los salarios para proponer un modelo econométrico que permita calcular la probabilidad de que se presente este tipo de salarios.

La principal limitante para el desarrollo de la investigación es la disponibilidad de información y los niveles de confidencialidad que manejan los empresarios del sector lo que dificulta la adquisición de la información primaria, esto requirió de un acercamiento con los empresarios a través de AUGURA para convencerlos de los beneficios de la investigación y la programación de trabajo de campo para la recolección de la información directamente en las fincas bananeras del área de Urabá.

Se toma como punto de partida para la investigación lo propuesto por Shapiro Stiglitz en su documento "Equilibrium Unemployment as a Worker Discipline Device" publicado en 1984, donde aseguran que el castigo que un trabajador recibe por eludir su trabajo es el despedido y por ende la manera de mitigar el fenómeno del desempleo es con la asignación de un salario eficiente acorde a su esfuerzo. Además caracterizan a dicha población como homogénea, es decir, todos los trabajadores y empresas son iguales y por tanto pagan el mismo salario, para el caso particular del sector dentro del alcance de la presente investigación esta situación en general se cumple.

Este trabajo, se divide en tres capítulos. En el primero se presentan algunos estudios realizados en torno a la teoría de salarios de eficiencia, unos a nivel internacional, por ejemplo los que están asociados al sector agrícola en economías como la mexicana y cubana. Otros trabajos se realizaron en Colombia y están relacionados con los salarios de eficiencia en el sector educativo. En el segundo capítulo se muestra el Marco teórico, dónde se postulan las principales teorías de salarios de eficiencia que enmarcan esta investigación, además de la de Shapiro Stiglitz la propuesta por Yellen - Arkeloft y otros autores. En la tercer capítulo se desarrolla la metodología, donde se presenta una caracterización profunda del sector y la manera de como la sindicalización y el orden han ayudado a mejorar los 
salarios. También se propone un modelo probit a partir de la teorías analizadas, además se incluyen algunas variables que se consideraron importantes dadas las características particulares del sector, como por ejemplo la sindicalización; todo esto con el fin de respaldar la existencia de salarios de eficiencia. Para este punto se realizó un trabajo de campo considerado un piloto, bajo el acompañamiento de AUGURA $^{1}$ con el fin de tener información de primera mano, con los datos obtenidos a través de las encuestas se pudo correr el modelo propuesto y determinar que variables son las que afectan los salarios en la zona y determinan si son de eficiencia. Por último se presentan las conclusiones obtenidas a partir del estudio realizado. Además se presentan algunas recomendaciones con el fin de fortalecer las políticas laborales en el gremio bananero.

\footnotetext{
${ }^{1}$ Asociación de Bananeros de Colombia
} 


\section{ESTADO DEL ARTE}

A nivel mundial se han realizado varios estudios a partir de la Teoría de Salarios de Eficiencia, en México por ejemplo en el año 2009, Salas Durazo y Murillo García escribieron un artículo sobre los "Salarios De Eficiencia y El Desempleo en México", donde realizan una revisión teórica sobre las diferentes posturas que explican la teoría de los salarios de eficiencia y concluyen que esta teoría una alternativa para explicar las diferencias salariales entre sectores, ya que a diferencia de la teoría neoclásica el salario sirve como instrumento para aumentar la productividad.

Por su parte González García (2008) en su artículo "Los salarios de eficiencia, una vía para accionar positivamente sobre la productividad del trabajo en Cuba", concluye que la baja productividad del trabajo en la economía cubana se debe principalmente a los bajos salarios reales sin dejar de lado otros factores, realiza una adaptación teórica del modelo de salarios de eficiencia de Shapiro - Stiglitz de 1984 a la realidad y las necesidades de Cuba, además afirma que es posible lograr un aumento de la productividad del trabajo para algunos sectores de la economía cubana a través de un aumento de los salarios que se pagan, todo esto de la mano de un aumento y mejoramiento de los mecanismos de control y supervisión del trabajo.

En Colombia se han realizado estudios sobre Salarios de Eficiencia, uno de ellos es el de Mauricio Rodríguez (2009)², el cual trata de explicar "el desempleo involuntario permanente y la rigidez de los salarios a la baja" bajo un modelo de "Crecimiento económico de generaciones traslapadas". (Rodríguez, 2009). El concluye que la que la Teoría de Salarios de Eficiencia logra explicar la persistencia del desempleo de equilibrio, la rigidez de los salarios y por ende porque se busca pagar salarios por encima del equilibrio walrasiano, el autor da cuatro razones: i) holgazanería de

\footnotetext{
${ }^{2}$ Salarios de Eficiencia En Un Modelo De Crecimiento Económico. 2009
} 
los trabajadores; ii) costos de rotación; iii) selección adversa; y iv) moral (motivación) de los trabajadores, además considera que los Salarios de Eficiencia pueden complementar la teoría del capital humano cuando se analizan los diferenciales salariales. (Rodríguez, 2009)

Un trabajo más reciente es el presentado por Elcira Solano y Gabriel Navarro ${ }^{3}$ donde analizan "los salarios de las universidades púbicas en Colombia en un modelo microeconómico de agencia con riesgo moral" (Solano \& Navarro, 2012) los autores afirman que la legislación que regula los salarios de los docentes está diseñada de manera que los motive a aumentar su rendimiento como sucede en el caso de la productividad académica. Según ellos los resultados del modelo econométrico confirman la importancia de los incentivos en los resultados del rendimiento de los estudiantes de la Universidad del Atlántico.

En el Estudio realizado por Iregui, Melo \& Ramírez $(2010)^{4}$ se encontró que los factores que las empresas consideran más importantes en el momento de definir los ajustes salariales son: la situación financiera de la empresa, la productividad de la firma, el desempeño individual y la inflación. Una razón fuerte que las empresas reportaron para no bajar los salarios básicos es evitar la pérdida de los trabajadores más productivos y con más experiencia, esto está asociado a la teoría de salarios de eficiencia, en su versión de selección adversa. En este punto las empresas buscan minimizar la rotación laboral, teniendo en cuenta que existe una alta probabilidad de retiro voluntario por una mejor oferta económica y que se dificulta llenar estas vacantes. También se encontraron otras razones relacionadas con la teoría del salario de eficiencia, en sus versiones de intercambio de regalos y de la hipótesis del salario justo-esfuerzo, tales como no afectar el esfuerzo, la productividad y la motivación de los trabajadores. Finalmente, concluyen que con la evidencia presentada, la teoría de salarios de eficiencia pareciera ser la mejor explicación del comportamiento de los salarios en el sector formal en Colombia.

${ }^{3}$ Remuneración salarial eficiente en la educación superior en Colombia. 2012

${ }^{4}$ Incrementos y rigideces de los salarios en Colombia: Un estudio a partir de una encuesta a nivel de firma. 2010 
En el caso específico del sector agrícola se encontró un artículo de gran interés denominado "Las diferencias salariales entre sectores económicos en Colombia" 5 el cual muestra como éstas están "condicionadas por los riesgos laborales, la necesidad de implementación de salarios de eficiencia, el poder de negociación de los trabajadores y la distribución de rentas extraordinarias"(Villar, Ramírez \& Malagón, 2013). En el país para el mismo nivel de cargo se ven grandes diferencias entre sectores, los trabajadores del sector de electricidad, gas, agua y minería son los de mayor remuneración a diferencia del sector agropecuario que se considera con la productividad más baja de la economía. Por lo que concluyen que la mejor estrategia para reducir la brecha entre los ingresos urbanos y rurales es proponer políticas que aumenten la productividad del campo.

Otro trabajo interesante es el presentado por Bose en 1996, donde al realizar el estudio de los salarios de eficiencia parte por suponer que los salarios urbanos son más altos que los rurales, la migración es costosa, y los trabajadores agrícolas no tienen acceso al crédito. Pero parte del hecho que cuando se presenta un salario rural superior se facilita el ahorro y esto hace más fácil para los trabajadores migrar al sector urbano, generando rotación en el sector agrícola. Por lo que afirma que cuando los salarios urbanos aumentan la migración se vuelve más atractiva y los empleadores rurales reducen la oferta salarial. El concluye que un salario de eficiencia de equilibrio puede ser pagado en el sector rural. En algunos casos, los cambios en los salarios urbanos producirían cambios en los salarios rurales (Bose, 1992).

Moretti y Perloff en 2002 en su artículo "Efficiency Wages, Deferred Payments, and Direct Incentives in Agriculture," concluyen que en el caso específico de Estados Unidos donde los trabajadores agrícolas se encuentran entre los peor pagados, los gobiernos estatales y federales debaten periódicamente leyes para ayudar a

\footnotetext{
5Editorial Informe Mensual del Mercado Laboral. Fedesarrollo. Septiembre 2013.
} 
protegerlos, ordenando algunos beneficios como vacaciones y otras bonificaciones, seguro de salud, seguro de desempleo y el establecimiento del salario mínimo. Aunque se cuestiona que tan bueno es exigir beneficios y regular esto con el argumento de que podría reducir los salarios. Además hay evidencia de que los empleadores agrícolas que proporcionan mayores beneficios tienden a pagar salarios altos. Y finaliza diciendo que teoría de los salarios de eficiencia explica algunos de estos efectos salariales (Moretti \& Perloff, 2002). 


\section{ASPECTOS TEÓRICOS Y CONCEPTUEALES}

\subsection{SALARIOS DE EFICIENCIA}

Dentro del análisis económico, se establece en primera medida, que la productividad es entendida como la producción generada por unidad de un factor específico. En este punto, se considera que entre más eficiente se utilizan los recursos para aumentar la producción, entonces la productividad, ya sea local o nacional será mayor. A ello, los análisis realizados por David Ricardo consideraban que el producto es el resultado de una combinación entre la renta, las ganancias y los salarios, en cuya finalidad se encuentra la acumulación de capital. Con estos elementos y como argumenta el propio Ricardo; "el capital es aquella parte de la riqueza de un país que se emplea con vistas a una producción futura" y añade también que "nadie acumula sino con el propósito de hacer productiva su inversión" (Ricardo, 1817, p. 209 y 291).

Ante los argumentos generados por Ricardo en el producto y el capital, los salarios son entonces la puja entre la oferta y demanda de los bienes producidos. A esto, el diferencial entre la mano de obra y la capacidad instalada para producir un bien, dependería de la necesidad de tener un trabajador para dicha finalidad. Es así, que los estudios de Smith, permitieron establecer la tasa de salarios para los trabajadores concentrando este elemento en la demanda por trabajo, a lo que en la actualidad es relevante desde el punto de vista productivo.

Los incentivos producidos por un aumento en el salario de un trabajador, producen un efecto positivo considerable en el incremento de la productividad de un sector económico específico. En general los modelos de Salarios de Eficiencia tienen como hipótesis central que salarios altos además de generar mayores costos también 
generan mayores beneficios para la empresa (Romer, 2006). Esto se puede dar por que al tener un salario alto:

i) El trabajador puede consumir más alimentos, por lo que está más nutrido y por ende ser más productivo (aplica sobre todo en los países emergentes),

ii) El trabajador aumenta su esfuerzo cuando no se puede controlar constantemente, pues valora más su trabajo,

iii) El trabajador mejora sus capacidades en aspectos que la empresa no puede controlar, por ejemplo estudiando, volviéndose más productivo y

iv) El trabajador tiene un sentimiento de lealtad hacia la empresa por lo que se esfuerza más. (Romer, 2006)

Al entrar a analizar las teorías de salarios de eficiencia, se puede establecer que dichas teorías son un grupo de modelos conceptualmente diferentes, donde la perspectiva común de dichos modelos radica en el papel de incentivos que juegan los salarios en cuanto al efecto del producto del trabajador (Riveros, 2009).

El primero en realizar una formulación de modelo centrado en los salarios de eficiencia fue Harvey Leibenstein (1957), quien lo aplico al análisis de la situación del subempleo en los países en vía de desarrollo. Este economista heterodoxo sostiene que la productividad del trabajador depende de su salud y vitalidad, es decir, de la renta que percibe, que para el caso agrícola se sustentaría en la eficiencia de la explotación de la tierra. Esta relación generada por Leibenstein tiene dos fases: la primera es la relación salario-nutrición, y la segunda la relación nutrición productividad, concluyendo una relación entre el salario y la productividad.

De otra parte, los salarios percibidos por los trabajadores en las actuales condiciones capitalistas estarán sujetos a condiciones de educación y de rendimiento cortoplacista. A ello, Solow (1979) da una primera aproximación al salario de eficiencia. Sostiene que las características intrínsecas entre el salario y la productividad son las que determinan el salario eficiente y no entre la relación de 
la oferta y la demanda del mercado como lo postulaban los clásicos. De esta forma Solow, sintetiza matemáticamente el salario de eficiencia partiendo de la siguiente función de producción de la empresa:

$$
Q=q(n, l)
$$

Donde $Q$ es la función de producción de la empresa, $q$ el volumen de producción de empresa, $n$ la productividad y $l$ el número de trabajadores. Con esta relación, el beneficio obtenido por la empresa se determina como:

$$
B=p_{q} q(n(w) L)-w L
$$

De acuerdo a la función (2), $B$ es el benficio de empresa que está sujeta a los cambios que susciten entre $p_{q}$ siendo esta el "precio", $Q$ la función de producción y $w L$ el producto entre el salario y el número de trabajadores. Dado esto, las condiciones de primer orden del beneficio respecto a $L$ y muestran que "la elasticidad con respecto a la productividad del trabajador es igual a uno"6 (Caraballo, 1996, p. 108). De esta manera Solow añade a su vez que "el desempleo que se genera es involuntario ya que, aunque los trabajadores estuvieran dispuestos a trabajar por un salario menor, la empresa no los contrataría porque no estaría maximizando beneficios" (Caraballo, 1996, p. 108).

La productividad estudiada desde el punto de vista de la explotación de recursos naturales y en su caso particular desde la producción agrícola, produciría efectos contradictorios y poco sutiles. Por esta razón, los salarios eficientes deben distinguirse según el campo de acción en donde se encuentren, que según Caraballo (1996) los modelos de salarios de eficiencia se pueden dividir en cuatro categorías:

${ }^{6}$ El resultado de esta hipótesis, se da cuando se somete a la ecuación (2) a la primera derivada del beneficio respecto al salario y respecto al número de trabajadores, por tanto:

$$
p_{q \frac{\partial q}{\partial H}}=\frac{w}{n(w)} \text { entonces } \frac{w \partial n}{n(w) \partial w}=1 ; \quad H=n(w) L
$$

Esto muestra que el incremento en el $1 \%$ en la productividad, el salario se incrementa proporcionalmente en $1 \%$. 
a. Modelo de regulación de la productividad: El cual supone que el empresario posee información imperfecta ${ }^{7}$ y costosa sobre la productividad del trabajador. Este asegurará un nivel mínimo de productividad con la fijación un salario que incentive a los trabajadores a desempeñar sus tareas con la intensidad requerida por la empresa ${ }^{8}$. Además muestra que el número de trabajadores es fijo y todos tienen las mismas características. A ello las empresas toman como dado el nivel de desempleo y los salarios asignados en las otras empresas, "por lo que encuentran óptimo ofrecer ese salario: no lo aumentan porque los trabajadores están trabajando con la intensidad debida y no necesitan ser estimulados con salarios superiores, y no lo recortan porque se trabajaría a una menor intensidad". (Caraballo, 1996, p. 110).

b. Los costes de movilidad de los trabajadores: Estos modelos muestran la relación salario-productividad que se basan en los costos que debe asumir la empresa cuando un trabajador, en el que previamente se le ha realizado una inversión para su contratación y aprendizaje, abandona su puesto de trabajo. Esto despliega en el empresario el pago de un mejor salario con la finalidad de que el trabajador no se desanime con sus actividades impuestas. Ello implica que los costos de movilidad disminuyan manteniendo su productividad media. Por tanto, "los salarios se aumentaran hasta que el costo de aumentar en una unidad el salario de un trabajador se iguale al ahorro de costos de aprendizaje debido a una unidad más de salario" (Caraballo, 1996, p. 113).

c. Modelo de selección adversa: Aquí la intensión del salario se enfocara en el proceso de selección de los trabajadores, ya que, en este tipo de modelos el salario afecta al número de candidatos y a la cualificación de los mismos. La empresa asigna un salario superior al competitivo porque puede captar a los

\footnotetext{
${ }^{7}$ Supone que el empresario no conoce de primera mano toda la información sobre el rendimiento y productividad de su trabajador.

${ }^{8}$ Este modelo basado en los salarios de eficiencia, Shapiro - Stiglitz (1984) le da mayor relevancia en estudios de productividad empresarial. También se puede observar en otros trabajos importantes los de Calvo (1979), Calvo y Wellisz (1979), Eaton y White (1982), Foster y Wan (1984) y Bulow y Summers (1986).
} 
mejores trabajadores. En ello, no se considera una buena idea reducir el salario pues los trabajadores más cualificados podrían dejar sus puestos. Por eso, "ante situaciones que implican un descenso en la demanda de mano de obra (por ejemplo, un retroceso de la demanda del producto), optará por el despido" (Caraballo, 1996, p. 115). En este tipo de modelos ${ }^{9}$ además de los supuestos habituales de la teoría de salarios de eficiencia, ${ }^{10}$ se tiene la heterogeneidad de la mano de obra la que según Shapiro - Stiglitz (1984), incide de manera contraria al proceso de selección adversa, si la mano de obra contratada goza de cierta rigidez en los procesos productivos, es decir, si la productividad alcanzada se debe a las características idénticas de calidad de cada uno de los trabajadores debido a una "disciplina laboral". Esta idea permite favorecer el desempleo siempre y cuando el salario competitivo sea inferior al salario de eficiencia, ya que, no se establece una situación de equilibrio. Por tal motivo "si todas las empresas ofrecen el salario competitivo, una empresa cualquiera que decida pagar el salario de eficiencia atraerá a los mejores trabajadores, por lo que sus costes descenderán y sus beneficios aumentarán con relación a los de las demás empresas".(Caraballo, 1996, p. 116).

d. Modelos sociológicos: Este tipo de modelos habla de un salario justo acorde a la tarea realizada. Akerlof (1982) propone una modelización sociológica los salarios de eficiencia y desarrolla el concepto de "giftexehange", que se da a partir de la relación que se establece entre los trabajadores y la empresa. En este punto el trabajador toma interés por la empresa y lo demuestra aumentando su productividad por encima de la exigida. Recíprocamente la empresa le otorga una prima salarial como recompensa a la lealtad de trabajador ofreciendo a la empresa un nivel de producción óptimo. Bajo esta

\footnotetext{
${ }^{9}$ Algunos de los teóricos de éste tipo de modelos son Weiss $(1980,1990)$. Guasch y Weiss $(1980)$ y Grccnwald (1986) hacen acotación a que el caso en que se genere desempleo, sucederá por la razón en que la oferta no se iguale con la demanda y los beneficios de los empresarios sean negativos.

${ }^{10}$ Los supuestos habituales a los que se hace referencia son: el salario de aceptación y el salario de reserva del trabajador como función creciente de su productividad. Otro supuesto es el salario ofrecido por la empresa en el que minimiza su coste laboral por unidad de eficiencia (se considera que la función de producción de la empresa sólo depende de las unidades de eficiencia del trabajo y de un coste fijo, que varía según la empresa). (Caraballo, 1996)
} 
premisa Caraballo (1996) hace acotación a que la productividad generada asociada al salario percibido, estará en función del tipo de trabajador con el que se disponga y la intensidad con que éste trabaje. Cuando la empresa decide otorgar una prima salarial, aparecerá un mercado de trabajo primario porque el salario percibido por sus trabajadores será superior al competitivo y será en este mercado donde se origine el desempleo.

Con las ideas expuestas por Caraballo, economistas como George Akerlof y Janet Yellen plantean la hipótesis de que el salario justo, es la idea relevante que tiene el trabajador sobre su labor y el salario que percibe. Por tanto, sostienen que si $W^{*}$ (siendo el salario justo) es mayor al salario que está recibiendo (salario real), el trabajador ejercerá un esfuerzo proporcionalmente menor, de manera que el esfuerzo estará determinado por $e=\min \left(W / W^{*}, 1\right)$ (donde e es el esfuerzo generado por la labor). Por otro lado si $\mathbf{w}^{\star}$ es mayor que el salario del mercado, se originará desempleo ${ }^{11}$.

Dado que el incentivo salarial proporciona un aumento de la productividad, las empresas buscan estrategias salariales para que su "ritmo productivo" sea cada vez más creciente. Ante ello, los postulados de Akerlof - Yellen, consideran que el salario justo solo se puede manejar a través de la reciprocidad entre el esfuerzo y la tarea asignada a ese esfuerzo. Esto de cierta manera contradice al hecho de que la productividad debe entenderse como la eficiencia al esfuerzo realizado.

Los estudios de Shapiro - Stiglitz así lo demuestran. Ellos consideran que los beneficios $(U)$ alcanzados por el trabajador estarán en función del salario que percibe $(w)$ y el esfuerzo que realiza ( $e$ ), por tanto $U=w-e$. Aquí, la decisión del trabajador de "eludir" sus tareas, estarán sujetas al mínimo esfuerzo que puede ofrecer por una tarea, pero se expone que por su baja eficiencia sea despedido. Si un trabajador realiza un nivel acostumbrado de esfuerzo por su trabajo, y si él no elude, recibe un salario de $w$ y conservará su puesto de trabajo hasta que factores

\footnotetext{
${ }^{11}$ En su artículo "The Fair Wage-Effort Hypothesis And Unemployment"
} 
exógenos provoquen su separación. Si elude, hay una cierta probabilidad q, por unidad de tiempo, que va a ser capturado. Si está atrapado eludiendo, él será despedido y obligado a entrar en la piscina de desempleo (Shapiro- Stiglitz, 1984, p. 435)

De acuerdo con lo anterior, lo eficiente no siempre puede estar relacionado con la calidad con la que se realice, ni tampoco afirmar que la cantidad y calidad son directamente proporcionales dentro de un análisis de remuneración eficiente. Tomando como base la teoría de la equidad de Adams (1963) y la teoría del intercambio social de Blau-Homans (1955, 1961), Adams hace referencia a que la cantidad y calidad del trabajo de una persona se puede generar a partir de cuatro situaciones: situaciones de sobrecompensación (mayor salario del que el sujeto se percibe merecedor), situación de infra compensación (menor salario del que el sujeto percibe que merece), situación de pago por horas y el último situación de pago a destajo (salario en función de las unidades producidas).

Las hipótesis generadas por Akerlof - Yellen (1990), solo limitan el espectro de la utilidad salarial obtenida por el trabajador debido a su esfuerzo, de hecho, las conclusiones de estos estudios se inclinan más por la conducta humana y las relaciones existentes entre la equidad y el intercambio social, argumentando que "cuando las personas no obtienen lo que merecen, ellos tratan de desquitarse" (Akerlof - Yellen; 1990).

De esta manera, el aspecto extrapolador de un salario eficiente se puede concretar en el esfuerzo desempeñado. Recurriendo nuevamente a los estudios generados por Shapiro - Stiglitz (1984), la estructura lógica de utilidad favorecida por un incremento salarial, se sostiene en la medida en que el salario eficiente o salario critico $(\widehat{w})$ se iguale a las variables endógenas laborales del salario percibido $(w)$, la tasa de paro o desempleo $\left(r V_{u}\right)$, la tasa de ganancia activa por trabajador $(r)$, la tasa de abandono $(b)$, la probabilidad de detectar a una persona eludiendo su trabajo $(q)$ y el esfuerzo $(e)$ : 


$$
w \geq r V_{u}+(r+b+q) e / q=\widehat{w}^{12}
$$

La ecuación (3), establece relaciones directamente proporcionales en cada una de sus variables. Con ello, el salario critico $\widehat{w}$, percibido por un trabajador será cada vez mayor, si las demás variables aumentan en la misma proporción. Por tanto, "la demanda de trabajo de la empresa se da al igualar el producto marginal del trabajo y el costo de contratar a un empleado adicional" (Shapiro - Stiglitz; 1984, p. 437).

Con estas premisas, se argumenta entonces que los trabajadores añadidos a una empresa, valoraran sus puestos de trabajo si son bien remunerados y si a su vez, la puja por un trabajo eficiente los pone a competir esperando que el empleador consiga la probabilidad optima de encontrar a un "holgazán" en sus filas para aumentar en la misma proporción la oferta laboral. De esta manera, el nivel de desempleo puede aumentar si el valor $(q)$ se atribuye a un "riego moral" generado por el trabajador, a lo cual el periodo de tiempo en conseguir otro empleo puede ser mayor si M empresas toman la misma decisión.

Ahora bien, si las condiciones macroeconómicas no son favorables en cuestión de empleo, el gobierno puede optar por políticas que favorezcan a éstas aumentando la demanda por trabajo. En estos casos, las empresas pueden reducir los salarios haciendo que los empleados estén tentados a no trabajar eficientemente. Esto a su vez favorece la variable $(q)$ diseñada por la empresa gestado positivamente a una demanda por trabajo contemplada por las autoridades gubernamentales. En estas circunstancias:

“El equilibrio se producirá cuando cada empresa, tomando como dados los salarios y los niveles de empleo de otras empresas, le resulta óptima ofrecer el salario vigente en lugar de un salario diferente. La variable clave de mercado que determina la conducta empresa individual bajo esta hipótesis,

\footnotetext{
12 La ecuación (3) es discutida y fundamentada en el documento Equilibrium Unemployment as a Worker Discipline Device, de Shapiro - Stiglitz, página 435
} 
es la utilidad esperada de un trabajador desempleado (Shapiro - Stiglitz; 1984, p. 437)"

En este orden de ideas, el salario de eficiencia solo representaría la productividad del sector de acuerdo al esfuerzo realizado por el trabajador. Sin embargo, la oferta laboral que se origina por la necesidad de conllevar procesos de producción y terminación de materias primas elaboradas, incide en la movilidad de mano de obra entre el sector rural y el urbano. Por ello, estudios realizados por Bose (1996) y Marjit, Kar, \& Acharyya (2007) muestran la dualidad que existe entre estos sectores cuando los salarios de eficiencia en alguno de los ellos genera desequilibrios poblacionales haciendo que el trabajador "migre" de un sector a otro generando en algunos casos desempleo.

Dada la hipótesis planteada por Shapiro-Stiglitz donde el desempleo es generado entre otras cosas por un desequilibrio en el salario sectorial entre empresas, es relevante considerar que los desequilibrios originados por la movilidad de capital y mano de obra también repercuten en el desarrollo intersectorial de lo urbano y lo rural.

Bajo esta percepción, la economía en América Latina se ha concentrado en la producción de bienes generados en el sector primario. Ante ello, Jouvin (1966) considera que la transformación de economías tradicionales -como las que se dieron en Inglaterra y Francia - en economías modernas, se debe a la diversificación y expansión del sector agrícola y recalca que:

"Un fuerte aumento en la producción agrícola engendra un flujo de ingresos suplementarios para el sector agrícola, que se transforma parcialmente en ahorro, cuya canalización directa o indirecta en favor de la inversión industrial se convierte en fuerza motriz para el desarrollo económico de la mayor parte de las grandes potencias industriales". (Jouvin, 1966, p. 452) 
De esta manera, la participación que genere el sector agrícola en el PIB, recaerá en el comportamiento del salario de los trabajadores. Para tal fin, el Gráfico 1 muestra la relación existente entre porcentaje de participación de trabajadores en la agricultura, frente al porcentaje de participación del sector agrícola en el PIB (relación únicamente para América Latina).

Gráfico 1: participación de la agricultura en el PIB y el empleo en América Latina $(1990-2012)$

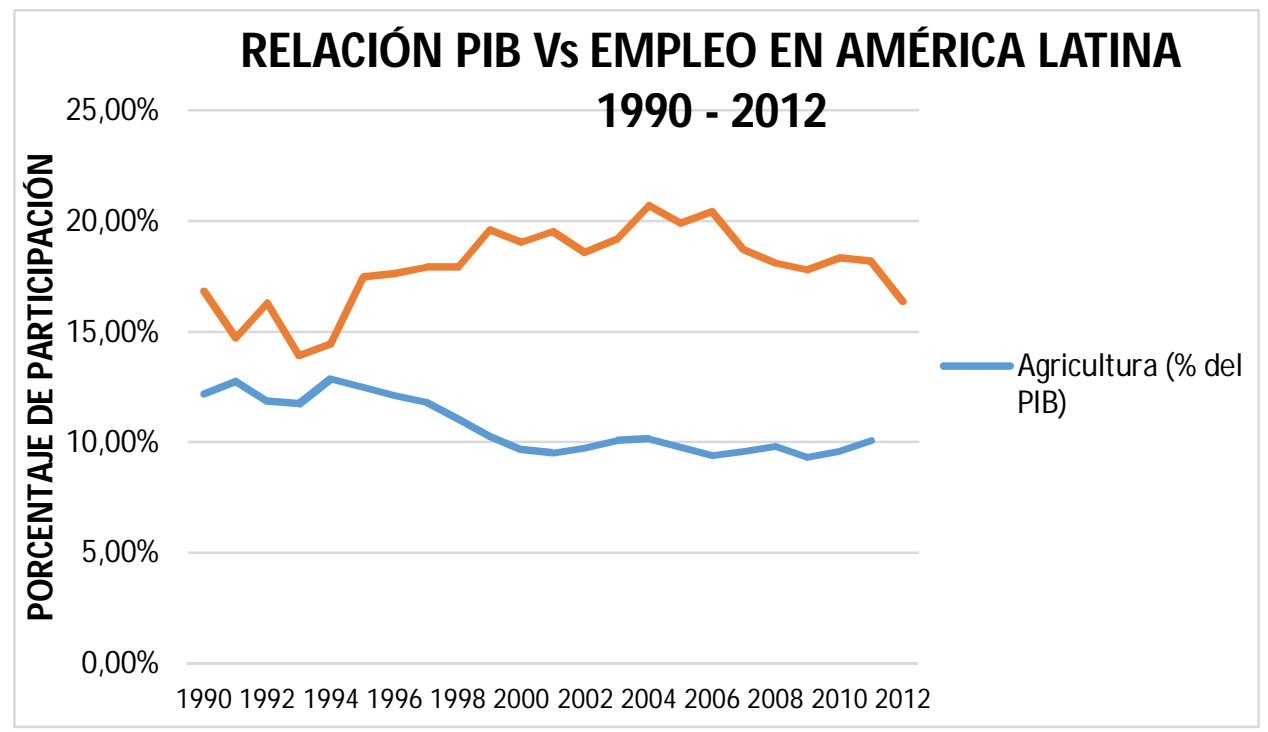

Fuente: Banco Mundial. Cálculo realizado por los autores.

De acuerdo al gráfico anterior se observa que durante los últimos 20 años, el número de personas empleadas en el sector agrario ha tenido fluctuaciones considerables, generadas en algunos momentos por reformas agrarias. Sin embargo, para el año 2004 la participación del empleo rural ha decaído pasando de un $20.71 \%$ a un $16.38 \%$ en el 2012 .

En este sentido, la migración es entonces, un factor decisivo en los procesos productivos agrícolas al interior de cada país. De esta manera Bose (1996) afirma que la migración solo se da si el salario $(w)$ percibido por un trabajador es mayor a sus costos fijos $(\alpha)$ y a los costos de desplazamiento $(s)$ entre periodos. De igual forma menciona que la utilidad neta recibida $(\widehat{U})$ por el trabajador es una función 
discreta que depende $w, \alpha y \beta_{\delta}$, siendo este último el "salario base" que recibe un trabajador rural de tipo $\delta^{13}$.

Los aportes de Bose (1996) frente a la migración intersectorial (urbana y rural) resaltan la importancia de manejar variables migratorias en el modelo presentado por Shapiro - Stiglitz. De allí que a pesar de manejar una variable de desempleo, esta se debe complementar con los beneficios económicos y no económicos que percibe el trabajador rural, que dentro del modelo de Bose (1996) implica la migración que realiza el trabajador rural para obtener un beneficio neto $(\widehat{U})$. De esta forma el consumo $R$ que hace el trabajador en cada periodo, será determinado por los beneficios recibidos por este en el periodo de tiempo determinado, y que serán reflejados en la oferta laboral del sector.

Los modelos de los salarios de eficiencia durante los últimos años, han recibido fuertes críticas de diferentes escuelas económicas, una de ellas es conocida como la "crítica de los bonos"14 donde plantea la posibilidad que los trabajadores "compren" su puesto de trabajo mediante el pago de un bono al empresario. Esta crítica elimina el resultado más importante del modelo: la justificación del desempleo involuntario. Sin embargo, al no haber suficiente evidencia empírica asociada a la crítica de los bonos, esta ha perdido fuerza en sus argumentos. (Caraballo, 1996).

Es importante resaltar el estudio realizado por Bulkley \& Myles (1996) dada la sindicalización del sector en estudio, ellos hacen un aporte a los modelos de salarios de eficiencia al examinar los efectos del a sindicalización sobre los salarios y esfuerzo. Los resultados de su estudio permiten ver que existe un margen para un sindicato y así elevar la utilidad esperada de sus miembros en un mercado laboral caracterizado por los salarios de eficiencia. También concluyen que Bulkley (1992)

\footnotetext{
${ }^{13}$ "El sector agrícola se compone de tres tipos de agentes, los terratenientes y los dos tipos de campesinos. Tipos de Campesinos indexados por $\delta(\delta=F, I)$ que se distinguen sólo en la base de sus opciones en el sector urbano" (Bose, 1996, p. 373). A ello $F$ son los trabajadores que buscan empleo en el sector formal e $I$ que encuentran trabajo en el sector informal

${ }^{14}$ Akerlof y Yellen (1996) la rechazan por el argumento de que no tiene sentido plantear controversia sobre un mecanismo que difícilmente se observa en la realidad.
} 
mediante un modelo bajo supervisión perfecta (lo cual es muy difícil que ocurra) los sindicatos llevan a menor esfuerzo, pero Bulkley \& Myles (1996) en su estudio proponen un modelo de supervisión imperfecta, lo cual es más real, la sindicalización hace que los miembros de esta sean más productivos haciendo que la empresa obtenga mayores beneficios. 


\section{DETERMINACIÓN DE LOS SALARIOSDE EFICIENCIA EN SECTOR BANANERO DE URABÁ}

\subsection{CARACTERIZACIÓN DEL SECTOR}

\subsubsection{La Agroindustria En Colombia}

En Colombia el término de agroindustria fue asimilado al de AGRIBUSINESS ${ }^{15}$, refiriéndose esta expresión a un conjunto de elementos sistemáticamente ordenados para el procesamiento de productos agrícolas en la que la industria y las firmas de cadena de mercado están inmersas en el desarrollo de esta actividad.

De acuerdo con López y Castrillón (2007), en Colombia desde el año de 1904 ya existían empresas que realizaban transformación de las materias primas que procedían del sector primario (productos agrícolas), entre ellas se contaba la madera, el algodón, el cuero, etc. En 1936 con las políticas del entonces presidente de la República Alfonso López Pumarejo (1934 - 1938), promulgo la ley 200 de 1936 en la que "buscaba instaurar un régimen adecuado de tenencia y explotación de tierras. Esta ley exigió la explotación económica de los predios y reconoció el derecho de los trabajadores rurales a la posesión de tierras" (Albán 2011, p. 344).

De esta forma se consagro en 1945 una reforma constitucional que entre otras, implemento planes de desarrollo económico municipal y urbana, con el objetivo de impulsar el desarrollo de la economía de manera eficiente desde la intervención estatal sobre el territorio. De esta forma, la ejecución de políticas que favorezcan el agro, sirvió para mejorar algunos procesos técnicos en favor de la transformación de productos de origen agrario que antes se manejaban de manera arcaica. De aquí

15 Este término fue elaborado por los economistas Ray Goldberg y John Davis (1957). Véase también http://www.biblioteca.udep.edu.pe/BibVirUDEP/tesis/pdf/1_108_185_67_1005.pdf 
que la industria de alimentos y bebidas para el año de 1945 representaba el 47\% del valor de todo el sector industrial y se empleaba el $27 \%$ del empleo en este sector (López, Castillón 2007, p. 27)

Bajo estos indicios y con la creación de la Comisión de Plan dado en $1968^{16}$, los productos agrícolas tuvieron una dinámica más relevante en la economía nacional. De allí que productos como azúcar, grasas, molienda, panificación, productos lácteos charcuterías etc., impulsaron el desarrollo agroindustrial dando un giro sistemático en la producción de alimentaria en Colombia.

De acuerdo a la CEPAL $(1998)^{17}$, no todas las relaciones entre la agroindustria y los productos agrícolas fijan un avance técnico y social dentro de la economía de este sector. A ello atribuyen que:

- La producción agrícola de ciertas unidades productoras primarias, deben tener la facilidad de expandirse eficientemente como lo hiciese una unidad productora dentro de una economía de escala. Ello determina, que el impacto social que estas unidades pequeñas representan en la sociedad mitiguen el impacto generado por el desempleo, a veces ocasionado, por la tergiversación de recursos para estos sectores productivos.

- Que las unidades productivas asociadas al sector primario, sean intensivas en mano de obra. De esta forma, puede asociarse a la transformación de productos agrícolas, familias que poseen poca formación técnica y que en el mercado laboral su fuerza de trabajo no sea transferible.

\footnotetext{
${ }^{16}$ Esta comisión buscaba debatir el plan de desarrollo económico del periodo. Como resultado de ello, se creó el CONPES (Consejo Nacional de Política Económica y Planeación) y el departamento Nacional de Planeación (DNP). A ello López y Castrillón (2007) manifiestan que el objetivo principal de la creación de estas dos entidades es establecer las políticas de planeación en Colombia. Véase también https://www.dnp.gov.co/CONPES/Paginas/conpes.aspx

17 Dada la generalidad y caracterización de la economía latinoamericana, la CEPAL genero un documento titulado "Agroindustria y pequeña agricultura: vínculos, potencialidades y oportunidades comerciales" en la que muestra la articulación de la agroindustria con los productos agrícolas como propósito esencial de progreso técnico y tecnológico en el sector primario.
} 
- Los productos asociados a la agroindustria deben ser perecederos, de tal manera que estos no sean almacenados y por el contrario, tengan salida como productos de primera necesidad en la canasta familiar.

- Deben ser productos de ciclos cortos en su producción, ya que, no ponen en peligro la sostenibilidad de la producción, debido a que de manera anticipada se requiere de capital el cual es adquirido en buena parte del sector financiero para facilitar el desarrollo de la producción.

\subsubsection{La Agroindustria Del Banano En Colombia}

La producción de banano en Colombia es una actividad de gran importancia, no solo desde el punto de vista económico, sino como aspecto de sostenibilidad social para las regiones productoras y el país. La generación de empleos directos e indirectos es quizás uno de los mayores aportes de un cultivo a la economía local debido a que su cadena productiva (Grafico 2) es intensiva en mano de obra. (Aktiva, 2015).

El área total de producción de banano tipo exportación en el país para el 2014 es de 46.625 hectáreas, de las cuales 34302 están ubicadas en la zona de Urabá (Augura, 2015). La zona bananera de Santa Marta está ubicada al norte del país (Gráfico 3) y sobre la década de 1880 se produjo por primera vez el cultivo del banano en ella. Para ese entonces, los señores José Manuel González Bermúdez y Santiago Pérez Triana ${ }^{18}$ se unieron para la producción y comercialización de este producto. De esta manera, la producción del banano permitió a esta asociación que

\footnotetext{
${ }^{18}$ Los dos empresarios colombianos, el primero residente en Colombia y el segundo residente en New York, se unieron para la producción del banano en esta zona. Según documento de Viloria (2009), la razón fundamental por la cual se inició la producción de este producto agrícola, fue por la accesibilidad que la tierra de esta región ofrece a este cultivo. Manifiesta que por ser una zona plana y de abastecerse de un gran caudal hídrico, favorece la cosecha del banano y su producción.
} 
en 1891 realizara la primera exportación con una carga de 1600 racimos hacia Estados Unidos (Viloria, 2007, p.15).

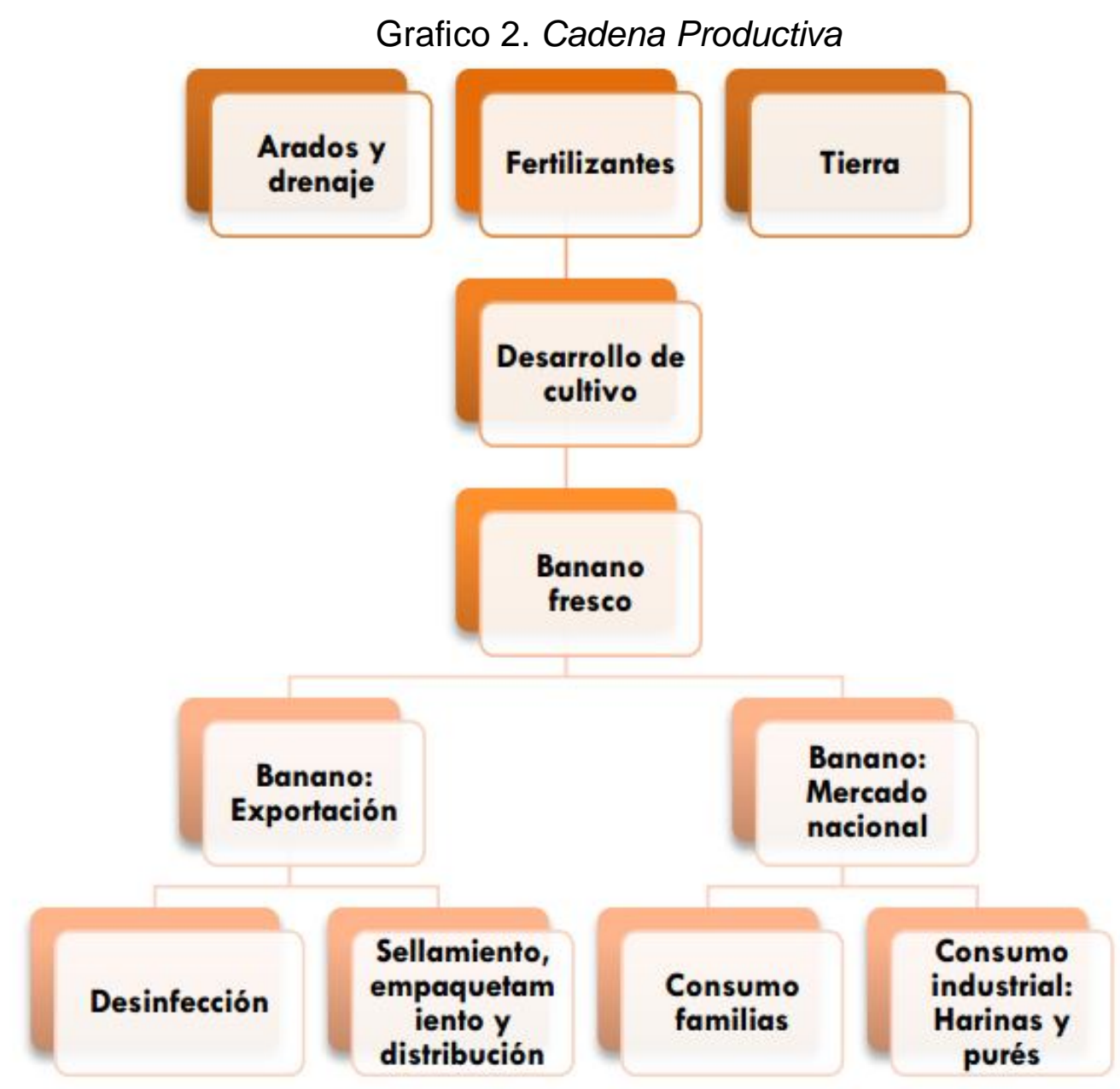

Fuente: Aktiva, 2015

El banano fue entonces el primer producto que atrajo la Inversión Extranjera en la región. Con firmas como J. Sanders (empresa norteamericana), Colombian Land Company (Empresa Inglesa) e Immobiliére (empresa Francesa), la producción del cultivo y comercialización del banano generó en la región más de 8.800 hectáreas de producción y alrededor de 485.385 racimos exportados desde la región del Magdalena a finales del siglo XIX ${ }^{19}$.

\footnotetext{
${ }^{19}$ Viloria Joaquín: “Historia empresarial del Guineo; empresas y empresarios bananeros en el departamento del magdalena 1870 - 1930". Cuadernos de historia económica empresarial, p. 16
} 
Grafico 3. Zona Bananera de Santa Marta (Departamento del Magdalena)

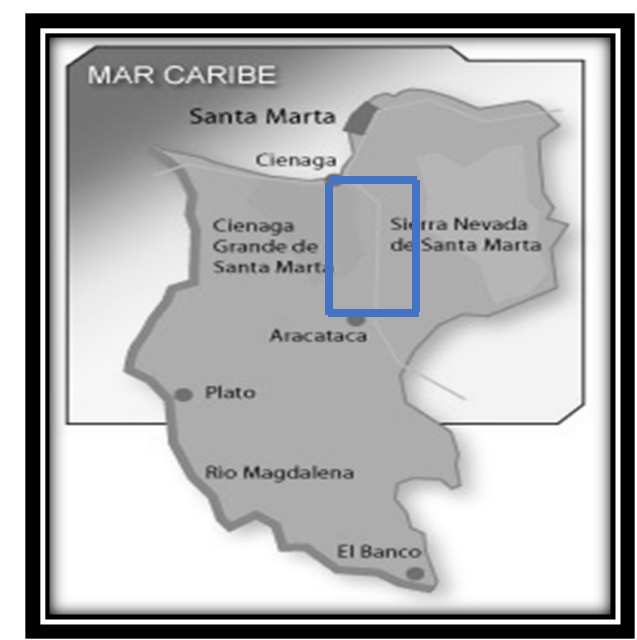

Fuente: Sena 2003

La zona bananera de Urabá se encuentra localizada al Noroeste del departamento de Antioquia (Gráfico 4) con una extensión de $11.664 \mathrm{~km}^{2}$, dentro de los cuales se encuentran los municipios de: Chigorodó, Carepa, Apartadó y Turbo. Sevilla Fruit Company fue quien implementó el cultivo de banano en Urabá, dieron garantías a los productores como asegurarles la compra de su producción durante los primeros cinco años, esto hizo que empresarios y obreros de otras zonas del país como Medellín, Chocó y Córdoba dirigieran la mirada hacia la zona dándose un proceso de colonización, convirtiéndose en el eje Bananero de Colombia. (Sena, 2003).

Grafico 4.Zona Bananera de Urabá (Departamento de Antioquia)

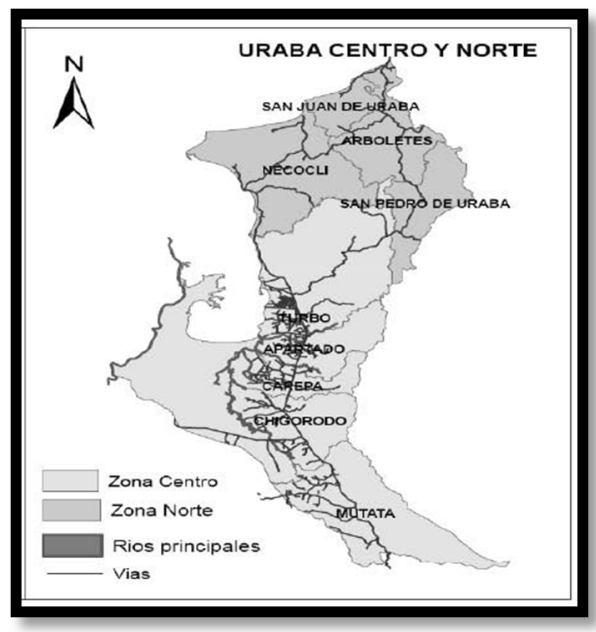

Fuente: Sena 2003. 
En Colombia el PIB entre el primer trimestre de 2013 y el cuarto trimestre de 2014 creció en promedio 4,8\%, mientras que el sector agrícola creció en $3,5 \%$, más de un punto por debajo del crecimiento del producto total del país. Por su parte el sector Bananero presentó una disminución de la productividad, esto debido a condiciones adversas en el clima de Urabá y Santa Marta lo que generó una contracción del $11,4 \%$ y $15 \%$, respectivamente, mientras que a nivel nacional la reducción en la productividad fue de 12,4\% (Gráfico 5) (Aktiva, 2015).

\section{Gráfico 5. Productividad Promedio}

Cajas por Hectárea

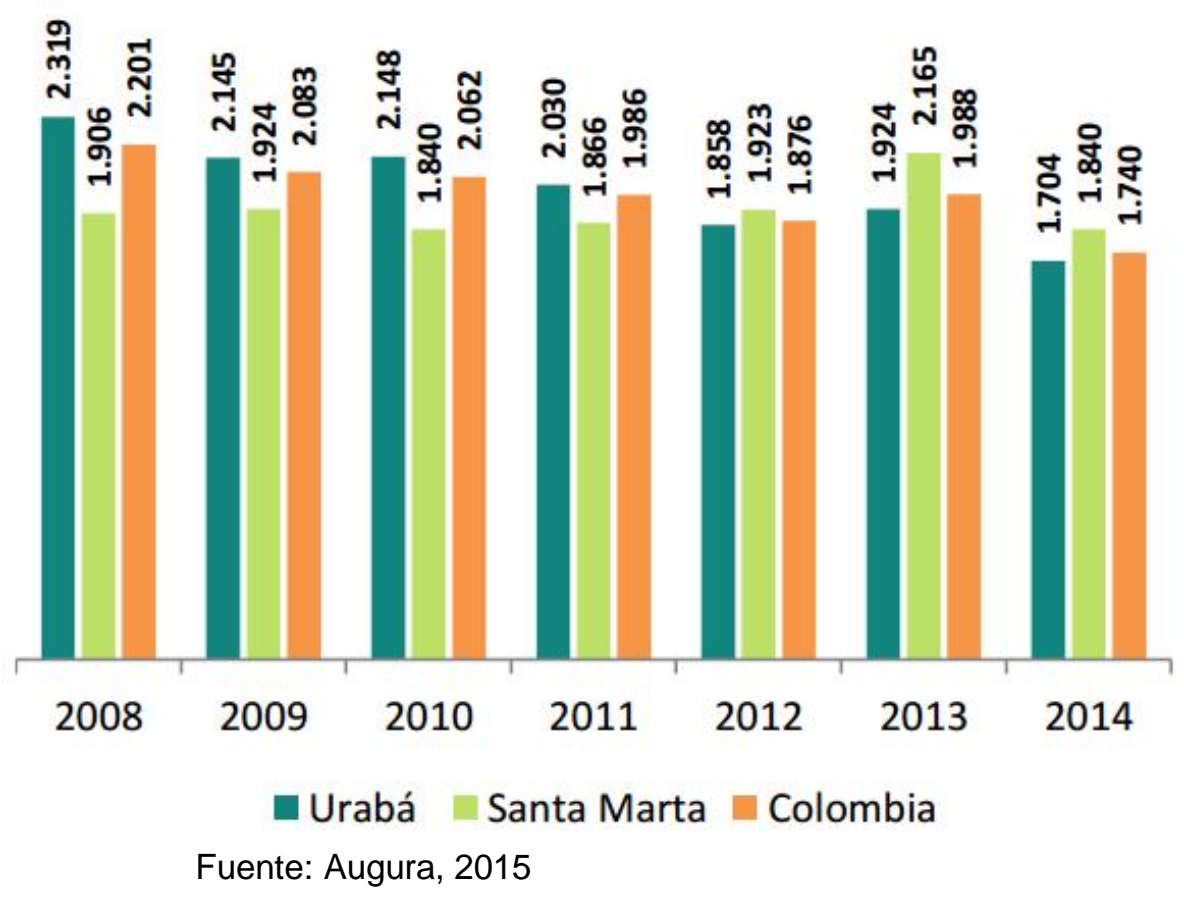

En tres empresas se concentra el $65 \%$ de la exportación de banano colombiano (Gráfica 6), la principal comercializadora es Uniban S.A, la cual en 2013 exportó alrededor de 38 millones de cajas, lo que representa el $39,6 \%$ del total de las exportaciones, para 2014 sus exportaciones disminuyeron a 34 millones de cajas cayendo un 9.89\% en comparación al 2013. Aun así su participación en el total exportado en 2014 aumentó al representar el 41,6\%. La segunda empresa es Banacol quien en 2013 sus exportaciones llegaron al 17,7\% del total y en 2014 
disminuyó al 13,8\%. La última empresa comercializadora con mayor peso fue Tecbaco. (Aktiva, 2015)

Gráfico 6. Exportaciones por Comercializadora 2014

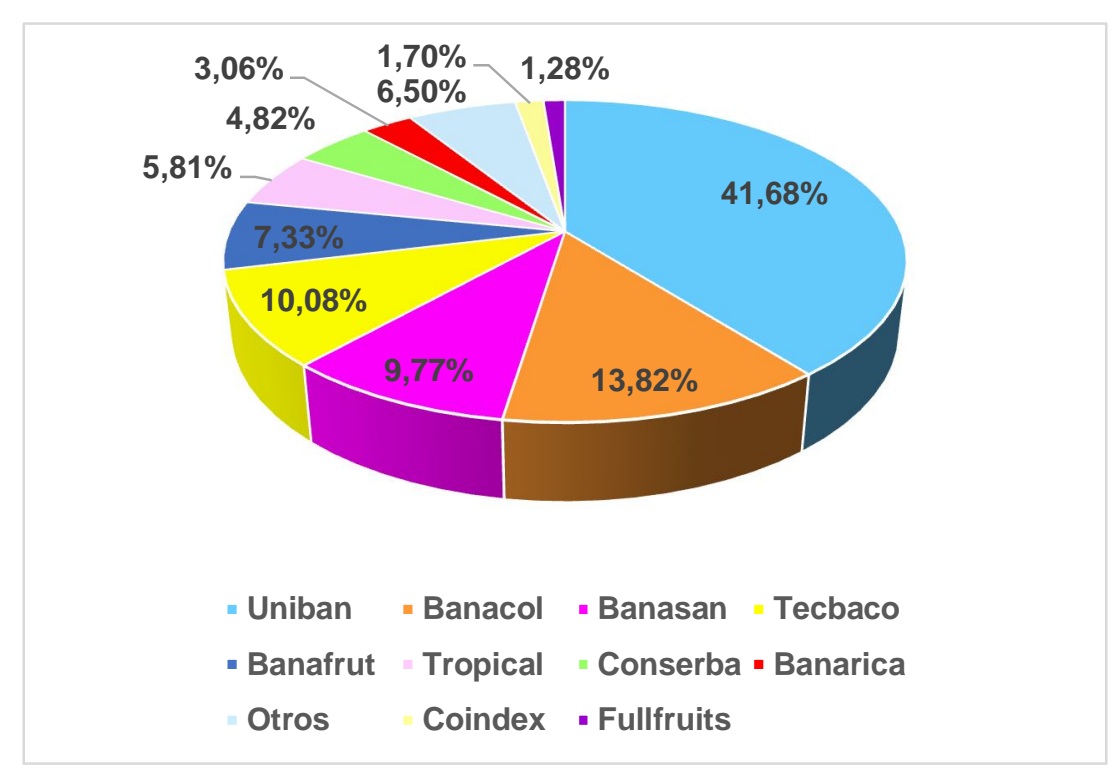

Fuente: Grafico realizado con datos suministrados por Augura 2015

Por su parte la oferta esperada de banano ha permanecido casi constante durante los últimos tres años (Gráfico 7); para 2013 se tenían más de 48.300 hectáreas, de las cuales el 73,3\% están ubicadas en la región de Urabá y el resto en la zona de Santa Marta (Aktiva, 2015).

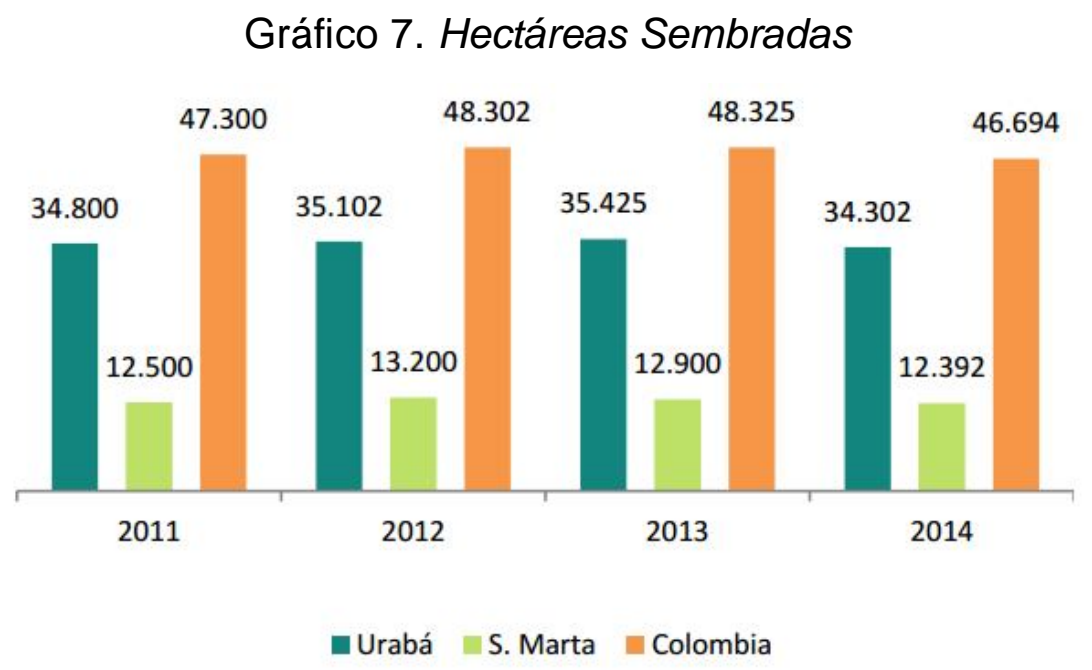

Fuente: Augura, 2015 
Dadas la demanda extranjera de banano y las exigencias en los estándares de comercialización de la Unión Europea como licencias sanitarias estrictas, procesos de empaque y embalaje específicos para el transporte, todo acorde con las normas internacionales de comercio de alimentos, se ha dado un aumento en la tecnificación del sector disminuyendo un poco la intensidad de mano de obra, lo que se refleja en los costos laborales que en algún momento llegaron hasta el $60 \%$ de los costos totales pasando en la actualidad del $52 \%$ al $56 \%$ en promedio.

La demanda de este producto ha mostrado una tendencia a la baja desde 2009, lo cual se ha atribuido a la recesión de las economías de los principales países importadores como los de la Unión Europea. En el 2013 la exportaciones aumentaron aún con la revaluación del peso contrario a lo que ocurrió en 2014 año en el que volvieron a disminuir (Gráfico 8) principalmente por las condiciones climáticas presentadas durante el año; de estas exportaciones el $70 \%$ fueron hacia la Unión Europea, mientras que Estados Unidos importa el 24\% del total del volumen de banano exportado por Colombia. (Augura, 2015)

\section{Gráfico 8. Exportaciones Banano Colombiano}

(En miles de cajas de $18.14 \mathrm{Kg}$ )

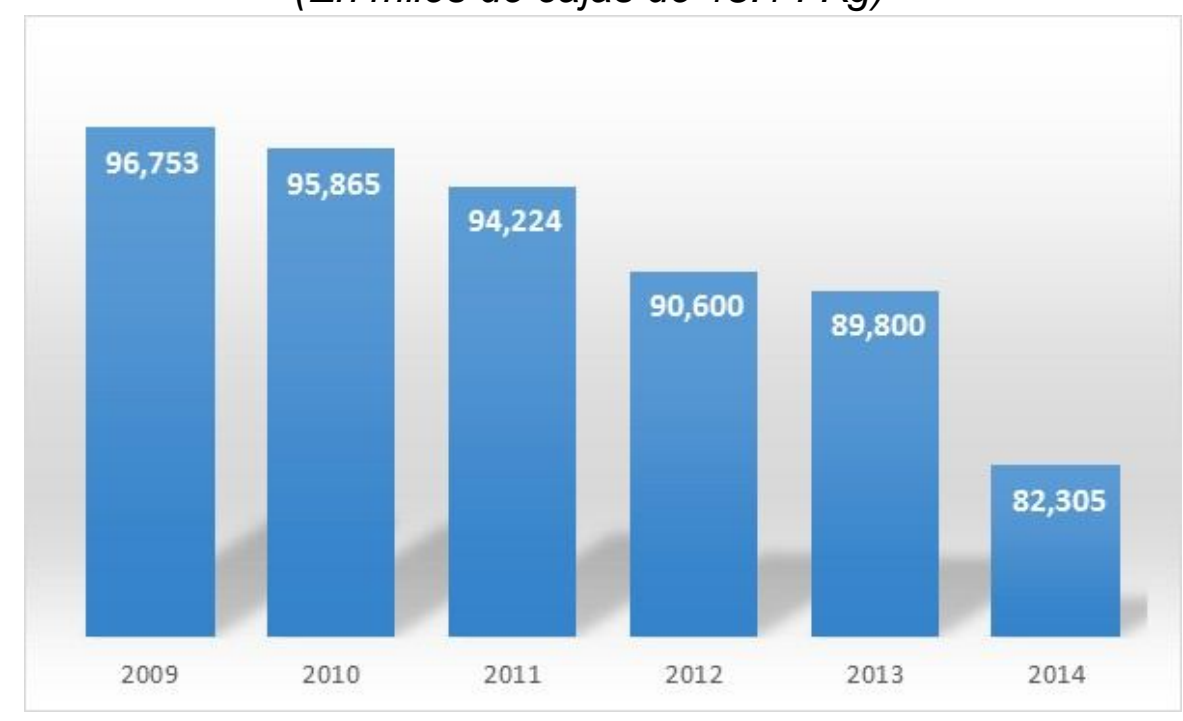

Fuente: Augura, 2015

\footnotetext{
20 Unidad de Análisis Económico y Estadístico de Augura. El \% del total de la mano de obra en la estructura de costos de ubica en un promedio del 52 al 56\% dependiendo de las labores de cada finca.
} 
Por su parte el precio internacional (FOB) ha estado estable, siendo de US\$900 por tonelada en 2014 y en marzo de este año alcanzó los US\$1045 por tonelada y US\$6,90 por caja ${ }^{21}$. Esto junto con la apreciación del dólar ha ayudado al repunte del sector ya que según Augura y algunos empresarios estaban produciendo a pérdida debido al bajo precio de la moneda extranjera. Para este año la FAO proyecta un precio cercano a los US\$900 (Grafico 9) debido a la reactivación de algunos de los mayores productores a nivel internacional (Augura, 2015).

En la parte social se puede apreciar como el sector invierte recursos a través de programas sociales ejecutados por las fundaciones sociales de las comercializadoras como Fundauniban, Fundeban, Fundafrut, Corbanacol, Euroban y Augura.

Gráfico 9. Precio Internacional del Banano

US/Toneladas

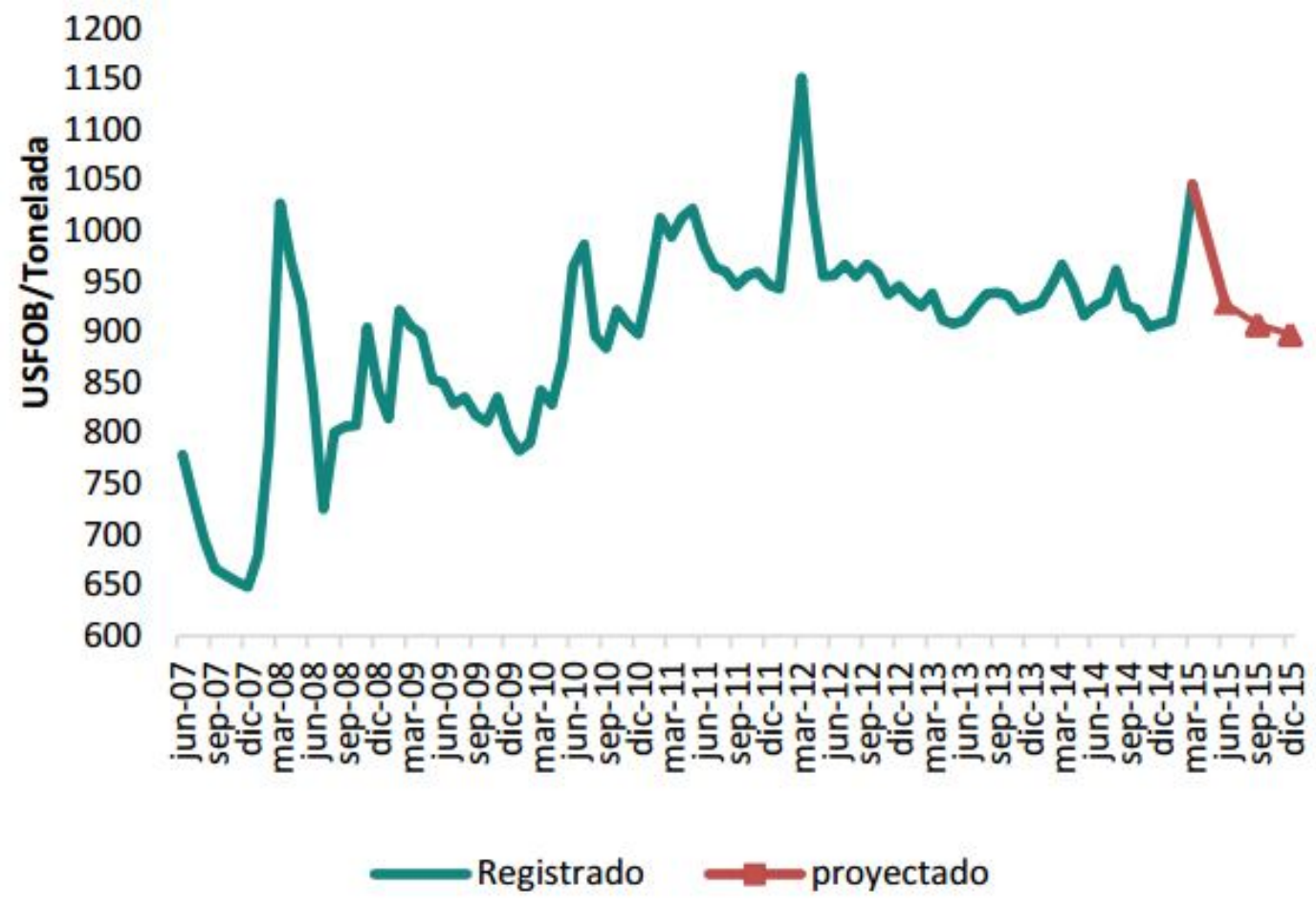

Fuente: FAO

${ }^{21}$ Datos Augura. 


\subsubsection{Sector Bananero Zona Urabá}

Al centrar el análisis en la zona de Urabá (Zona de Estudio) encontramos que la industria bananera genera 25 mil empleos directos representados en trabajadores de campo, fábricas de producción de cajas, sellos, plásticos, astilleros, servicio de fumigación y otras actividades del proceso de integración vertical que se ha desarrollado alrededor de esta actividad; y 75 mil indirectos, así mismo emplea otras 3.000 personas. (Augura, 2015).

Además del banano, otras actividades económicas en la zona son la exportación de plátano, cacao, ganadería, palma, piña, sector financiero, comercio y turismo (Augura, 2015). La población rural que no se desempeña en el sector bananero se dedica a actividades de economía campesina, explotación de bosques maderables y ganadería (Sena, 2003).

La economía solidaria es fuerte, en este sector pequeños productores están organizados en cooperativas y la gran mayoría están agremiados en Cordesu²2. Para el año 2001, estas cooperativas tenían cultivadas en promedio 385 hectáreas, generaba más de 180 empleos directos y 50 indirectos y comercializaban su producción a través de Uniban, Delmonte y Proban. Otra organización cooperativa importantes Coomuban, quienes se dedican a la comercialización interna del rechazo del banano generando más de 250 empleos indirectos (Sena, 2003).

La entidad gremial del sector y que se estableció en Urabá en 1963 es AUGURA, esta asociación representa los intereses de productores y comercializadoras de la industria ante entidades públicas y privadas, tanto nacionales como extranjeras. Es una corporación de derecho civil de interés colectivo sin ánimo de lucro, ayuda a fortalecer el sector por medio de programas de producción sostenible, que buscan valorar el recurso humano y natural, además del bienestar social de la zona, todo

22 Único Organismo de integración y representación gremial en la zona para el sector solidario 
esto dentro del marco del fortalecimiento de las exportaciones. Además aporta a la investigación y transferencia de tecnología y participa de forma activa en el desarrollo y proyección de las regiones productoras de banano de exportación (Augura, 2015).

Las empresas pertenecientes a esta zona se clasifican según sus hectáreas (Tabla 1) y se encuentran repartidas según su ubicación geográfica como lo muestra el Gráfico 10:

Tabla 1. Empresas Zona Urabá

\begin{tabular}{|l|c|c|}
\hline TIPO EM PRESA & HECTARIAS & \# EM PRESAS \\
\hline CATEGORIA I & $0-30$ & 37 \\
\hline CATEGORIA II & $31-80$ & 155 \\
\hline CATEGORIA III & $81-120$ & 82 \\
\hline CATEGORIA IV & Más 121 & 60 \\
\hline
\end{tabular}

Fuente: Sena, 2003

Gráfico 10. Distribución Geográfica Empresas Bananeras Urabá

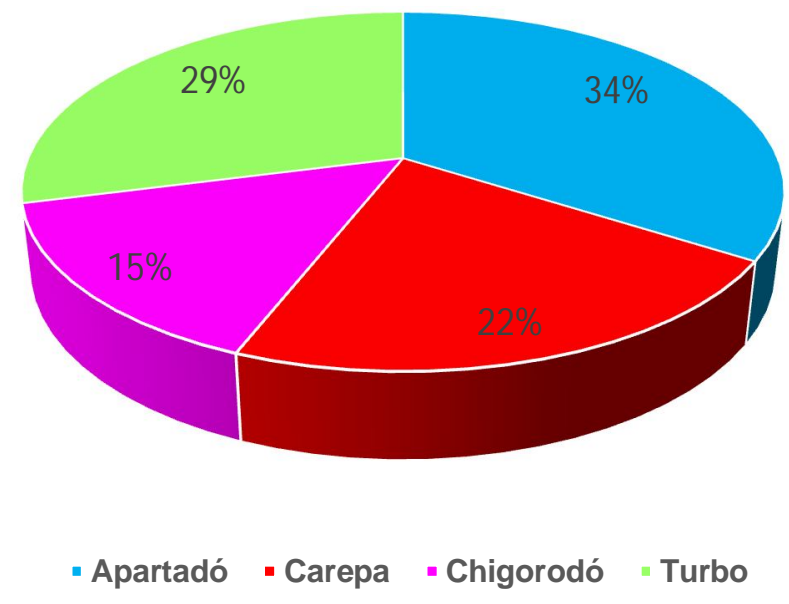

Fuente: Sena 2003 
Una característica de estas empresas es que en la medida en que sean más grandes aumenta el número de trabajadores técnicos operarios, mientras que los de nivel administrativo se mantienen.

En la zona se ha formado una fuerza laboral asentada, esto debido a que la demanda por mano de obra en las empresas bananeras es estable. La remuneración en el sector es superior al salario promedio a nivel nacional. Las negociaciones colectivas han contribuido a que el trabajador bananero reciba salarios muy superiores a otros cultivos agrícolas del país y muy por encima de un gran número de actividades industriales y comerciales, además se han logrado mayores prestaciones extralegales. (Ramírez \& Henao, 1987)

Los bananeros de la región de Urabá y Sintrainagro ${ }^{23}$, convienen los Acuerdos Generales, los cuales son difundidos en las convenciones colectivas en cada una de las fincas o en las personas jurídicas constituidas, que son las únicas que tienen capacidad jurídica para celebrar las convenciones cada dos años. En general las relaciones obrero patronales evolucionaron en medio del conflicto laboral y altos niveles de violencia.

La fuerte presencia de actores armados influía en la relación laboral y a ello se sumaba el tráfico de armas y el narcotráfico. Estos grupos ejercían presión, de una o de otra manera sobre trabajadores, empresarios y la población en general distorsionando ostensiblemente el ambiente laboral, lo que originó, a su vez, la necesidad de aumentar la presencia militar y, además un fuerte protagonismo de la Iglesia a fin de contribuir a la paz de la región. A pesar de esta situación se obtuvieron resultados que mejoraron significativamente los ingresos y prestaciones de la familia del trabajador bananero. Los incrementos salariales fueron superiores al $30 \%$, en contraste con los porcentajes obtenidos en otros sectores de la producción nacional. (Torres \& Guarnizo, 2004)

${ }^{23}$ Sindicato Nacional de los Trabajadores de la Industria Agropecuaria 
Las exportaciones de banano de la zona para el 2014 fue de 58,4 millones de cajas por valor de US\$518,9 millones, dándose una baja de $14,23 \%$ en el volumen y del $11,97 \%$ en el valor con respecto al 2013. Las hectáreas sembradas en el 2014 en las zonas fueron de 34.302; las cuales fueron 1.123 menos que en 2013. La productividad promedio también disminuyó respecto al 2013 pasaron de 1.924 cajas por hectárea al año a 1.704 .

En Urabá, UNIBAN fue la mayor exportadora con 31 millones de cajas de banano con una participación del 52,67\% del total exportado por Urabá. Luego esta BANACOL con 11 millones de cajas y una participación del 19,46\%.La tercera comercializadora en participación fue BANAFRUT, con el 10,32\% y 6 millones de cajas. La comercializadora TROPICAL, por su parte, con una participación del $8,18 \%$ ocupa el cuarto lugar (Tabla 2). (Augura, 2015)

Tabla 2. Exportación de Banano Urabá

Caja $20 \mathrm{Kg}$.

\begin{tabular}{|c|c|c|c|c|c|c|c|c|}
\hline Comercializ. & 2012 & Partic. & 2013 & Partic. & 2014 & Partic. & Var. $13 / 12$ & Var. 14/13 \\
\hline$\longdiv { \text { Uniban } }$ & $33,006,014$ & $51.23 \%$ & $33,724,881$ & $49.49 \%$ & $30,784,322$ & $52.67 \%$ & $2.18 \%$ & $-8.72 \%$ \\
\hline Banacol & $14,838,192$ & $23.03 \%$ & $17,002,286$ & $24.95 \%$ & $11,376,315$ & $19.46 \%$ & $14.58 \%$ & $-33.09 \%$ \\
\hline Banur & 411,411 & $0.64 \%$ & 510,949 & $0.75 \%$ & $\cdot$ & $0.00 \%$ & $24.19 \%$ & $-100.00 \%$ \\
\hline Conserba & $4,183,424$ & $6.49 \%$ & $4,482,253$ & $6.58 \%$ & $3,966,958$ & $6.79 \%$ & $7.14 \%$ & $-11.50 \%$ \\
\hline Banafrut & $6,252,025$ & $9.70 \%$ & $6,596,591$ & $9.68 \%$ & $6,033,492$ & $10.32 \%$ & $5.51 \%$ & $-8.54 \%$ \\
\hline Tropical & $5,268,676$ & $8.18 \%$ & $4,672,439$ & $6.86 \%$ & $4,779,577$ & $8.18 \%$ & $-11.32 \%$ & $2.29 \%$ \\
\hline Banarica & 240,709 & $0.37 \%$ & 237,219 & $0.35 \%$ & 111,274 & $0.19 \%$ & $-1.45 \%$ & $.53 .09 \%$ \\
\hline Coindex & 220,447 & $0.34 \%$ & 923,115 & $1.35 \%$ & $1,399,921$ & $2.39 \%$ & $318.75 \%$ & $51.65 \%$ \\
\hline$\sqrt{\text { Total }}$ & $\overline{64,420,898,08}$ & $100 \%$ & $68,149,733.00$ & $100 \%$ & $58,451,859.49$ & $100 \%$ & $\overline{5.79 \%}$ & $-14.23 \%$ \\
\hline
\end{tabular}

Fuente: Augura, 2015

En 2014 el 27,26\% del banano exportado por la región fue a Bélgica (15,9 millones de cajas). Al Reino Unido se exportó el 24,46\% (14,3 millones de cajas). A Estados Unidos se envió el 22,76\%. Hacia la Unión Europea se despacharon 44,026 millones de cajas que representan el $75,32 \%$ de la fruta exportada por la región (Tabla 3). 
Tabla 3. Exportación de Banano Urabá por Puerto de Destino Caja $20 \mathrm{Kg}$.

\begin{tabular}{|c|c|c|}
\hline País & Volumen & Partic. \\
\hline $\begin{array}{l}\text { Alemania } \\
\text { Bélgica } \\
\text { Costa Rica } \\
\text { España } \\
\text { Holanda } \\
\text { Italia } \\
\text { Mediterraneo } \\
\text { Portugal } \\
\text { Reino Unido } \\
\text { U.S.A. } \\
\end{array}$ & $\begin{array}{r}3,973,306 \\
15,936,714 \\
74,660 \\
340,972 \\
882,919 \\
8,550,676 \\
1,044,643 \\
44,246 \\
14,297,739 \\
13,305,984 \\
\end{array}$ & $\begin{array}{r}6.80 \% \\
27.26 \% \\
0.13 \% \\
0.58 \% \\
1.51 \% \\
14.63 \% \\
1.79 \% \\
0.08 \% \\
24.46 \% \\
22.76 \% \\
\end{array}$ \\
\hline $\begin{array}{l}\text { Total } \\
\text { Total U.E. }\end{array}$ & $\begin{array}{l}58,451,859 \\
44,026,572 \\
\end{array}$ & $\begin{array}{r}100.00 \% \\
75.32 \% \\
\end{array}$ \\
\hline
\end{tabular}

Fuente: Augura 2015.

\subsubsection{Estructura Salarial Urabá}

La región de Urabá ha sido señalada por su situación de orden público hasta finales del siglo XX, cuando el estado, autoridades civiles y religiosas, gremios, trabajadores y la población en general se reunieron para terminar con este ciclo de violencia que llevaba 30 años. (Augura,2014)

Las relaciones obrero - patronales han sufrido un largo proceso, el cual se puede dividir en cuatro fases, la primera se da de 1979 a 1987, el cual se caracteriza por las negociaciones colectivas realizadas por cada uno de los productores y por la suscripción de los primeros acuerdos sindicales. La fase dos va desde 1987 a 1989 y se caracteriza por una negociación realizada por un grupo de productores. La tercera fase va desde 1989 a 1995 en esta fase cada empresa conserva su autonomía al suscribir su propia convención la cual está sometida a los Acuerdos Generales. De estas fases se obtuvieron resultados importantes como la legitimización de Augura como interlocutor del proceso, la definición de dos temas; las condiciones laborales y de orden social; y por último se creó un mecanismo de concertación permanente. La fase actual cuenta con dos elementos adicionales, el 
preámbulo que tiene los principios, valores y metas de las relaciones obrero patronales y la comisión de verificación y seguimiento. (Augura, 2014)

La organización sindical en la actividad bananera de la zona tuvo su consolidación y auge a partir de 1984, al tener los acuerdos del proceso de paz de la administración Betancur, cuando un gran número de fincas con pacto colectivo pasaron a negociar convenciones colectivas. (Ramírez \& Henao, 1987)

En Septiembre de 1988 las ocho agrupaciones sindicales se declararon en cese de actividades indefinido como protesta por la carnetización donde todos los habitantes de la región deberían tener un carné de identificación. El paro se levantó 13 días después y el proceso de carnetización continuó en forma parcial. Sin embargo, en octubre del mismo año, como consecuencia de haber promovido un paro regional y apoyado a su vez uno nacional, el Ministerio de Trabajo suspendió la personería jurídica de Sintrabanano y Sintagro, por lo que estas organizaciones no podían negociar las convenciones colectivas de trabajo para 1989. Esto hizo que los trabajadores se agruparan en el Sindicato Nacional de Trabajadores de la Industria Agropecuaria SINTRAINAGRO el cual existía desde1975convirtiéndose en el sindicato más grande y con más fuerza pues concentró a la gran mayoría de los trabajadores. (Torres \& Guarnizo, 2004)

A partir de estos acontecimientos se determinó que los contratos de trabajo de las actividades permanentes de las fincas serian a término indefinido, menos cuando se trate de aumentos en la producción, transporte, vacaciones, licencias, incapacidades, practicantes y siembras nuevas; en estos casos se podrán firmar contratos a término fijo.(Sena, 2003)

Los Salarios en el sector han evolucionado a la par con el IPC más el aumento que se ha determinado en las convenciones, dando como resultado un salario mínimo promedio más alto que el Salario Mínimo Legal (Tabla 4) (Gráfico 11) (Anexo 1 y 2) 
y los incrementos salariales en su mayoría son superiores a los que se obtienen en otro sector de la producción nacional (Grafico 12). (Ramírez \& Henao, 1987)

Tabla 4. Salario Mínimo Legal Vs. Salario Mínimo Sector Bananero Urabá

\begin{tabular}{|c|c|c|c|c|c|}
\hline Año & $\begin{array}{l}\text { Salario mínimo } \\
\text { mensual }\end{array}$ & $\begin{array}{l}\text { Variación \% } \\
\text { SMLV }\end{array}$ & $\begin{array}{l}\text { Salario minino promedio } \\
\text { sector bananero }\end{array}$ & $\begin{array}{l}\text { Variación } \\
\% \text { SMB }^{\star}\end{array}$ & $\begin{array}{l}\text { Relación } \\
\text { SMB/SMLV }\end{array}$ \\
\hline 1984 & $11,298.00$ & $22 \%$ & $20,800.00$ & $16.66 \%$ & 1.84 \\
\hline 1985 & $13,558.00$ & $19,99 \%$ & $25,200.00$ & $18.26 \%$ & 1.86 \\
\hline 1986 & $16,811.00$ & $24,01 \%$ & $30,700.00$ & $22.45 \%$ & 1.83 \\
\hline 1987 & $20,510.00$ & $22,00 \%$ & $50,000.00$ & $20.95 \%$ & 2.44 \\
\hline 1988 & $25,637.00$ & $25,00 \%$ & $59,575.00$ & $19.15 \%$ & 2.32 \\
\hline 1989 & $32,560.00$ & $26,99 \%$ & $76,327.49$ & $28.12 \%$ & 2.34 \\
\hline 1990 & $41,025.00$ & $26,01 \%$ & $96,348.19$ & $26.23 \%$ & 2.35 \\
\hline 1991 & $51,716.00$ & $26,07 \%$ & $127,536.10$ & $32.37 \%$ & 2.47 \\
\hline 1992 & $65,190.00$ & $26,04 \%$ & $161,741.28$ & $26.82 \%$ & 2.48 \\
\hline 1993 & $81,510.00$ & $25,03 \%$ & $186,956.75$ & $15.59 \%$ & 2.29 \\
\hline 1994 & $98,700.00$ & $21,09 \%$ & $229,227.67$ & $22.61 \%$ & 2.32 \\
\hline 1995 & $118,934.00$ & $20,50 \%$ & $281,033.12$ & $22.60 \%$ & 2.36 \\
\hline 1996 & $142,125.00$ & $19,50 \%$ & $335,722.17$ & $19.46 \%$ & 2.36 \\
\hline 1997 & $172,005.00$ & $21,02 \%$ & $408,372.44$ & $21.64 \%$ & 2.37 \\
\hline 1998 & $203,826.00$ & $18,50 \%$ & $408,372.44$ & $0.00 \%$ & 2.00 \\
\hline 1999 & $236,460.00$ & $16,01 \%$ & $493,926.47$ & $20.95 \%$ & 2.09 \\
\hline 2000 & $260,100.00$ & $10,00 \%$ & $553,197.65$ & $12.00 \%$ & 2.13 \\
\hline 2001 & $286,000.00$ & $9,96 \%$ & $601,602.44$ & $8.75 \%$ & 2.10 \\
\hline 2002 & $309,000.00$ & $8,04 \%$ & $655,746.66$ & $9.00 \%$ & 2.12 \\
\hline 2003 & $332,000.00$ & $7,44 \%$ & $701,583.35$ & $6.99 \%$ & 2.11 \\
\hline 2004 & $358,000.00$ & $7,83 \%$ & $757,710.02$ & $8.00 \%$ & 2.12 \\
\hline 2005 & $381,500.00$ & $6,56 \%$ & $799,384.07$ & $5.50 \%$ & 2.10 \\
\hline 2006 & $408,000.00$ & $6,95 \%$ & $851,344.04$ & $6.50 \%$ & 2.09 \\
\hline 2007 & $433,700.00$ & $6,30 \%$ & $889,484.25$ & $4.48 \%$ & 2.05 \\
\hline 2008 & $461,500.00$ & $6,41 \%$ & $953,438.17$ & $7.19 \%$ & 2.07 \\
\hline 2009 & $496,900.00$ & $7,67 \%$ & $1,029,713.22$ & $8.00 \%$ & 2.07 \\
\hline 2010 & $515,000.00$ & $3,64 \%$ & $1,050,307.49$ & $2.00 \%$ & 2.04 \\
\hline 2011 & $535,600.00$ & $4,00 \%$ & $1,108,074.40$ & $5.50 \%$ & 2.07 \\
\hline 2012 & $566,700.00$ & $5,81 \%$ & $1,149,405.57$ & $3.73 \%$ & 2.03 \\
\hline 2013 & $589,500.00$ & $4,02 \%$ & $1,195,381.79$ & $4.00 \%$ & 2.03 \\
\hline 2014 & $616,000.00$ & $4,50 \%$ & $1,218,572.20$ & $1.94 \%$ & 1.98 \\
\hline 2015 & $644,350.00$ & $4,60 \%$ & $1,291,686.53$ & $6.00 \%$ & 2.00 \\
\hline
\end{tabular}

Fuente: Cálculos propios a partir de datos del Banco de la República y de los Acuerdos Generales del sector a partir de 1987.

*Salario mínimo promedio sector bananero 


\section{Grafico 11. Evolución SMLV y SMB}

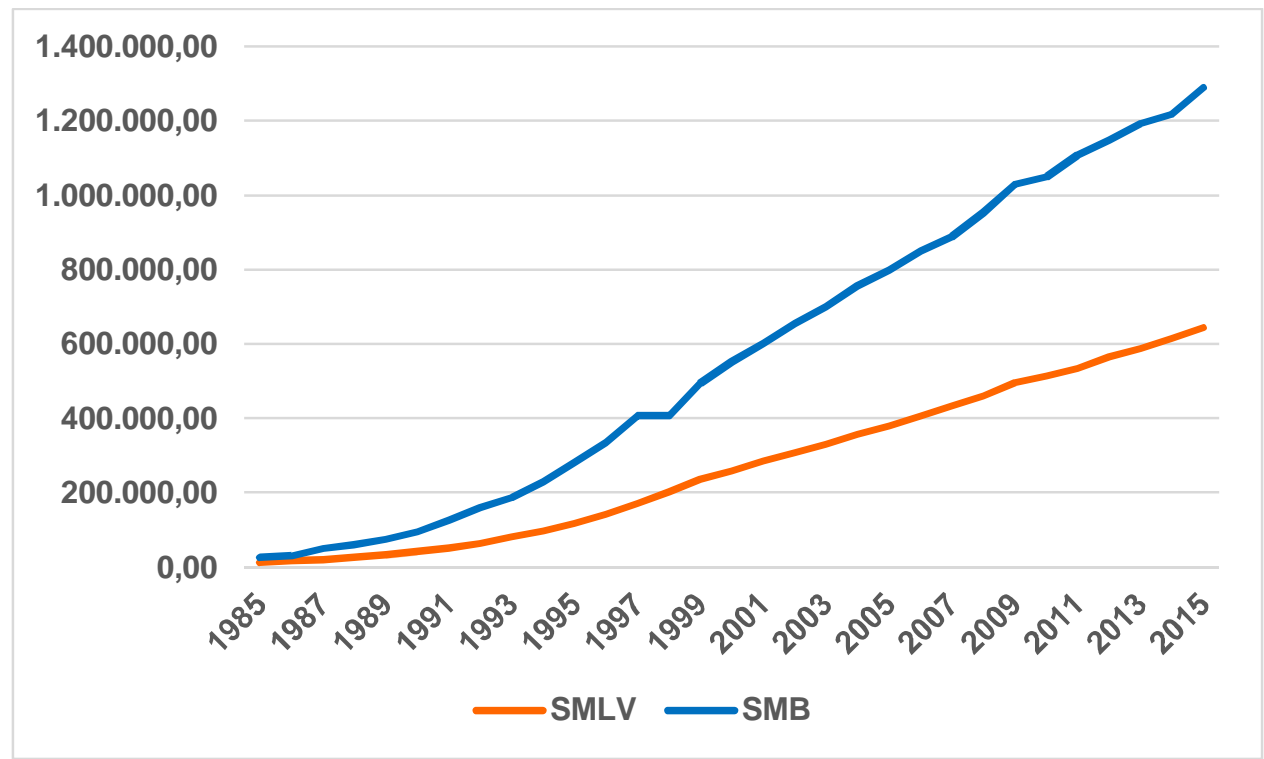

Fuente: cálculos de los autores recogidos a través de la Tabla 4

\section{Grafico 12. Aumentos $S M L V$ y $S M B^{*}$}

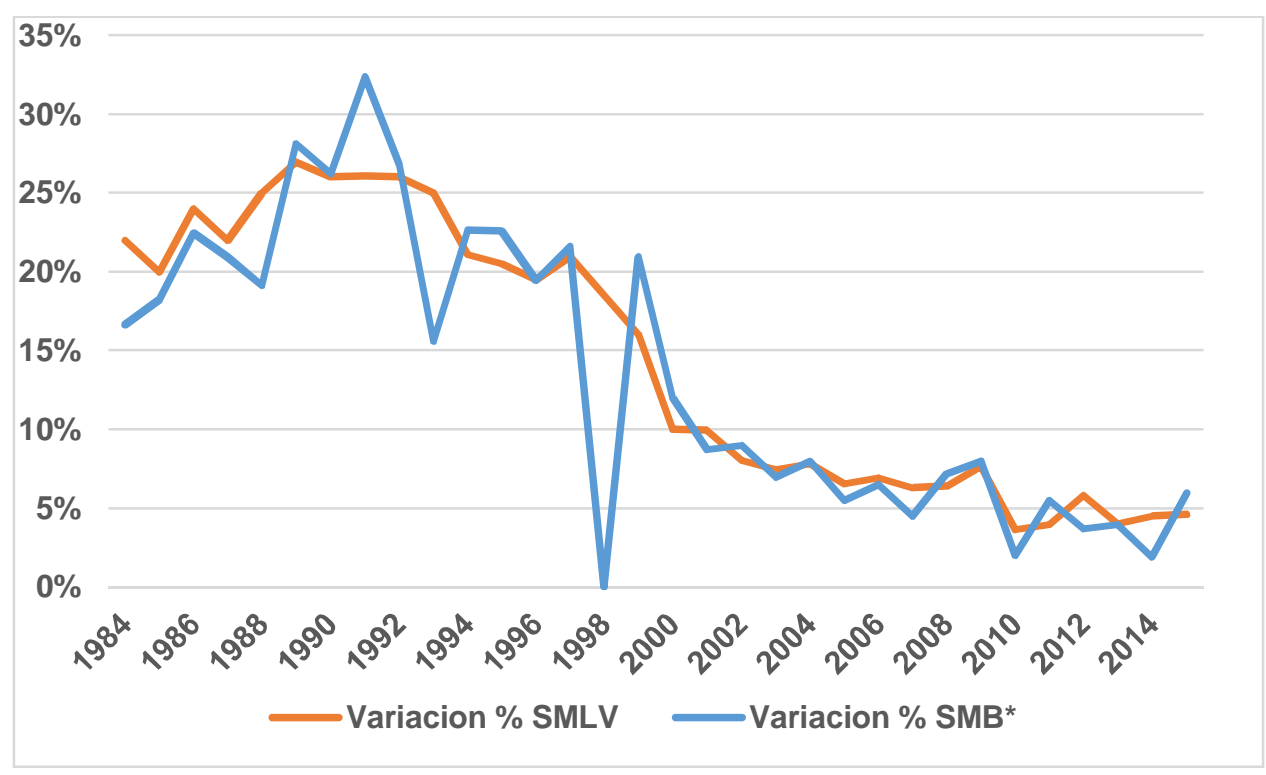

Salario Mínimo Sector Bananero

Fuente: Datos Tabla 4

Las convenciones han hecho que se mejoren los salarios y beneficios de los trabajadores del sector (Tabla 5), dichas convenciones se realizan cada dos años y en ellas se determinan los Acuerdos Generales, los que contienen generalmente los 
acuerdos relativos a las garantías sindicales, reconocimientos sindicales, licencias, permisos, auxilios sindicales, los sistemas de contratación de personal, jornadas de trabajo, formas de remuneración, procedimientos disciplinarios y de despido, conformación de los comités obrero patronales, vigencia de las convenciones, incrementos salariales, incrementos en prestaciones extralegales, compensaciones económicas, dotaciones y servicios de transporte, fondos de calamidad doméstica y de vivienda, educación, recreación y cultura, pago de incapacidades y acuerdos sobre creación de labores nuevas.

Tabla 5. Prestaciones Extralegales

\begin{tabular}{|c|}
\hline NOMBRE PRESTACION \\
\hline Auxilio maternidad \\
Auxilio vacaciones \\
Auxilio aguinaldo \\
\hline Auxilio arriendo \\
\hline Auxilio escolaridad primaria \\
\hline Auxilio escolaridad \\
secundaria \\
\hline Auxilio muerte de familiar \\
\hline Auxilio de casino \\
\hline Fuente: Convención 2011 - 2013 \\
\hline
\end{tabular}

En el presente año se realizó la última convención donde los Acuerdos Generales suscritos tienen específicamente los siguientes temas:

- Aspectos sindicales y normativos: Campo de aplicación, Viáticos para comisiones obreras, Auxilios a Sintrainagro, Modificación parcial al acuerdo sobre aportes a la seguridad social por directivos en licencia no remunerada y la Adición al acuerdo sobre aplicación del artículo 21 de ley 50 de 1990.

- Asuntos sobre seguridad y salud en el trabajo: Modificación del acuerdo sobre traslado de trabajadores enfermos, Acuerdo adicional a la disposición convencional sobre pago de incapacidad y transcripción de incapacidades, Adición sobre "constancias de asistencia al servicio médico", modificación del 
acuerdo convencional sobre "exámenes médicos", modificación al acuerdo sobre trabajadores reubicados, Acuerdo sobre suministro de dotación de labor.

- Fondos sociales: Fondos paritarios convencionales de vivienda, aporte extra convencional de educación, recreación cultura y deporte, Creación de la comisión paritaria de concertación laboral.

- Aspectos económicos: Incremento salarial, incremento en prestaciones extralegales, vigencia de las convenciones colectivas, incorporación de disposiciones convencionales, auxilio sindical especial por la negociación en etapa de arreglo directo (2015-2017), proceso de vaciado de las convenciones, finalización del conflicto colectivo. (Augura \& Sintrainagro, 2015)

\subsection{ASPECTOS METODOLÓGICOS}

Como se mencionó en la descripción del sector, la zona de Urabá abarca el $73,3 \%$ de hectáreas total cultivadas referentes al banano concentrándose en 334 fincas distribuidas en diferentes categorías de producción. ${ }^{24}$ Esto implica que la mano de obra en producción del total de fincas en el sector es de aproximadamente 18.000 trabajadores, de los cuales algunos son residentes de la zona y otros emigrantes de otras regiones del país.

Los acercamientos que se realizaron al subsector bananero fueron iniciados desde AUGURA, entidad que permitió el acceso a la información preliminar que se tiene del sector en referencia a la productividad, estructura de costos y salarios. De esta

\footnotetext{
${ }^{24}$ Referirse a la tabla 3 del apartado 4.1.3
} 
forma se pudo acceder a datos y fuentes secundarias (revistas, folletos, publicaciones, investigaciones, etc.) además de entrevistas con algunos empresarios y trabajadores del sector.

La metodología utilizada en la investigación fue exploratoria $y$ descriptiva, considerando que este diseño investigativo parte del supuesto que existe muy poca referencia teórica y de análisis respecto al salario de eficiencia en el subsector agroindustrial del banano. ${ }^{25}$

\subsubsection{Información Primaria}

Este aparte tuvo como objetivo fundamental, recoger información del sector bananero de Urabá que midiera el impacto de la productividad y demás variables en los salarios de los trabajadores. Luego de los acercamientos y visitas realizadas a la Asociación de Bananeros de Colombia (AUGURA), en donde se recogió información del sector sobre convención sindical, productividad, estudios del sector a nivel socio- económicos, etc., el Dr. Jhon Jairo Gallego - Secretario General Augura- y el Dr. Luis Alberto Sanín -Gerente de la empresa Agrochiguiros -junto con el Dr. Gustavo Díaz tutor y acompañante en esta investigación, procedieron a revisar la encuesta (Anexo 3) propuesta con la cual se utilizó como herramienta para encontrar las variables más relevantes que avalen el salario eficiente que se otorga en el sector (Anexo 4), esto basado en principio en el modelo teórico de ShapiroStiglitz.

Las encuestas fueron aplicadas directamente en las fincas del sector. Para ello se utilizó una muestra de 9 fincas bananeras a 213 empleados relacionadas de la siguiente manera:

\footnotetext{
${ }^{25}$ De acuerdo a los estudios referentes a la metodología de la investigación autores como Sampieri afirman que los diseños investigativos exploratorios tiene como objetivo "examinar un tema o problema de investigación poco estudiado o que no ha sido abordado antes" (Sampieri, 2006, p. 102). En este mismo sentido, también se ajusta para el estudio de investigación el diseño descriptivo con lo cual "busca especificar las propiedades que son sometidas para un análisis" (Sampieri, 2006, p. 102)
} 
Tabla 6. Fincas Encuestadas

\begin{tabular}{|c|c|c|c|c|}
\hline $\begin{array}{l}\text { NOMBRE DE } \\
\text { LA FINCA }\end{array}$ & $\begin{array}{c}\text { No DE } \\
\text { HECTÁREAS }\end{array}$ & $\begin{array}{c}\text { CANTIDAD TOTAL } \\
\text { DE } \\
\text { TRABAJADORES }\end{array}$ & $\begin{array}{c}\text { NUMERO DE } \\
\text { PERSONAS } \\
\text { ENCUESTADAS }\end{array}$ & $\begin{array}{l}\text { PORCENTAJE } \\
\text { DE MUESTRA } \\
\text { ENCUESTADA }\end{array}$ \\
\hline PARAÍSO & 243 & 198 & 35 & $18 \%$ \\
\hline CANTARRANA & 72,18 & 50 & 26 & $52 \%$ \\
\hline CHAMBACÚ 1 & 23,78 & 15 & 11 & $73 \%$ \\
\hline CHAMBACÚ 2 & 77,44 & 70 & 12 & $17 \%$ \\
\hline ESPERANZA & 104 & 70 & 17 & $24 \%$ \\
\hline REINO & 76,27 & 56 & 4 & $7 \%$ \\
\hline ELANTOJO & 168 & 115 & 44 & $38 \%$ \\
\hline UCRANIA & 124 & 85 & 47 & $55 \%$ \\
\hline MARYLAND & 95.24 & 44 & 17 & $39 \%$ \\
\hline
\end{tabular}

Fuente: Augura y cálculos de los autores

Es preciso notar que los datos obtenidos desde el punto de vista estadístico son datos de corte transversal llamados así porque la muestra se tomó o se recogieron los datos en un momento dado en el tiempo ${ }^{26}$. Se aclara también que la muestra obtenida es para realizar una prueba piloto a petición de Augura para hacer un estudio inicial, por lo que la muestra es del 1,96\% de la población total del sector.

\subsubsection{Información secundaria}

Se realizó el estudio de la documentación existente en el centro de documentación estudios de AUGURA, dónde se consultaron los Acuerdos Generales de las negociaciones realizadas e investigaciones llevadas a cabo por la agremiación y otras instituciones como el SENA. También se consultó literatura de la agroindustria Colombiana y de otros países. Las bases de datos del Banco Mundial, DANE, el SENA, CEPAL, todas éstas correspondientes a registros estadísticos de la agricultura mundial y de la región, apoyan éste trabajo para

\footnotetext{
${ }^{26}$ Véase Wooldrige capítulo 1 "La naturaleza de la econometría y los datos económicos"
} 
determinar las variables que influyen en el salario eficiente que se genera en el sector bananero de Urabá.

\subsection{MODELO PROBIT EN LA DETERMINACIÓN DE LOS SALARIOS DE EFICIENCIA}

En la presentación del modelo, cabe resaltar que uno de los objetivos específicos en la consolidación de esta investigación radica en "analizar las variables que determinan los salarios en el sector Bananero de la región de Urabá", por tanto y haciendo mención en la Tabla 4 la probabilidad de obtener un salario eficiente bajo variables que afectan éste pago, son determinadas mediante modelos de regresión de respuesta cualitativa.

En este sentido los modelos Logit y Probit, juegan un papel fundamental en la modelación que se exige para justificar desde el orden econométrico avalar los salarios de eficiencia en el sector bananero de Urabá. A diferencia de los modelos de regresión cuantitativa ${ }^{27}$ estos modelos llamados "modelos de probabilidad" buscan dar a la variable dependiente o regresora valores entre 0 y 1 definidos mediante: $P(y=1 \| x)=P\left(y=1 \| x_{1}, x_{2}, \ldots, x_{3}\right)$ donde $P$ es la probabilidad de obtener un valor en $y$ dado unas variables $(x)$ llamadas regresoras.

A partir del planteamiento anterior, es importante resaltar algunos aspectos de orden matemático y estadístico relevantes que cuestionan la utilización de un Modelo Lineal de Probabilidad- MLP- para hallar su valor estimado. Los Modelos Lineales de Probabilidad -MLP-, fueron en su momento una extensión del Modelo Lineal General (Ilamado también Mínimos Cuadrados Ordinarios), en la que una nube de puntos generada por la variable explicativa debía ajustarse al MLP a una función lineal que fuera capaz de explicar lo mejor posible lo acontecido con dichas variables. De esta forma se utilizaría la siguiente función:

\footnotetext{
${ }^{27}$ Estos modelos tienen como objetivo estimar el valor esperado de las variables regresoras, es decir, $E\left(Y_{1} \|\right.$ $\left.X_{1 i}, X_{2 i}, \ldots X_{k i}\right)$ (Gujarati, 2009)
} 


$$
\begin{aligned}
& \quad Y_{i}=\alpha+\beta_{k} X_{k i}+\varepsilon_{i} \\
& Y_{i}\left\{\begin{array}{c}
1 \text { si ocurre } \\
0 \text { si no ocurre }
\end{array}\right. \\
& X_{k i}\{\text { Variables explicativas } \\
& \varepsilon_{i}\left\{\text { Término error que se distribuye normal } N\left(0, \delta^{2}\right)\right.
\end{aligned}
$$

Sin embargo, la utilización de éste modelo presenta algunas limitaciones:

- La utilización del MLP mediante el método de MCO no garantiza que los valores estimados de $\hat{Y}$ estén entro 0 y 1 . De acuerdo a ello puede utilizarse el Modelo Probabilístico Lineal Truncado haciendo ajustes en el estimador, pero esto genera que los estimadores sean sesgados e inconsistentes (Gujarati, 2009). ${ }^{28}$

- $\quad$ El término error puede no seguir una distribución normal, lo cual impide realizar contraste de hipótesis tales como $t$-Student, F-Snedecor, etc.

- $\quad$ Se produce problemas de homocedasticidad, es decir que la varianza de los errores no es constante.

- Con las limitaciones presentadas, es conveniente utilizar modelos de probabilidad no lineales, que garantice un resultado de la estimación entre un rango de 0-1. Una de las funciones que responde mejor a este comentario son las funciones de distribución, las cuales son continuas y manejan intervalos comprendidos entre $0-1$.

Lo anterior justifica el hecho de utilizar funciones de distribución logística (modelo Logit) o la función de distribución normal tipificada (modelo Probit). Para ambos

\footnotetext{
${ }^{28}$ Un estimador es sesgado cuando $E[\hat{\theta}] \neq \theta$, por tanto $E[\hat{\theta}]-\theta \neq 0$. En este sentido se dice que son inconsistentes cuando al crecer el tamaño de la muestra, las estimaciones de $\hat{\theta}$ se aproximan cada vez más al valor del parámetro
} 
casos la $P(y=1 \| x)=P\left(y=1 \| x_{1}, x_{2}, \ldots, x_{3}\right)$ seria ajustada por medio de una función que asume valores estrictamente entre 0 y 1 como sigue:

$P(y=1 \| x)=G\left(\beta_{0}+\beta_{1} x_{1}+\cdots, \beta_{k} x_{k}\right)=G\left(\beta_{0}+x \beta\right), \quad 0 \leq G(z) \leq 1, \forall z \in R$

En este sentido $G(z)$, sería entonces la función que garantizaría que la probabilidad del estimador esté entre 0 y 1 (Wooldrige, 2010). Por lo anterior la Tabla 7 muestra una relación entre los dos modelos considerando elementos de orden econométrico importantes a tener en cuenta en la decisión de tomar el modelo probit como el modelo general en la estimación de los salarios de eficiencia en el sector bananero de Urabá:

Tabla 7. Relación Modelo Probit y Logit

\begin{tabular}{|c|c|c|}
\hline \multirow[b]{3}{*}{ FUNCIÓN } & \multicolumn{2}{|c|}{ MODELO } \\
\hline & LOGIT & PROBIT \\
\hline & $\widehat{Y}_{l}=\frac{e^{\alpha+\beta_{k} X_{k i}}}{1+e^{\alpha+\beta_{k} X_{k i}}}+\varepsilon_{i}$ & $\widehat{Y}_{l}=\int_{-\infty}^{\alpha+\beta x_{i}} \frac{1}{(2 \pi)^{1 / 2}} e^{\frac{-y^{2}}{2}} d y+\varepsilon_{i}$ \\
\hline $\begin{array}{c}\text { EFECTOS } \\
\text { MARGINALES }\end{array}$ & $\frac{\partial P}{\partial X_{k}}=P(1-P) \beta_{k}$ & $\frac{\partial P}{\partial X_{k}}=G(z)(\beta X) \beta_{k}$ \\
\hline $\begin{array}{l}\text { INTERPRETACIÓN DE } \\
\text { LAS VARIABLES }\end{array}$ & $\begin{array}{c}{ }^{* *} \text { Ratio Odds: } \\
\frac{P_{1}}{1-p_{i}}=\ln \left(e^{\alpha+\beta_{k} X_{k i}}\right)=\alpha+\beta_{k} X_{k i}\end{array}$ & $\begin{array}{c}{ }^{\star * *} \text { Efecto marginal } \\
\frac{\partial P}{\partial X_{k}} \frac{\partial P}{\partial Y} \beta_{k}=\frac{1}{(2 \pi)^{1 / 2}} e^{\frac{-y^{2}}{2}} \beta_{k}\end{array}$ \\
\hline
\end{tabular}

** El Ratio Odds linealiza la ecuación del modelo Logit haciendo que los valores estimados estén obligatoriamente entre 0 y 1 (Gujarati, 2009).

${ }^{* \star *}$ La interpretación de los coeficientes estimados a través de máxima verosimilitud se interpretan como el cambio marginal de la probabilidad dado un cambio en el valor de la variable independiente (Rosales, Perdomo, Morales \& Urrego, 2010).

Fuente: Gujarati (2009) \& Wooldrige (2010)

Se aclara que el método de máxima verosimilitud ${ }^{29}$ se resalta en este tipo de modelos debido a que las variables a trabajar son limitadas (Wooldrige 2010).

${ }^{29}$ Éste método se basa en la idea de tomar como valor del parámetro estimado la probabilidad máxima de obtener la una muestra observada. Dentro de los modelos Logit y Probit, este método se analiza a través de la función de densidad conjunta o de verosimilitud que para cada caso es la función logística y la función de distribución normal tipificada - $G(z)$ - respectivamente (Wooldrige 2010) 
La utilización del modelo probit o logit dependerá de que tan ajustados estén los estimadores dentro del modelo. De aquí que una de las justificaciones más fuertes en la utilización del modelo Probit radica en:

1. Los residuos evitan violar los supuestos de homocedasticidad y normalidad presentados en los MCO y en los MLP, dado que estos conllevan a errores en las pruebas de hipótesis y errores de estándar válidos (Camargo, 2014).

2. A pesar que cualitativamente son parecidos (Logit y Probit), el Probit implica dentro de su modelo una variable latente continua al cual el investigador esta interesado en estudiar ${ }^{30}$.

3. El error de la variable dependiente truncada en modelos de auto-selección son generados por una distribución normal y por lo tanto se puede modelar mediante el Probit. (Echautegui 2010)

4. En modelos de mercado laborales como el que se está ajustando, en específico el de salarios de eficiencia, por la evidencia empírica el modelo Probit es mejor que el Logit (Posada \& Arango, 2002), (Ortíz, Uríbe \& García 2007), (Camargo, 2014).

De esta forma el modelo Probit nos determinará si el salario percibido por el trabajador es eficiente teniendo en cuenta que desde la teoría propuesta por Shapiro - Stiglitz se aduce que en la medida en que el salario eficiente o crítico se iguale a las variables endógenas del salario percibido, generará una utilidad favorable cuando se haga un aumento salarial. De aquí que se tiene:

$$
w \geq r V_{u}+(r+b+q) e / q=\widehat{w}
$$

\footnotetext{
${ }^{30}$ Para el caso de los salarios de eficiencia en el sector de Urabá, se consideran variables como la tasa activa de ganancia, el tiempo en la finca, la cantidad de convenciones a las cuales ha pertenecido, etc., que hacen más probable encontrar los estimadores a partir de este modelo.
} 
A este modelo se le incorporaron algunas variables que se consideraron de manera intuitiva importantes debido a que pueden afectar el salario percibido, que para el caso es el de eficiencia.

El modelo propuesto para avalar los salarios de eficiencia en el sector bananero de Urabá es el que a continuación se menciona:

$$
\beta_{0}+r t_{d}+I+S+T+\frac{(r+b+q) e}{q}=\widehat{w}
$$

Este modelo muestra la relación que tiene el salario de equilibrio $\widehat{w}$ respecto a las variables endógenas suscritas desde la teoría de Shapiro-Stiglitz y las propuestas en ésta investigación:

\section{$>$ La tasa de desempleo $\left(\boldsymbol{r} \boldsymbol{t}_{\boldsymbol{d}}\right)$}

Dados los conceptos establecidos por Shapiro-Stiglitz (1984) referente a este ajuste, la tasa de desempleo del sector aumentará en la medida en que los empleados los encuentren holgazaneado. De esta manera la variable "tasa de desempleo" será directamente proporcional con el salario eficiente, implicando que a mayor desempleo el salario será más eficiente por que los empleados que quedan después del recorte se esfuercen en producir igual o más de lo que inicialmente hacían.

Dentro del sector bananero de Urabá y considerando que los datos obtenidos se hicieron en un momento dado de tiempo, esta tasa de desempleo será una constante según los criterios establecidos por el modelo ${ }^{31}$. De esta manera, la variable $\boldsymbol{r} \boldsymbol{t}_{\boldsymbol{d}}$ no entrará dentro del análisis del modelo final.

\footnotetext{
${ }^{31}$ Debido a la utilización del modelo Probit, este no diferenciará dentro de la matriz de estimación valores diferentes. Por lo tanto el modelo lo asumirá como un único dato el cual no representará ningún cambio o significancia dentro de los valores de las variables regresoras, específicamente la tasa de desempleo.
} 


\section{$>$ Incentivos $(\boldsymbol{I})$}

Como se propone desde las ideas de Riveros (2009), los incentivos caracterizados a través de la rotación laboral, la lealtad a los objetivos organizacionales y beneficios futuros, deduce que esta variable afecta de manera significativa el salario eficiente. Para Romer (2006) los compromisos que adquieran las firmas a sus trabajadores en cuanto a un pago mayor sin aumentar los costos radica principalmente en el incentivo retributivo, es decir, generando incentivos en especie que haga al trabajador más "feliz" dentro de su labor diaria.

Dentro de la caracterización del sector Bananero de Urabá, los incentivos que se generen se basan dentro de la lógica emanada por Riveros y Romer, el cual incide de manera directa sobre el clima laboral ${ }^{32}$ dado por cada una de las fincas.

Para el análisis del estudio, esta variable sale de la caracterización de las preguntas referidas a la encuesta establecida (Anexo 3) que determina el incentivo recibido por el trabajador de acuerdo a la finca en la que labora (Anexo 5).

\section{$>$ Existencia de convenciones sindicalistas $(\boldsymbol{S})$}

Dentro de los estudios realizados por Bulkley \& Myles (1996) mencionan que la percepción que se tiene sobre los sindicatos es que los trabajadores que pertenecen a estos grupos realizan un menor esfuerzo. Sin embargo, la evidencia empírica desarrollada por estos autores demuestra lo contrario. Manifiestan que si se tiene una supervisión imperfecta del sindicato y al tener éstos el poder de decisión,

\footnotetext{
${ }^{32}$ El clima laboral o medio ambiente interno, se define como "el ambiente que los empleados perciben de una serie de características propias de la empresa. De acuerdo con ello se define si los comportamientos de los empleados son adecuados o no para el bienestar de una empresa" (Universidad Nacional de Colombia 1994).
} 
permite un mayor salario que conducen a un mayor esfuerzo por parte de los trabajadores sindicalizados.

En el sector bananero de Urabá la existencia de sindicatos genera para los trabajadores mejores salarios debido a los Acuerdos Generales obtenidos dentro de las convenciones que se desarrollan para establecer criterios de aumentos y beneficios extralegales. En estas convenciones se sostiene el hecho de que "beneficiará a los trabajadores afiliados a Sintrainagro que se encuentren vinculados laboralmente a la empresa $(. . .)^{33 "}$.

Con la información extraída de las encuestas aplicadas, la pregunta a la cual se asocia esta variable se describe como ¿Qué tiempo lleva en la finca? Con esta información y acorde con la cantidad de convenciones realizadas entre los empresarios y el sindicato dadas a partir del año de 1987, se obtiene un valor en años que mide la participación sindical de cada trabajador (Anexo 5). Esto se justifica en el hecho referenciado sobre el objetivo de la convención, la cual se realiza cada dos años.

\section{$>$ Tasa de ganancia activa por trabajador $(\boldsymbol{r})$}

Del modelo general presentado por Shapiro -Stiglitz en su artículo Equilibrium Unemployment as a Worker Discipline Device, la tasa activa de ganancia por trabajador representa la utilidad que cada trabajador genera a la empresa. Dada esta definición se calculó dicha tasa para cada trabajador encuestado de la siguiente forma:

$$
r=\frac{\text { Utilidad generada por trabajador }}{\text { Utilidad de la Empresa }}
$$

\footnotetext{
33 Tomado de la Negociación colectiva entre Sintrainagro y los empresarios Bananeros de Urabá; acuerdos generales 2013 - 2015
} 
Donde la utilidad generada por trabajador es igual a los ingresos promedios por trabajador menos los costos laborales y de producción que corresponden a cada trabajador (Anexo 5). Ésta relación se tomó semanalmente.

\section{$>$ Tasa de abandono o tareas no terminadas $(\boldsymbol{b})$}

Esta variable se refiere aquellos aspectos intrínsecos dentro del ejercicio laboral, los argumentos de Shapiro-Stiglitz (1984) indican que el aumento de la tasa de abandono o la disminución del mismo convergen de una u otra manera a cambios sustanciales en el salario. De esta manera la consecuencia en el cambio de esta variable se ve reflejada en el salario eficiente que de una u otra forma induce a las personas a trabajar. Así mismo Desormeaux (2010) relaciona la tasa de abandono con una caída en los salarios nominales producidos por el shock de la oferta agregada deducida a partir de la caída en la oferta monetaria.

De esta relación, la variable en estudio dentro del sector bananero de Urabá dependerá exclusivamente de la cantidad de ausencias presentadas por parte de los trabajadores (Anexo 5) respecto a su actividad laboral relacionada en la encuesta anexa. No obstante otras variables como "el cambio de oficio" genera de una forma u otra una relación directa con la tasa de abandono justificada solamente desde el punto de vista psicológico asociado a los incentivos (Anexo 5).

\section{$>$ Persona eludiendo su trabajo $(\boldsymbol{q})$}

La teoría de salarios de eficiencia descrita por Shapiro - Stiglitz, argumenta que eludiendo un trabajador sus tareas, éste puede tener una alta probabilidad de enfilar la listas del desempleo si y solo si existe un pleno empleo y la supervisión es imperfecta. De otra parte, manifiesta que el aumento en el salario debido a su esfuerzo reduce la probabilidad de encontrar un trabajador holgazaneando, 
generando así mismo un desempleo involuntario. Este argumento es veraz y relevante dentro del modelo de salarios de eficiencia.

Con estos elementos, es de considerar que dentro del sector bananero de Urabá un trabajador que posea estas características de "holgazanear" se da si dentro de las fincas en las que labora, los supervisores los encuentran realizando actividades de ocio que implique despedirlos. A tal fin y dentro de la dinámica que se trabaja en el sector bananero, la variable resultaría de dividir la cantidad de supervisores entre la cantidad total de trabajadores que hay en cada finca. De esta manera se encontraría la probabilidad de encontrar o no un trabajador eludiendo sus tareas (Anexo 5).

$$
q=\frac{\text { Cantidad supervisores en la finca }}{\text { Cantidad de empleados en la finca }}
$$

\section{$>$ Tasa de cambio $(\boldsymbol{T})$}

Aunque la teoría sobre los salarios de eficiencia no detalla de forma endógena este componente, es preciso hacer mención del mismo dentro de las variables de ajuste. Una de las razones por las cuales se debe tener en cuenta dentro del modelo, radica en la comercialización del producto en el exterior. Debido a ello y a lo largo de la historia desde la fundación de AUGURA, el banano dentro del último quinquenio representa el $0.4 \%$ del PIB colombiano y $3 \%$ de las exportaciones totales ${ }^{34}$ en promedio, indicando una relación estrecha entre la producción de este producto respecto a la TRM.

Los valores de la TMR se tomaron de la base de datos del DANE y del Banco de la República de manera semanal, para ajustar las demás variables que están dentro del modelo pero no entrará como una variable a analizar dentro de la ecuación inicial debido a que es una constante en el proceso.

\footnotetext{
${ }^{34}$ Datos tomados de Augura: http://www.augura.com.co/
} 


\section{$>\operatorname{Esfuerzo}(\boldsymbol{e})$}

Esta variable siendo relevante junto a la probabilidad de encontrar a un trabajador eludiendo sus tareas, son el grueso de la teoría en los salarios de eficiencia descrito por Shapiro - Stiglitz (1984). En este sentido el modelo propuesto por estos autores se basa en la hipótesis de la utilidad recibida por individuo debido a su trabajo y el esfuerzo que genera ese trabajo.

De esta forma y como lo plantea Shapiro - Stiglitz "si un trabajador realiza un nivel acostumbrado de esfuerzo por su trabajo - lo que significa no eludir -, recibe un salario w y conservará su puesto de trabajo hasta tanto no sea capturado eludiendo lo que indica un despido estando en la piscina del desempleo". Sin embargo, esta teoría va más allá de esta simple lógica determinada en la que el esfuerzo es entonces una relación directa entre la cantidad de productividad generada y el salario eficiente que recibe gracias a ese esfuerzo realizado.

En las observaciones realizadas dentro del sector bananero, la variable de esfuerzo se tomo como la productividad de cada trabajador en términos del salario (Número de cajas producidas semanalmente de acuerdo al salario que declararon haber recibido (Anexo 5)), el cual se calculó de la siguiente forma:

valor caja en terminos de salario $=\frac{\text { Productividad semanal de la finca en pesos }}{\text { Salario promedio semanal }}$

Dónde la productividad semanal de la finca (en pesos) es igual al número de cajas producidas semanalmente por el precio de éstas (en pesos).

$$
e=\frac{\text { Salario recibido semanalmente por trabajador }}{\text { Valor caja en términos de salario }}
$$




\subsection{RESULTADOS ENCONTRADOS}

Con la descripción de las variables anotadas anteriormente, se realizó la prueba econométrica en el programa Stata 11. De allí se obtiene una valoración inicial respecto a las variables tomadas de acuerdo al modelo descrito en la ecuación (4):

En la Tabla 8 se aprecia el primer modelo propuesto donde las variables $I, b$ correspondientes a los incentivos y la tasa de abandono de las tareas respectivamente, no son estadísticamente significativas (en el Anexo 6 se pueden observar estas variables en los modelos Logit y Probit.), sus valores están por encima del $1 \%, 5 \%$ y $10 \%$, es decir sus $p$-valor son superiores a estos rangos.

Tabla 8. Primer Modelo Probit Propuesto

(Efectos Marginales)

\begin{tabular}{|c|l|}
\hline \multicolumn{2}{|c|}{ MODELO PROBIT } \\
\hline VARIABLES EXPLICATIVAS & \multicolumn{1}{|c|}{ EFECTO MARGINAL } \\
\hline Sindicato & $0.031^{* *}$ \\
\hline Incentivos & 0.868 \\
\hline Tasa activa de ganancia & $0.015^{* *}$ \\
\hline Abandono de tareas & 0.612 \\
\hline Eludiendo el trabajo & $0.000^{* * *}$ \\
\hline
\end{tabular}

Fuente: Elaboración propia a partir de las encuestas realizadas.

Datos Obtenidos al correr el modelo en Stata.

${ }^{*} p<0.1{ }^{* *} p<0.05^{* * *} p<0.01$

Éstas variables $(I, b)$ al no influir en la asignación de un salario eficiente en el sector no serán tenidas en cuenta dentro del modelo final. Por otra parte, los incentivos no marcan la diferencia en pagar un salario eficiente como si ocurrió en el estudio de "los salarios de las universidades púbicas en Colombia en un modelo microeconómico de agencia con riesgo moral" escrito por Solano \& Navarro en el 
2012. Ello se debe a que los incentivos percibidos por los trabajadores del sector de Urabá no generan un "valor adicional" dentro de su actividad laboral si no que estos están inmersos dentro del salario que reciben ${ }^{35}$. De otra parte la actividad económica de este sector es un proceso productivo homogéneo que dista del riesgo moral.

A su vez "la tasa de abandono de las tareas" manifestada como una variable no significativa, se cambiará por "ha pensado cambiarse de este oficio por otro tipo de ofertas diferentes a esta". La decisión de este cambio radica en que las tareas no terminadas, generan atraso en la productividad conjunta lo cual no está contemplado dentro de las labores que se realizan en cada finca. A ello, si un trabajador no termina sus tareas, éste hace que la producción se frene en todo su conjunto afectando las tareas de todos. Debido a esto y como lo argumenta Caraballo (1996) en el modelo sociológico de la categoría de salarios de eficiencia, el trabajador toma interés por la empresa y lo demuestra aumentando su productividad por encima de la exigida, refiriéndose ésta al clima laboral discutido anteriormente (véase pie de página número 31). Al realizar los cambios mencionados, se genera entonces el siguiente modelo:

$$
\beta_{0}+S+\mathbf{r}+q+\mathbf{e}+\mathbf{c o}=\widehat{w}
$$

Las encuestas realizadas en el sector de Urabá, se utilizaron para el análisis de la regresión que determinará las variables que afectan el pago de un salario eficiente en la zona bananera de Urabá. Para ello, en Tabla 9 se presentan las estimaciones correspondientes a las variables descritas anteriormente con la salvedad que la variable "co" anotada en la ecuación (8) representa el cambio de oficio. Alí se puede observar que todas las variables son altamente significativas. Por tanto, se tiene que dentro del modelo Probit cuatro de las cinco variables son significativas al 1\% (Ver Anexo 7 donde se ve que en el modelo Logit una variable es significativa

\footnotetext{
${ }^{35}$ Es un problema de percepción, los trabajadores consideran los beneficios extralegales como parte del salario.
} 
al $10 \%$ y dos de las cinco variables son significativas al $1 \%$, justificando a un más la utilización del modelo Probit).

Tabla 9. Modelo Probit Propuesto

(Efectos Marginales)

\begin{tabular}{|c|c|}
\hline VARIABLES & $\begin{array}{c}\text { EFECTOS } \\
\text { MARGINALES }\end{array}$ \\
\hline Existencia de convenciones Sindicalistas (S) & $0.039 * *$ \\
\hline Tasa activa de ganancia $(r)$ & $0.009 * * *$ \\
\hline Eludir el trabajo (q) & $0.000 * * *$ \\
\hline Cambio de oficio (co) & $0.007 * * *$ \\
\hline Esfuerzo ( e ) & $0.000 * * *$ \\
\hline
\end{tabular}

Fuente: Elaboración propia a partir de las encuestas realizadas.

Datos Obtenidos al correr el modelo en Stata.

${ }^{*} p<0.1{ }^{* *} p<0.05^{* \star *} p<0.01$

Al realizar las pruebas de Akaike (AIC) y Schwarz (BIC) ${ }^{36}$, (Anexo 8), se puede observar que el valor de AIC en el modelo Probit es menor que en el modelo Logit. De esta misma manera el estadístico BIC indica que es mejor el modelo Probit que el Logit.

La prueba de Wald o también llamado razón de verosimilitud ${ }^{37}$, es un test o prueba de significancia conjunta - global - que examina si los estimadores son relevantes globalmente. Para ello al medir el ajuste del modelo se considera que la hipótesis nula $\mathrm{H}_{0}: \beta_{1}+\beta_{2}+\beta_{3}+\beta_{4}+\beta_{5}=0$ (se considera que la contante tiene estimador $\beta_{0}$ ), de lo contrario existe por lo menos un $\beta_{k} \neq 0$. A ello la razón de verosimilitud (LR) o de Wald (W) debe ser mayor al $5 \%$ para rechazar la hipótesis nula, es decir que siendo el estadístico mayor al 5\% el modelo está bien ajustado. (Anexo 9).

\footnotetext{
${ }^{36}$ Estas pruebas consisten en una puntuación global a partir de cada modelo estimado a partir de las consideraciones de las estimaciones de los estadísticos de bondad de ajuste obtenidos en el modelo y de la cantidad de parámetros utilizados en el mismo. (Aguirre, 1994)

${ }^{37}$ El estadístico de Wald después de una transformación es esencialmente el estadístico $\mathrm{F}$, el cual tiene una distribución ji-cuadrada asintótica con gl (grados de libertad) igual al número de restricciones que se están aprobando (Wooldrige 2010)
} 
Otra prueba de bondad de ajuste para el modelo es la matriz de clasificación. Esta matriz determina si el valor de la predicción coincide con el valor real. Por tanto en el Anexo 10 muestra para el modelo Probit una probabilidad de $84.17 \%$ de predecir correctamente a quienes perciben el salario de eficiencia. En este sentido la especificidad nos indica que existe una probabilidad del $78.49 \%$ en predecir correctamente aquellos trabajadores que no perciben un salario de eficiencia. Por tal motivo el modelo clasifica correctamente el $81.69 \%$ de las observaciones.

La Curva ROC (Receiver Operating Characteristic) ${ }^{38}$ es una herramienta que se tiene para determinar si el modelo está bien especificado, el área bajo la curva (Anexo 11) representa la probabilidad que una persona elegida al azar tenga mayor probabilidad estimada en tener un salario eficiente que otra que no lo tenga que también haya sido elegida al azar (capacidad para discriminar). Por tanto lo más aconsejable es que esta curva este más lejos de su diagonal y superior a 0.7 para que se muestre que el modelo está ajustado. De ello se establece que el área bajo la curva ROC para los salarios de eficiencia es de 0.91 , mostrando su especificad.

Luego de establecer la bondad de ajuste del modelo y determinar las pruebas para establecer la pertinencia del mismo, procedemos a interpretar las variables estimadas acorde a los datos obtenidos por la encuesta y corridas a través del paquete estadístico.

El Anexo 12 muestra que el valor de la existencia de convenciones sindicalistas (S) es de 0,210089 indicando que al aumentar en una convención sindical (considerando que estas se rigen cada dos años) la participación de un trabajador, la probabilidad de tener un salario eficiente debido a los acuerdos que allí se llegan aumenta en un $21 \%$. Esto resalta la importancia que el sector al estar organizado mediante convenciones sindicalistas, aumenta de forma directa el salario nominal que recibe un trabajador.

\footnotetext{
${ }^{38}$ Esta sigla traduce: característica de funcionamiento del receptor
} 
Por otra parte la tasa de ganancia activa por trabajador (r) reflejada en el modelo de Shapiro-Stiglitz, muestra la utilidad que un empresario recibe de un trabajador que es eficiente en sus labores o funciones. De ello, al aumentar la productividad ésta se ve expresada en la utilidad de la empresa y como consecuencia, en los salarios que reciben los trabajadores. Ante esto se muestra que al aumentar en un punto la tasa de ganancia activa, la probabilidad de tener un salario eficiente aumenta en un $434.43 \%$.

Otra variable significativa desde el modelo de Shapiro - Stiglitz es eludir el trabajo o holgazanear (q), que para el análisis teórico aumenta la probabilidad de ser despedido si es "pillado", debido a que la productividad baja. En este sentido si un trabajador de una finca elude su trabajo la probabilidad de no tener un salario eficiente disminuye en un $853.46 \%$. Este valor es lógico debido a que la producción se genera bajo una secuencia de actividades una dependiente de la otra (llamada en la zona como actividad al destajo). En este sentido si un trabajador elude una de esas tareas, hace que la producción se detenga ya que el oficio siguiente depende de la actividad que el trabajador está realizando y decidió eludir.

Como se mencionó líneas atrás, la variable de "abandono de tareas", fue reemplazada por la de "cambio de oficio (co)", la cual y dentro del modelo es un factor decisivo en la productividad de la finca. La razón de ello y como lo argumenta Caraballo (1996), el clima laboral y el ambiente en el que se trabaje aumenta las posibilidades del trabajador de esforzarse siempre y cuando éstas características conduzcan al bienestar del trabajador. Por tanto el estar pensando un trabajador en cambiar de oficio disminuye la probabilidad de obtener un salario eficiente en un $35.34 \%$. Esto se ve reflejado en la actitud del trabajador frente a su desempeño empobreciendo su esfuerzo y de esta manera la productividad de la finca.

Al ritmo que se trabaje dentro de cada una de las fincas en las horas laborales establecidas, así mismo se obtendrá una productividad reflejada en la cantidad de cajas de $18.5 \mathrm{Kg}$ listas para exportar. De esta forma la variable esfuerzo (e), que 
mide la cantidad de cajas/hombre que se sacan influye de manera directa y pertinente en el modelo. Por tanto, un trabajador que aumente su esfuerzo en tener una caja lista para embarque el salario aumenta en un $66.39 \%$. El reflejo se ve en la productividad alcanzada por el conjunto de personas que trabajan al mismo ritmo.

Por tanto el modelo general que describe los comportamientos de las variables mencionadas está dado por:

$$
0.210089 S+4.344397 r-8.534685 q+0.663948 \mathrm{e}-0.3534178 \mathrm{co}=\widehat{w}
$$

Podemos ver en la Tabla 10 un comparativo entre los modelos propuestos por varios autores y el encontrado en esta investigación:

Tabla 10. Comparativo Modelo Propuesto

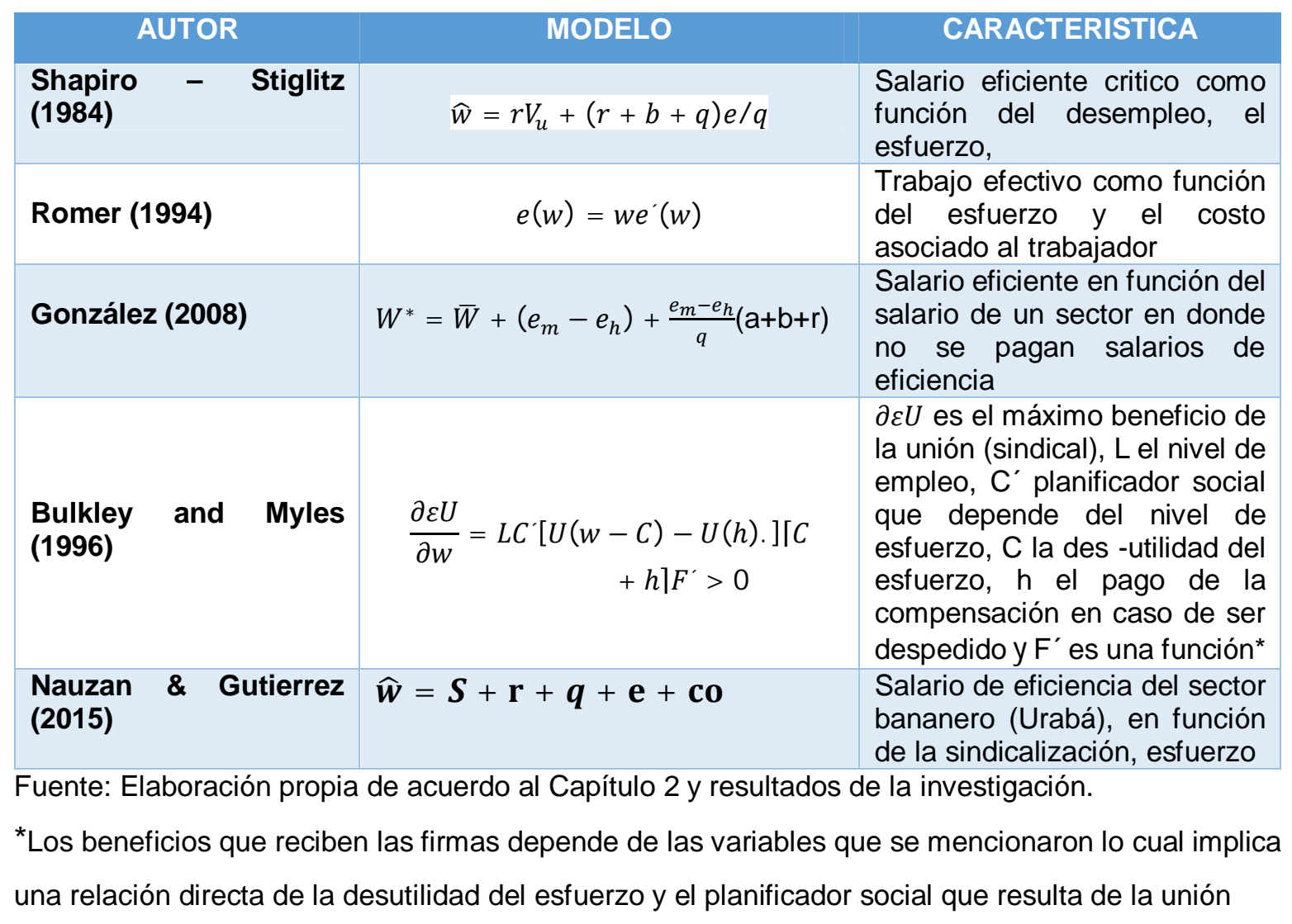


Los resultados encontrados, muestran que en conjunto la probabilidad de pagar salarios eficientes en el sector bananero de Urabá es del 74,09\%. Esta probabilidad es alta debido a la percepción que se tiene del sector y sobre todo que el salario nominal en la zona es mayor que el salario mínimo legal vigente (ver estructura salarial Urabá). Aquí se demuestra que siendo el sector organizado dentro de su estructura salarial, los trabajadores reciben un beneficio en términos económicos superiores a los de otros sectores agrarios aun por encima del salario mínimo legal vigente.

Ahora bien, los datos anteriores y el modelo justifican el pago eficiente de los salarios en el sector bananero de Urabá. Con estas consideraciones, la probabilidad conjunta de la muestra recogida en el sector (213 empleados) dada en el 74,09\% es una probabilidad alta teniendo en cuenta que el valor se acerca al 100\%. Por otra parte solo un cuarto (1/4) del valor total de la probabilidad ${ }^{39}$ tiene una tendencia al no darse salarios de eficiencia mientras que las tres cuartas partes (3/4) restantes indican que si se pueden dar.

Aun cuando cada variable explicativa del modelo muestra una tendencia significativa en el pago eficiente de salarios, la comparación entre fincas (firmas o empresas desde la teoría de Shapiro - Stiglitz) genera un valor de probabilidad alto o bajo a cada trabajador acorde a las características antes señaladas por el modelo final. Es decir que si se escogen dos trabajadores al azar y de diferentes fincas, uno de ellos pueda que perciba el pago de su salario menos que el otro o más que el otro. Para esto veamos un ejemplo consignado en la Tabla 11:

\footnotetext{
${ }^{39} \mathrm{El}$ valor del 74,09\% de probabilidad conjunta es el valor $p$, por tanto 1-p es el valor restante de no darse un salario eficiente
} 
Tabla 11. Estimación Probabilidad de Salarios Eficientes

\begin{tabular}{|c|c|c|c|c|c|c|}
\hline Trabajador & $\begin{array}{l}\text { Convenciones } \\
\text { sindicalistas }\end{array}$ & $\begin{array}{l}\text { Tasa de } \\
\text { ganancia } \\
\text { activa }\end{array}$ & $\begin{array}{l}\text { Probabilidad } \\
\text { de encontrarlo } \\
\text { eludiendo }\end{array}$ & $\begin{array}{l}\text { Cambio } \\
\text { de } \\
\text { oficio }\end{array}$ & Esfuerzo & $\begin{array}{l}\text { Probabilida } \\
\text { d final de } \\
\text { tener salario } \\
\text { eficiente }\end{array}$ \\
\hline $\operatorname{Tr}=1$ & 3 & $7 \%$ & $2 \%$ & SI & 30 & $2.42 \%$ \\
\hline $\operatorname{Tr}-2$ & 6 & $9 \%$ & $2 \%$ & NO & 40 & $93.67 \%$ \\
\hline
\end{tabular}

Fuente: cálculos de los autores realizados en el programa Stata 11.

Al escoger al azar dos trabajadores de las 334 fincas, observa que cada uno tendrá probabilidades diferentes debido a dos factores importantes: el primero es la cantidad de convenciones a las participa y lo segundo al cambio de oficio. Con respecto a este último se desenvuelven las demás variables ya que, al no pensar en cambiar de oficio (dado por los esfuerzos de las convenciones) su esfuerzo aumenta y también la tasa de ganancia activa, repercutiendo en un salario más alto o eficiente generando un beneficio mutuo tanto para él como trabajador como para la empresa.

Ahora bien, dentro de la parte social y como aspecto relevante dentro de la investigación, cada una de las variables estudiadas que están dentro del modelo final conllevan a un impacto positivo dentro del sector que se manifiesta como:

1. La variable denominada sindicalización (s), con una probabilidad del $21 \%$ por cada persona que este agremiada y que goce de los beneficios de los acuerdos generales, muestra que influye de manera directa en el nivel de vida de cada trabajador y de su familia, por ende en el de la sociedad debido a que la gran mayoría de las personas en edad de trabajar se desempeñan en este sector de manera directa o indirecta. Por tanto el reflejo del bienestar social de este sector se observa en la organización que se tiene en mismo el cual es un indicador que se debe copiar en otros sectores.

2. La segunda variable denominada como la tasa activa de ganancia ( $r$ ) la cual indica que por cada unidad de utilidad que genere (unidad = pesos) el 
trabajador para la empresa, hay una probabilidad del $434 \%$ de que se den salarios de eficiencia. Como efecto social de esta variable y de este valor, se puede determinar que las fincas asocian el salario eficiente de manera implícita a las utilidades dándose de manera recíproca la motivación al trabajador en obtener un salario mayor. Esto impacta de manera positiva al trabajador y a la sociedad debido a que al generar mayores utilidades se pueden dar mayores inversiones sociales aumentando la productividad y el bienestar.

3. La tercera variable denominada eludiendo trabajo (q), muestra que la probabilidad de "pillar" a un trabajador evadiendo sus obligaciones, genera una probabilidad negativa del 833\%. Esto muestra que el acompañamiento que se tiene dentro de la finca por el supervisor o gerente de la misma al trabajador es mas de confianza que de represión haciendo que el riesgo moral del trabajador (manifestado desde el punto de vistas ético del trabajador al realizar las funciones) disminuya, lo cual se puede ver reflejado en el cambio ético de la sociedad de Urabá. Esto permite ver que los trabajadores asocien este comportamiento con el progreso del sector y la zona manifestándose a su vez en los cambios positivos que se han tenido a nivel social y de seguridad.

4. La cuarta variable llamada esfuerzo (e) muestra que por cada caja adicional que produzca un trabajador existe la probabilidad de un $66.3 \%$ de obtener un salario eficiente. Esto de manera conjunta con las demás variables estudiadas hacen que la productividad del trabajador aumente y esto trae consigo desarrollo y competitividad además de generar mayores salarios que en otros sectores económicos; al igual que las variables anteriores trae consigo un impacto positivo en el bienestar de la sociedad.

5. La quinta variable llamada cambio de oficio (co) muestra que la probabilidad de obtener un salario eficiente disminuye en un $35,34 \%$ si un trabajador decide o piensa en cambiar de oficio. Teniendo como referente la tasa de abandono, el cambio de oficio siendo un aspecto psicológico, puede mitigarse siempre y cuando los incentivos o reconocimientos tanto morales como en 
especie se manifiesten a los trabajadores. De esta manera el efecto social que esto puede generar ayudaría a extrapolar a otros sectores agrícolas en el que el esfuerzo asociado a las tareas del agro mejoran sustancialmente el estado de los trabajadores haciéndolos más participes en estas labores. De aquí que la migración a otros sectores disminuye ya que el bienestar moral del trabajador aumenta con este incentivo.

A partir de esta investigación se puede ver el progreso y desarrollo en la zona desde la óptica de los salarios de eficiencia. Esto se evidencia por ejemplo con la llegada de nuevas universidades a la zona y el desarrollo de ciertos sectores económicos como el bancario, todo esto en beneficio de la sociedad de Urabá. La calidad de vida ha mejorado debido a que las comercializadoras por medio de algunas fundaciones sociales y Augura han tratado de generar bienestar en la sociedad, el sector ha jalonado el desarrollo de la zona, generando una buena infraestructura vial y en salud (Aunque esta podría ser mejor), además de los programas de vivienda apoyados por los auxilios para los trabajadores, todo esto es el resultado de una política salarial y obrero patronal donde los empresarios se concientizaron de que el mejoramiento de las condiciones de vida de los trabajadores y sus familias fortalecerían el sector y la sociedad, destinando recursos para construir infraestructura social y apoyar a Augura, quienes invitan a otras entidades e instituciones para impulsar y desarrollar programas conjuntos y finalmente, a convocar al estado para que cumpla con su responsabilidad (Torres \& Guarnizo, 2004). 


\section{CONCLUSIONES Y RECOMENDACIONES}

Este trabajo presenta por primera vez, según lo investigado, la aplicación del modelo de salarios de eficiencia de Shapiro-Stiglitzal al sector agrícola, específicamente al sector Bananero de la zona de Urabá, permitiendo establecer la existencia de salarios de eficiencia en el mismo. Esta metodología se presenta como una nueva herramienta para la toma de decisiones a nivel salarial y de políticas sectoriales con respecto a la productividad que puede ser aplicada en otros sectores agrícolas.

Se utilizó el modelo Shapiro - Stiglitz junto con la teoría propuesta por Bulkley \& Myles (1996) debido a que dentro los modelos estudiados son los que presentan una mejor formalización matemática referente a la aplicabilidad de salarios de eficiencia, además contienen mayor número de variables explicativas y no presentan variables latente, los supuestos del modelo principalmente la homogeneidad de las empresas y trabajadores se ajustan al sector y se puede aplicar el estudio de Bulkley - Myles al introducir la sindicalización. De esta forma se obtiene un modelo econométrico que al aplicarlo permitió obtener la probabilidad de existencia del salarios de eficiencia $(74,09 \%)$ y mostrar que las variables: la existencia de convenciones sindicales, la tasa activa de ganancia, la elución de trabajo, el esfuerzo y el cambio de oficio, son estadísticamente significativas a un valor del $1 \%$ (excepto la variable de la existencia de convenciones sindicalistas con una significancia al 5\%). Por tanto, al realizar las pruebas de bondad de ajuste al modelo se pudo concluir y demostrar que está bien especificado bajo la rigurosidad estadística.

La prueba piloto permitió avalar la existencia de salarios de eficiencia en el sector Bananero de Urabá, además dejo ver como el esfuerzo, el cual se midió en términos de productividad, es una de las principales variables que afectan el SE, con un valor 
probabilístico del 66,39\% y una significancia del 1\%, por lo que se considera que la productividad de cada trabajador tiene un impacto directo muy fuerte en su salario.

A partir de las encuestas realizadas se pudo observar que la percepción de los trabajadores frente a este tipo de salarios no es muy clara, dado que no toman los beneficios extralegales como incentivo, sino que los asumen como parte normal de su salario.

El clima laboral es un factor decisivo en la productividad y por ende en el salario, este factor se incluyó en el modelo como "Cambio de Oficio" (siglas co de la pregunta 17 de la encuesta) y tiene una probabilidad de forma negativa respecto al salario eficiente, que al estar las fincas organizadas y tener convenciones periódicas favorece de forma directa el pago de salarios de eficiencia al incidir en un $21 \%$. Lo anterior indica que el objetivo abarcado en las convenciones si favorece el bienestar de los trabajadores y la sostenibilidad de éstos en el tiempo, como medida de limitar los problemas que puedan ocasionar el relevo generacional.

La disponibilidad de información y los niveles de confidencialidad que manejan los empresarios dificultó la adquisición de la información primaria, por lo tanto al momento de extender este estudio a todo el sector bananero del país o al aplicarlo a otros sectores es necesario contar con la colaboración de los empresarios para suministrar la información necesaria y suficiente que permita aplicar el modelo y la disponibilidad de los investigadores para recolectar la información en los sitios de trabajo directamente con los trabajadores del sector en estudio.

No hay suficiente literatura sobre salarios de eficiencia en el sector agrícola del país, sin embargo, se encontraron referencias como las desarrolladas por Bose (1996), donde hace una comparación dentro del marco de los salarios de eficiencia pagados en el sector rural y el beneficio obtenido por el trabajador al migrar a la ciudad. Dada la escasez de literatura se pueden realizar este tipo de investigaciones en otros sectores como el cafetero y palma de aceite entre otros, que tengan características 
similares al estudiado para así generar comparaciones intersectoriales que favorezcan la organización y el beneficio al trabajador rural.

Dado el modelo final propuesto se considera necesario establecer ciertas políticas a nivel social, según cada variable:

- La sindicalización siendo un efecto positivo dentro del sector, deberá ser base para la aplicación en toros sectores agroindustriales, ya que incentivan la participación de los trabajadores y esto motiva al crecimiento regional.

- La tasa activa de ganancia se puede generar una política en la que los trabajadores obtengan una participación de las utilidades obtenidas por la finca en un periodo de un año, motivándolos aún más para aumentar su productividad y eficiencia buscando generar un impacto positivo para ellos y la sociedad.

- Para la elusión del trabajo es importante seguir realizando la misma manera de producción (a destajo) debido a que todos los trabajadores desarrollan eficientemente su trabajo de manera coordinada. Esto es impulsado a su vez por los beneficios obtenidos en la participación de los acuerdos generales y permiten disminuir el riesgo moral.

- Para el cambio de oficio es necesario, como se concluyó anteriormente, que se implementen políticas de clima laboral y acompañamientos constantes a los trabajadores para mitigar el aspecto sociológico. Esto permitirá que ellos se apropien más de sus oficios generando un mayor sentido de pertenencia hacia la empresa y las labores agrarias, lo cual impactaría de manera positiva al sector como a otros sectores agrarios si imitan este modelo de producción. De ello dependerá el resurgimiento del agro en el país.

Finalmente, a partir de la investigación se propone que además de seguir con las políticas establecidas para la asignación de salarios, se involucre al Estado de forma directa para impulsar el desarrollo tecnológico y la diversificación del producto final, teniendo como objetivo una mayor competitividad y mitigar el impacto que tiene la tasa representativa del mercado en el sector, es decir aumentar las exportaciones 
por calidad e innovación y no por devaluación del peso. También se debe analizar y revisar las políticas asociadas al ambiente laboral. Dado esto y con el hecho de que el sector bananero de Urabá es pionero en demostrar que los salarios de eficiencia en el sector agroindustrial si son aplicables y que la sindicalización ayuda al bienestar del sector, se debe tomar como ejemplo a seguir al momento de forjar políticas públicas sectoriales, de esta manera se podrá superar en el largo plazo el problema de productividad y competitividad que aqueja a muchos sectores agrícolas. 


\section{Anexo 1. Cambios Legales en el Salario Mínimo en Colombia}

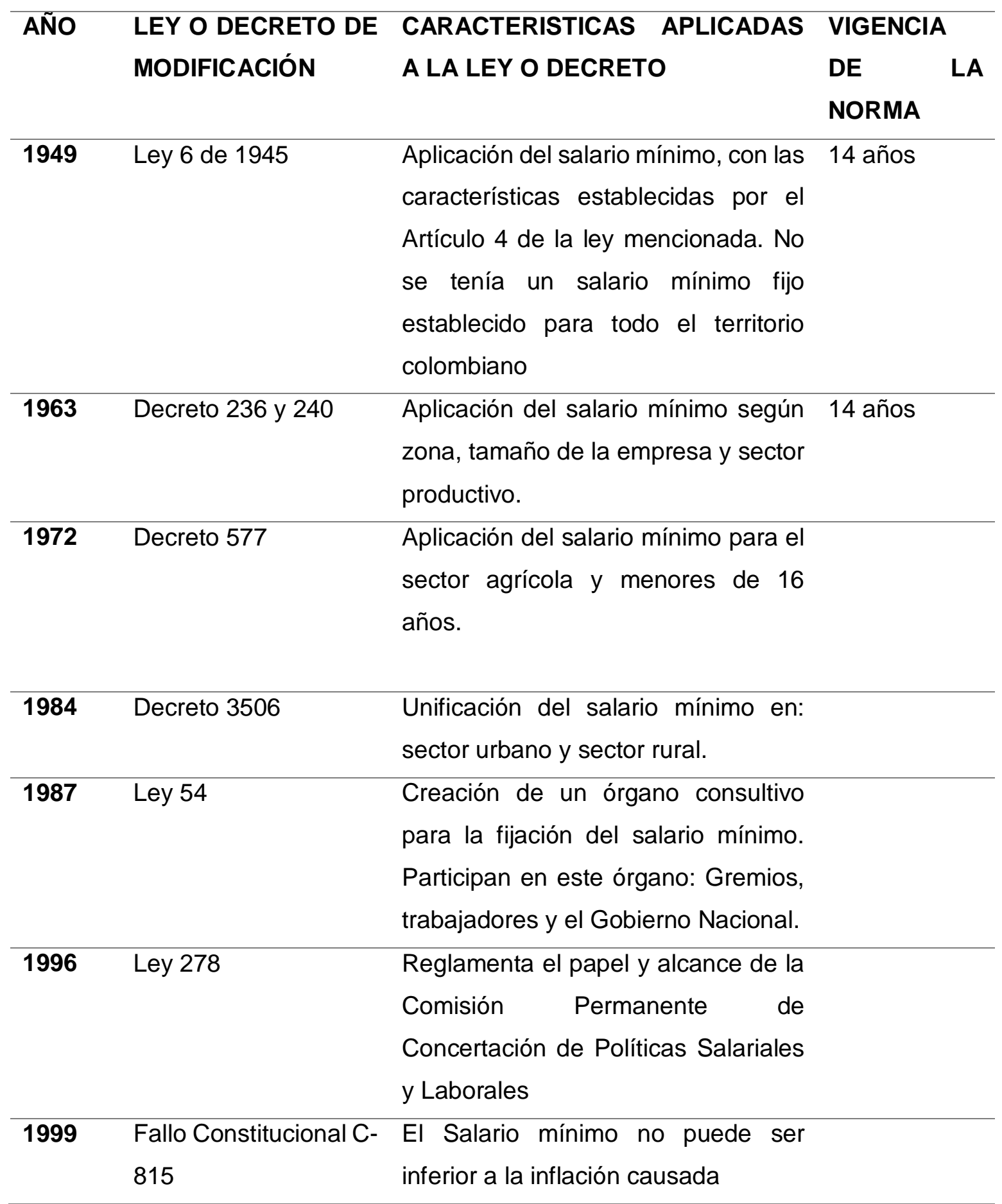

.Fuente: construcción de los autores a partir de la información del Ministerio de proyección social, Dane, Banco de la República y Ministerio del trabajo 


\section{Anexo 2: Salario mínimo legal en Colombia}

\section{Serie Histórica en Pesos Colombianos}

\begin{tabular}{|c|c|c|c|c|}
\hline \multicolumn{5}{|c|}{ Información disponible desde 1 de julio de 1984} \\
\hline Año & Salario m ínim o diario & Salario mínimo mensual & Variación \% anual * & Decretos del Gobierno Nacional \\
\hline 1984 & 376,60 & $11.298,00$ & 0,00 & NA \\
\hline 1985 & 451,92 & $13.558,00$ & 20,00 & 0001 de enero de 1985 \\
\hline 1986 & 560,38 & $16.811,00$ & 24,00 & 3754 de diciembre de 1985 \\
\hline 1987 & 683,66 & $20.510,00$ & 22,00 & 3732 de diciembre de 1986 \\
\hline 1988 & 854,58 & $25.637,00$ & 25,00 & 2545 de diciembre de 1987 \\
\hline 1989 & $1.085,32$ & $32.560,00$ & 27,00 & 2662 de diciembre de 1988 \\
\hline 1990 & $1.367,50$ & $41.025,00$ & 26,00 & 3000 de diciembre de 1989 \\
\hline 1991 & $1.723,87$ & $51.716,00$ & 26,10 & 3074 de diciembre de 1990 \\
\hline 1992 & $2.173,00$ & $65.190,00$ & 26,10 & 2867 de diciembre de 1991 \\
\hline 1993 & $2.717,00$ & $81.510,00$ & 25,00 & 2061 de diciembre de 1992 \\
\hline 1994 & $3.290,00$ & $98.700,00$ & 21,10 & 2548 de diciembre de 1993 \\
\hline 1995 & $3.964,45$ & $118.934,00$ & 20,50 & 2872 de diciembre de 1994 \\
\hline 1996 & $4.737,50$ & $142.125,00$ & 19,50 & 2310 de diciembre de 1995 \\
\hline 1997 & $5.733,50$ & $172.005,00$ & 21,00 & 2334 de diciembre de 1996 \\
\hline 1998 & $6.794,20$ & $203.826,00$ & 18,50 & 3106 de diciembre de 1997 \\
\hline 1999 & $7.882,00$ & $236.460,00$ & 16,00 & 2560 de diciembre de 1998 \\
\hline 2000 & $8.670,00$ & $260.100,00$ & 10,00 & 2647 de diciembre 23 de 1999 \\
\hline 2001 & $9.533,33$ & $286.000,00$ & 10,00 & 2579 de diciembre 13 de 2000 \\
\hline 2002 & $10.300,00$ & $309.000,00$ & 8,00 & 2910 de diciembre 31 de 2001 \\
\hline 2003 & $11.066,67$ & $332.000,00$ & 7,40 & 3232 de diciembre 27 de 2002 \\
\hline 2004 & $11.933,33$ & $358.000,00$ & 7,80 & 3770 de diciembre 26 de 2003 \\
\hline 2005 & $12.716,67$ & $381.500,00$ & 6,60 & 4360 de diciembre 22 de 2004 \\
\hline 2006 & $13.600,00$ & $408.000,00$ & 6,90 & 4686 de diciembre 21 de 2005 \\
\hline 2007 & $14.456,67$ & $433.700,00$ & 6,30 & 4580 de diciembre 27 de 2006 \\
\hline 2008 & $15.383,33$ & $461.500,00$ & 6,40 & 4965 de diciembre 27 de 2007 \\
\hline 2009 & $16.563,33$ & $496.900,00$ & 7,70 & 4868 de diciembre 30 de 2008 \\
\hline 2010 & $17.166,67$ & $515.000,00$ & 3,60 & 5053 de diciembre 30 de 2009 \\
\hline 2011 & $17.853,33$ & $535.600,00$ & 4,00 & 033 de enero 11 de 2011 \\
\hline 2012 & $18.890,00$ & $566.700,00$ & 5,80 & 4919 de diciembre 26 de 2011 \\
\hline 2013 & $19.650,00$ & $589.500,00$ & 4,02 & 2738 de diciembre 28 de 2012 \\
\hline 2014 & $20.533,33$ & $616.000,00$ & 4,50 & 3068 de diciembre 30 de 2013 \\
\hline 2015 & $21.478,33$ & $644.350,00$ & 4,60 & 2731 de diciembre 30 de 2014 \\
\hline
\end{tabular}

Fuente: Ministerio del Trabajo y decretos del Gobierno nacional.

Nota: desde el 1 de julio de 1984 se unificó el salario mínimo para todos los sectores de la economía.

* Variación porcentual con respecto al dato del año imediatamente anterior. 


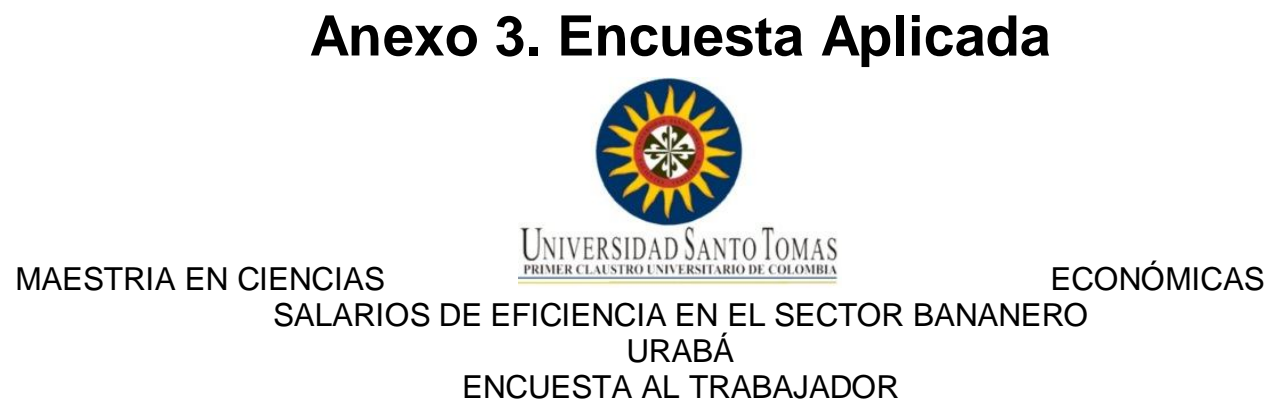

Objetivo de la Encuesta: Determinar las variables que determinan el salario en el sector Bananero.

Agradecemos su colaboración en responder las siguientes preguntas marcando con una $\mathrm{X}$ en cada una de las preguntas:

1. Edad del trabajador:

2. Estado civil: Casado(a)

3. Tiene usted hijos: Si:

Unión libre

Separado(a)

viudo(a)

4. Nivel de estudio: Primaia ¿Cuantos?

4. Nivel de estudio: Primaria Bachillerato Profesional Ninguno

5. Número de personas que dependen económicamente de usted:

6. ¿Cuánto tiempo lleva en la empresa o finca?

7. ¿Está afiliado(a) alguna Administradora de Riesgos Laborales (ARL)? Si

No

8. Su contrato es: Término fijo Término Indefinido Prestación de servicios Otro ¿cuál?

9. ¿Cuál es el salario que recibe en el mes?:

Entre $\$ 400.000$ a $\$ 600.000$ Entre $\$ 600.001$ a $\$ 700.000$ Entre $\$ 700.001$ a $\$ 900.000$

Entre $\$ 900.001$ a $\$ 1^{\prime} 100.000$ Entre $\$ 1^{\prime} 100.001$ a $\$ 1^{\prime} 400.000$ Más de $\$ 1^{\prime} 400.001$

10. ¿El pago de los salarios se hace de manera puntual? Si No

11. ¿La empresa o finca se siente satisfecha con la labor que usted realiza? Si

No

12. ¿Cuántas veces de las que a continuación se nombra, se ha ausentado del trabajo por problemas de salud o familiar?: De 1 a 5 veces por mes De 6 a 10 veces por mes Más de 10 veces por mes Ninguna vez

13. Durante los dos últimos años, ¿cuántas veces ha cambiado de finca bananera? Ninguna vez Una vez Dos veces Más de dos veces

14. ¿El cambio en el precio del dólar afecta el pago de su salario? Si

No

15. ¿Ha recibido algún incentivo económico o en especie por parte de la empresa o finca por su desempeño laboral? $\mathrm{Si}$ No Cual

16. Su lugar de trabajo queda: Retirado de su lugar de vivienda Cerca de su lugar de vivienda

17. ¿Ha pensado en retirarse de este oficio por otro tipo de ofertas diferentes a esta? $\mathrm{Si}$

No

18. ¿Cuántas horas por semana en promedio trabaja?

19. ¿El salario recibido, depende de la cantidad de horas trabajadas?: Si No 


\section{Anexo 4. Hechos Estilizados}

\begin{tabular}{|c|c|c|c|}
\hline PREGUNTA & CATEGORIA & SIGLA & MEDICION \\
\hline 1 & Edad & ED & Número de años \\
\hline 2 & Estado Civil & EC & 1 (casado) 2 (union libre) 3 (separado) 4 (viudo) 5(soltero) \\
\hline 3 & Número de Hijos & $\mathrm{NH}$ & Cantidad de Hijos \\
\hline 4 & Nivel de Estudio & $\mathrm{NE}$ & 1 (primaria) 2 (bachillerato) 3 (profesional que en este caso es tecnico) 4 (ninguno) \\
\hline 5 & $\begin{array}{l}\text { Número de personas que } \\
\text { dependen } \\
\text { Economicamente }\end{array}$ & PDE & Cantidad de personas que dependen económicamente \\
\hline 6 & Tiempo en la Finca & TF & Cantidad de Semanas \\
\hline 7 & Labor que Desempeña & LD & $\begin{array}{l}\text { 1(Selección) 2(Palero) } 3 \text { (Fertilizador) } 4 \text { (oficios Varios) } 5 \text { (Desmachador) } 6 \\
\text { (Servicios Generales) } 7 \text { (embolsador) } 8 \text { (Guantelete) } 9 \text { (Coordinador de Campo) } 10 \\
\text { (Control Calvise) } 11 \text { (Corte y empaque) } 12 \text { (Fumigador) } 13 \text { (amarrador) } 14 \\
\text { (Barcadillero) } 15 \text { (Hercule) } 16 \text { (oficinista) } 17 \text { (Inspector de Calidad) } 18 \text { (Almacenista) } \\
19 \text { (Jefe de finca) } 20 \text { (Ecoquei) } 21 \text { (administrador) } 22 \text { (Cablero) } 23 \text { (Salud y } \\
\text { Seguridad Laboral) } 24 \text { (siembra) } 25 \text { (practicante) } 26 \text { (sellador) } 27 \text { (pesador) } 28 \\
\text { (asistente de Admón) } 29 \text { (jefe de compras) } 30 \text { (Analista de Nomina) }\end{array}$ \\
\hline 8 & Afiliación a ARL & ARL & $1(\mathrm{Si}) 0$ (No) \\
\hline 9 & Tipo de Contrato & $\mathrm{TC}$ & 1 (Termino Fijo) 2 (Termino Indefinido) 3 (Prestación de Servicios) 4 (Otro) \\
\hline 10 & Salario & S & Salario Semanal promedio \\
\hline 10 & Puntualidad Pago Salario & PPS & $1(\mathrm{Si}) 0(\mathrm{No})$ \\
\hline 11 & $\begin{array}{l}\text { Satisfacción con el } \\
\text { Desempeño por parte de } \\
\text { la empresa }\end{array}$ & SDL & 1 (Si) 0 (No) \\
\hline 12 & Ausentismo & A & $\begin{array}{l}1 \text { ( } 1 \text { a } 5 \text { veces al mes) } 2 \text { ( } 6 \text { a } 10 \text { veces al mes) } 3 \text { (mas de } 10 \text { veces al mes) } 4 \text { (ninguna } \\
\text { vez) }\end{array}$ \\
\hline 13 & Rotación en Fincas & RF & $\begin{array}{l}\text { Numero de veces que ha cambiado de finca en los dos últimos años: 0, 1, 2, y } 30 \\
\text { mas años }\end{array}$ \\
\hline 14 & $\begin{array}{l}\text { Afectacion de la TRM en el } \\
\text { salario }\end{array}$ & ATC & $1(\mathrm{Si}) 0(\mathrm{No})$ \\
\hline 15 & Incentivos Recibidos & INCT & $1(\mathrm{Si}) 0(\mathrm{No})$ \\
\hline 16 & Distancia Lugar de Trabajo & LGT & 1 (Retirado de su lugar de vivienda) 2 (Cerca de su lugar de Vivienda) \\
\hline 17 & $\begin{array}{l}\text { intención de cambio de } \\
\text { oficio }\end{array}$ & $\mathrm{CO}$ & $1(\mathrm{Si}) 0(\mathrm{No})$ \\
\hline 18 & Horas de Trabajo & HST & Cantidad de Horas semanales trabajadas en promedio \\
\hline 19 & $\begin{array}{l}\text { Dependencia del Salario a } \\
\text { Horas trabajadas }\end{array}$ & SHT & $1(\mathrm{Si}) 0$ (No) \\
\hline 20 & Horas Extras & $\mathrm{HE}$ & $1(\mathrm{Si}) 0(\mathrm{No})$ \\
\hline & Horas extras Semanales & HES & Cantidad de horas extras semanales en promedio \\
\hline
\end{tabular}




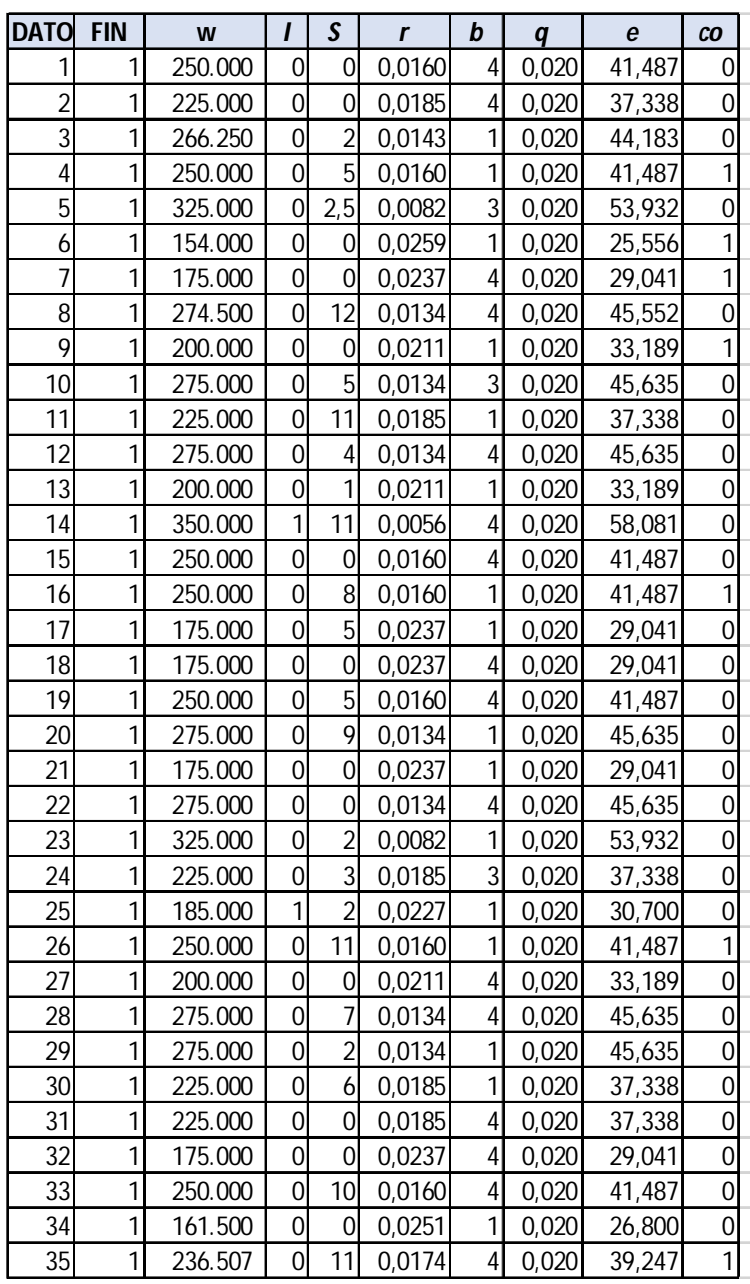

\section{Anexo 5. Base de Datos}

\begin{tabular}{|c|c|c|c|c|c|c|c|c|c|c|c|c|c|c|c|c|c|c|c|}
\hline DATO & FIN & $\mathbf{w}$ & 1 & $S$ & $r$ & b & q & e & co & DATO & FIN & w & 1 & 5 & $\mathrm{r}$ & b & $q$ & e & $c$ \\
\hline 36 & 2 & 00.000 & 0 & 7 & 0,0520 & 1 & 0,080 & 35,971 & 1 & 71 & & 25.000 & 1 & 2 & 0,1127 & 4 & 0,043 & 44,175 & \\
\hline 37 & 2 & 3330 & 0 & 7 & 138 & 1 & 0,080 & 41,965 & 0 & 72 & 3 & 5.000 & 0 & 4 & 1127 & 1 & 43 & ,175 & \\
\hline 38 & 2 & 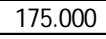 & 0 & 0 & 0582 & 4 & 0,080 & 31,474 & 0 & 73 & 4 & 9.900 & 0 & 0 & 250 & 4 & 57 & 371 & \\
\hline 39 & 2 & 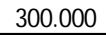 & 0 & 1 & 0274 & 4 & 0,080 & 53,956 & 0 & 74 & 4 & 200. & 0 & 0 & 0239 & 4 & 057 & 465 & \\
\hline 40 & 2 & 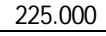 & 0 & 2 & 0459 & 3 & 0,080 & 40,467 & 0 & 75 & 4 & 189 & 0 & 11 & 0250 & 3 & ,057 & 9,371 & \\
\hline 41 & 2 & 26 & 0 & 0 & 20 & 4 & 0,080 & \begin{tabular}{|l|}
35,971 \\
\end{tabular} & 0 & 76 & 4 & 225. & 0 & 12 & 212 & 1 & 0,057 & 5,649 & \\
\hline 42 & 2 & & 1 & 2 & 29 & 4 & 0,080 & 35,296 & 0 & 77 & 4 & 170 & 0 & 1 & 0271 & 3 & 057 & 5,246 & \\
\hline 43 & 2 & & 0 & 0 & 57 & 1 & 0,080 & 33,273 & 0 & 78 & 4 & 1 & 0 & 0 & 0288 & 1 & ,057 & 1,928 & \\
\hline 44 & 2 & & 0 & 3 & 20 & 1 & 0,080 & 35,971 & 0 & 79 & 4 & 2 & 1 & 11 & 239 & 1 & 057 & 1,465 & \\
\hline 45 & 2 & & 1 & 6 & 22 & 1 & 0,080 & 37,320 & 0 & 80 & 4 & 150 & 1 & 6 & 293 & 1 & 0,057 & 1,099 & \\
\hline 46 & 2 & & 1 & 3 & 9 & 2 & 0,080 & 44,064 & 0 & 81 & 4 & 225 & 1 & 0 & 212 & 2 & 057 & 5,649 & \\
\hline 47 & 2 & & 1 & 1 & 0,0520 & 4 & 0,080 & 35,971 & 0 & 82 & 4 & 200 & 1 & 3 & 239 & 1 & 0,057 & 1,465 & \\
\hline 48 & 2 & & 1 & 0 & 0495 & 4 & 0,080 & 37,769 & 0 & 83 & 4 & 150 & 0 & 0 & 293 & 4 & 057 & 1,099 & \\
\hline 49 & 2 & & 0 & 0 & 0,0489 & 1 & 0,080 & 38,219 & 0 & 84 & 4 & 225 & 0 & 3 & 212 & 4 & 057 & 5,649 & \\
\hline 50 & 2 & & 0 & 4 & 0409 & 1 & 0,080 & 44,064 & 0 & 85 & 5 & 375 & 0 & 9 & 558 & 4 & 057 & 0,702 & \\
\hline 51 & 2 & & 0 & 10 & 0,0465 & 1 & 0,080 & 40,017 & 0 & 86 & 5 & 175 & 1 & 1 & 346 & 4 & 057 & 2,994 & \\
\hline 52 & 2 & & 0 & 6 & 0,0520 & 1 & 0,080 & 35,971 & 0 & 87 & 5 & & 1 & 6 & 382 & 2 & 057 & 8,281 & \\
\hline 53 & 2 & & 0 & ] & 0,0366 & 4 & 0,080 & 47,211 & 0 & 88 & 5 & & 1 & 6 & 346 & 4 & 057 & 2,994 & \\
\hline 54 & 2 & & 0 & 2 & & 4 & 0,080 & 40,467 & 0 & 89 & 5 & & 0 & 3 & & 4 & 057 & 1,479 & \\
\hline 55 & 2 & & 1 & 6 & 512 & 1 & 0,080 & 29,226 & 0 & 90 & 5 & & 0 & 2 & 274 & 1 & 0,057 & 2,421 & \\
\hline 56 & 2 & & 0 & 8 & & 3 & 0,080 & 31,474 & 0 & 91 & 5 & & 0 & 1 & 364 & 4 & 057 &, 638 & \\
\hline 57 & 2 & & 0 & 9 & & 1 & 0,080 & 49,460 & 0 & 92 & 5 & & 1 & 4 & 292 & 4 & 057 & 0,065 & \\
\hline 58 & 2 & & 1 & 2 & & 4 & 0,080 & 40,467 & 0 & 93 & 5 & 21 & & 2 & 92 & 4 & 057 & $\mid 0,065$ & \\
\hline 59 & 2 & & 0 & 2 & & 1 & 0,080 & 40,017 & 0 & 94 & 5 & & & 0 & & 4 & 57 & 37,708 & \\
\hline 60 & 2 & & 0 & o & & 4 & 0,080 & 37,320 & 0 & 95 & 5 & & 0 & 4 & 82 & 4 & \begin{tabular}{|l|}
0,057 \\
\end{tabular} & 28,281 & \\
\hline 61 & 2 & & 1 & 0 & & 1 & 0,080 & 49,460 & 0 & 96 & 5 & & 1 & 3 & 556 & 4 & \begin{tabular}{|l|}
0,057 \\
\end{tabular} & 44,778 & \\
\hline 62 & 3 & & 1 & 7 & 27 & 4 & 0,043 & 44,175 & 0 & 97 & 5 & & 1 & 2 & 74 & 1 & \begin{tabular}{|l|}
0,057 \\
\end{tabular} & 42,421 & \\
\hline 63 & 3 & & 1 & 0 & & 4 & 0,043 & 34,358 & 0 & 98 & 5 & & 4 & 2 & 353 & 4 & 0,057 & 2,052 & \\
\hline 64 & 3 & & 0 & 7 & 27 & 4 & 0,043 & 44,175 & 0 & 99 & 5 & 250 & -4 & 1 & 38 & 4 & \begin{tabular}{|l|}
0,057 \\
\end{tabular} & 47,135 & \\
\hline 65 & 3 & & 0 & 0 & 127 & 4 & 0,043 & 44,175 & 0 & 100 & 5 & 225.000 & 4 & 7 &, 0274 & 1 & \begin{tabular}{|l|} 
\\
\end{tabular} & 42,421 & \\
\hline 66 & 3 & & 1 & 2 & & 4 & 0,043 & 29,450 & 0 & 101 & 5 & 185.000 & 4 & 7 & 331 & 4 & \begin{tabular}{|l|}
0,057 \\
\end{tabular} & 34,880 & \\
\hline 67 & 3 & 1 & 0 & 0 & 0,1569 & 4 & 0,043 & 29,450 & 0 & 102 & 6 & 162 & 0 & 0 & 0,0441 & 1 & \begin{tabular}{|l|}
0,071 \\
\end{tabular} & 30,948 & \\
\hline 68 & 3 & 2 & 0 & 5 & 0,1275 & 1 & 0,043 & 39,267 & 0 & 103 & 6 & 275 & 0 & 3 & 0,0250 & 4 & \begin{tabular}{|l|}
0,071 \\
\end{tabular} & 52,373 & \\
\hline 69 & 3 & 175. & 0 & 0 & 0,1422 & 4 & 0,043 & 34,358 & 0 & 104 & 6 & 175 & 1 & 1 & 0,0420 & 4 & \begin{tabular}{|l|}
0,071 \\
\end{tabular} & 33,328 & \\
\hline 70 & 3 & 225.000 & 0 & 0 & 0,1127 & 4 & 0,043 & 44,175 & 0 & 105 & 6 & 225.000 & 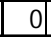 & 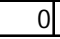 & 0,0335 & 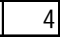 & 0,071 & 42,851 & \\
\hline
\end{tabular}

FIN: Finca 1:Paraiso, 2: Cantarana, 3:Chambacú 1, 4: Chambacú 2, 5: Esperanza, 6:Reina, 7:Antojo, 8: Ucrania, 9: Mandalay. 


\section{Anexo 5. Base de Datos}

\begin{tabular}{|r|r|c|r|r|c|r|r|r|r|}
\hline DATO & FIN & w & I & S & r & b & q & e & co \\
\hline 106 & 7 & 248.950 & 0 & 1 & 0,0131 & 1 & 0,035 & 53,944 & 1 \\
\hline 107 & 7 & 125.000 & 0 & 0 & 0,0182 & 1 & 0,035 & 27,086 & 0 \\
\hline 108 & 7 & 245.000 & 1 & 3 & 0,0132 & 4 & 0,035 & 53,088 & 1 \\
\hline 109 & 7 & 150.000 & 0 & 0 & 0,0172 & 1 & 0,035 & 32,503 & 0 \\
\hline 110 & 7 & 154.000 & 0 & 4 & 0,0170 & 3 & 0,035 & 33,370 & 0 \\
\hline 111 & 7 & 120.000 & 1 & 0 & 0,0185 & 4 & 0,035 & 26,002 & 0 \\
\hline 112 & 7 & 200.000 & 0 & 5 & 0,0151 & 1 & 0,035 & 43,337 & 1 \\
\hline 113 & 7 & 212.500 & 0 & 0 & 0,0146 & 4 & 0,035 & 46,046 & 1 \\
\hline 114 & 7 & 175.000 & 0 & 1 & 0,0162 & 1 & 0,035 & 37,920 & 0 \\
\hline 115 & 7 & 300.000 & 0 & 2 & 0,0109 & 2 & 0,035 & 65,006 & 1 \\
\hline 116 & 7 & 200.000 & 0 & 3 & 0,0151 & 1 & 0,035 & 43,337 & 1 \\
\hline 117 & 7 & 250.000 & 0 & 0 & 0,0130 & 1 & 0,035 & 54,172 & 1 \\
\hline 118 & 7 & 250.000 & 0 & 4 & 0,0130 & 4 & 0,035 & 54,172 & 0 \\
\hline 119 & 7 & 300.000 & 0 & 0 & 0,0109 & 4 & 0,035 & 65,006 & 0 \\
\hline 120 & 7 & 250.000 & 0 & 0 & 0,0130 & 4 & 0,035 & 54,172 & 0 \\
\hline 121 & 7 & 215.000 & 0 & 7 & 0,0145 & 4 & 0,035 & 46,588 & 1 \\
\hline 122 & 7 & 250.000 & 0 & 3 & 0,0130 & 4 & 0,035 & 54,172 & 0 \\
\hline 123 & 7 & 275.000 & 0 & 1 & 0,0120 & 4 & 0,035 & 59,589 & 0 \\
\hline 124 & 7 & 200.000 & 0 & 6 & 0,0151 & 4 & 0,035 & 43,337 & 0 \\
\hline 125 & 7 & 225.000 & 0 & 6 & 0,0141 & 4 & 0,035 & 48,755 & 1 \\
\hline 126 & 7 & 300.000 & 0 & 0 & 0,0109 & 4 & 0,035 & 65,006 & 0 \\
\hline 127 & 7 & 213.000 & 1 & 1 & 0,0146 & 4 & 0,035 & 46,154 & 1 \\
\hline 128 & 7 & 200.000 & 0 & 0 & 0,0151 & 3 & 0,035 & 43,337 & 0 \\
\hline 129 & 7 & 150.000 & 0 & 0 & 0,0172 & 4 & 0,035 & 32,503 & 0 \\
\hline 130 & 7 & 200.000 & 1 & 0 & 0,0151 & 4 & 0,035 & 43,337 & 0 \\
\hline 131 & 7 & 250.000 & 1 & 8 & 0,0130 & 1 & 0,035 & 54,172 & 0 \\
\hline 132 & 7 & 150.000 & 1 & 0 & 0,0172 & 3 & 0,035 & 32,503 & 0 \\
\hline 133 & 7 & 200.000 & 1 & 5 & 0,0151 & 1 & 0,035 & 43,337 & 0 \\
\hline 134 & 7 & 175.000 & 0 & 0 & 0,0162 & 4 & 0,035 & 37,920 & 0 \\
\hline 135 & 7 & 250.000 & 0 & 0 & 0,0130 & 3 & 0,035 & 54,172 & 0 \\
\hline 136 & 7 & 300.000 & 1 & 0 & 0,0109 & 4 & 0,035 & 65,006 & 0 \\
\hline 137 & 7 & 225.000 & 1 & 7 & 0,0141 & 4 & 0,035 & 48,755 & 0 \\
\hline 138 & 7 & 322.500 & 0 & 0 & 0,0100 & 4 & 0,035 & 69,881 & 1 \\
\hline 139 & 7 & 237.500 & 0 & 6 & 0,0135 & 4 & 0,035 & 51,463 & 1 \\
\hline 140 & 7 & 242.900 & 1 & 5 & 0,0133 & 3 & 0,035 & 52,633 & 0 \\
\hline 141 & 7 & 150.000 & 1 & 6 & 0,0172 & 2 & 0,035 & 32,503 & 0 \\
\hline & & & & & & & & & \\
\hline
\end{tabular}

\begin{tabular}{|r|r|c|r|r|r|r|r|r|r|}
\hline DATO & FIN & w & l & S & r & b & q & e & co \\
\hline 142 & 7 & 400.000 & 1 & 10 & 0,0067 & 4 & 0,035 & 86,675 & 0 \\
\hline 143 & 7 & 450.000 & 1 & 10 & 0,0046 & 4 & 0,035 & 97,509 & 0 \\
\hline 144 & 7 & 250.000 & 1 & 0 & 0,0130 & 1 & 0,035 & 54,172 & 0 \\
\hline 145 & 7 & 275.000 & 1 & 7 & 0,0120 & 4 & 0,035 & 59,589 & 0 \\
\hline 146 & 7 & 161.063 & 0 & 0 & 0,0167 & 4 & 0,035 & 34,900 & 0 \\
\hline 147 & 7 & 275.000 & 1 & 0 & 0,0120 & 4 & 0,035 & 59,589 & 0 \\
\hline 148 & 7 & 325.000 & 1 & 8 & 0,0099 & 4 & 0,035 & 70,423 & 0 \\
\hline 149 & 7 & 275.000 & 1 & 1 & 0,0120 & 4 & 0,035 & 59,589 & 0 \\
\hline 150 & 8 & 250.000 & 1 & 0 & 0,0480 & 4 & 0,035 & 40,273 & 1 \\
\hline 151 & 8 & 200.000 & 0 & 1 & 0,0686 & 4 & 0,035 & 32,218 & 1 \\
\hline 152 & 8 & 225.000 & 0 & 0 & 0,0583 & 3 & 0,035 & 36,246 & 1 \\
\hline 153 & 8 & 175.000 & 1 & 11 & 0,0789 & 1 & 0,035 & 28,191 & 0 \\
\hline 154 & 8 & 225.000 & 0 & 11 & 0,0583 & 1 & 0,035 & 36,246 & 0 \\
\hline 155 & 8 & 225.000 & 0 & 7 & 0,0583 & 1 & 0,035 & 36,246 & 0 \\
\hline 156 & 8 & 275.000 & 0 & 6 & 0,0377 & 1 & 0,035 & 44,300 & 0 \\
\hline 157 & 8 & 225.000 & 0 & 3 & 0,0583 & 4 & 0,035 & 36,246 & 0 \\
\hline 158 & 8 & 225.000 & 0 & 7 & 0,0583 & 4 & 0,035 & 36,246 & 0 \\
\hline 159 & 8 & 200.000 & 0 & 7 & 0,0686 & 4 & 0,035 & 32,218 & 0 \\
\hline 160 & 8 & 225.000 & 1 & 9 & 0,0583 & 1 & 0,035 & 36,246 & 0 \\
\hline 161 & 8 & 237.500 & 0 & 0 & 0,0532 & 4 & 0,035 & 38,259 & 0 \\
\hline 162 & 8 & 215.000 & 0 & 0 & 0,0624 & 4 & 0,035 & 34,635 & 0 \\
\hline 163 & 8 & 225.000 & 0 & 0 & 0,0583 & 4 & 0,035 & 36,246 & 0 \\
\hline 164 & 8 & 225.000 & 1 & 11 & 0,0583 & 4 & 0,035 & 36,246 & 0 \\
\hline 165 & 8 & 225.000 & 1 & 8 & 0,0583 & 1 & 0,035 & 36,246 & 0 \\
\hline 166 & 8 & 225.000 & 1 & 7 & 0,0583 & 1 & 0,035 & 36,246 & 0 \\
\hline 167 & 8 & 500.000 & 1 & 12 & $-0,0550$ & 1 & 0,035 & 80,546 & 1 \\
\hline 168 & 8 & 175.000 & 1 & 8 & 0,0789 & 1 & 0,035 & 28,191 & 1 \\
\hline 169 & 8 & 225.000 & 0 & 0 & 0,0583 & 4 & 0,035 & 36,246 & 0 \\
\hline 170 & 8 & 250.000 & 1 & 9 & 0,0480 & 1 & 0,035 & 40,273 & 0 \\
\hline 171 & 8 & 217.500 & 0 & 6 & 0,0614 & 4 & 0,035 & 35,038 & 1 \\
\hline 172 & 8 & 225.000 & 1 & 1 & 0,0583 & 1 & 0,035 & 36,246 & 0 \\
\hline 173 & 8 & 175.000 & 0 & 6 & 0,0789 & 1 & 0,035 & 28,191 & 1 \\
\hline 174 & 8 & 200.000 & 0 & 0 & 0,0686 & 1 & 0,035 & 32,218 & 1 \\
\hline 175 & 8 & 140.000 & 1 & 9 & 0,0934 & 1 & 0,035 & 22,553 & 1 \\
\hline 176 & 8 & 215.000 & 0 & 3 & 0,0624 & 4 & 0,035 & 34,635 & 0 \\
\hline 177 & 8 & 200.000 & 0 & 7 & 0,0686 & 1 & 0,035 & 32,218 & 0 \\
\hline
\end{tabular}

\begin{tabular}{|r|r|c|r|r|r|r|c|c|c|}
\hline DATO & FIN & w & I & \multicolumn{1}{|c|}{ S } & r & b & q & e & co \\
\hline 178 & 8 & 212.500 & 0 & 3 & 0,0635 & 4 & 0,035 & 34,232 & 0 \\
\hline 179 & 8 & 175.000 & 1 & 8 & 0,0789 & 4 & 0,035 & 28,191 & 0 \\
\hline 180 & 8 & 225.000 & 0 & 5 & 0,0583 & 4 & 0,035 & 36,246 & 1 \\
\hline 181 & 8 & 200.000 & 0 & 8 & 0,0686 & 4 & 0,035 & 32,218 & 1 \\
\hline 182 & 8 & 201.250 & 1 & 7 & 0,0681 & 4 & 0,035 & 32,420 & 0 \\
\hline 183 & 8 & 200.445 & 0 & 10 & 0,0684 & 1 & 0,035 & 32,290 & 1 \\
\hline 184 & 8 & 275.000 & 0 & 5 & 0,0377 & 4 & 0,035 & 44,300 & 0 \\
\hline 185 & 8 & 200.000 & 0 & 0 & 0,0686 & 4 & 0,035 & 32,218 & 0 \\
\hline 186 & 8 & 200.000 & 1 & 0 & 0,0686 & 1 & 0,035 & 32,218 & 0 \\
\hline 187 & 8 & 210.000 & 0 & 1 & 0,0645 & 3 & 0,035 & 33,829 & 0 \\
\hline 188 & 8 & 250.000 & 0 & 6 & 0,0480 & 1 & 0,035 & 40,273 & 0 \\
\hline 189 & 8 & 200.000 & 1 & 9 & 0,0686 & 4 & 0,035 & 32,218 & 0 \\
\hline 190 & 8 & 175.000 & 0 & 11 & 0,0789 & 4 & 0,035 & 28,191 & 0 \\
\hline 191 & 8 & 250.000 & 0 & 2 & 0,0480 & 1 & 0,035 & 40,273 & 0 \\
\hline 192 & 8 & 225.000 & 0 & 4 & 0,0583 & 4 & 0,035 & 36,246 & 0 \\
\hline 193 & 8 & 225.000 & 0 & 0 & 0,0583 & 4 & 0,035 & 36,246 & 0 \\
\hline 194 & 8 & 310.000 & 0 & 9 & 0,0233 & 1 & 0,035 & 49,939 & 1 \\
\hline 195 & 8 & 225.000 & 0 & 9 & 0,0583 & 1 & 0,035 & 36,246 & 0 \\
\hline 196 & 8 & 250.000 & 0 & 10 & 0,0480 & 1 & 0,035 & 40,273 & 0 \\
\hline 197 & 9 & 625.000 & 1 & 12 & $-0,1396$ & 1 & 0,068 & 97,632 & 0 \\
\hline 198 & 9 & 235.000 & 0 & 1 & 0,1521 & 4 & 0,068 & 36,710 & 0 \\
\hline 199 & 9 & 237.500 & 1 & 4 & 0,1502 & 4 & 0,068 & 37,100 & 0 \\
\hline 200 & 9 & 300.000 & 1 & 1 & 0,1035 & 1 & 0,068 & 46,864 & 0 \\
\hline 201 & 9 & 312.500 & 0 & 11 & 0,0941 & 4 & 0,068 & 48,816 & 0 \\
\hline 202 & 9 & 200.000 & 0 & 12 & 0,1783 & 4 & 0,068 & 31,242 & 0 \\
\hline 203 & 9 & 237.500 & 1 & 6 & 0,1502 & 4 & 0,068 & 37,100 & 0 \\
\hline 204 & 9 & 275.000 & 1 & 8 & 0,1222 & 4 & 0,068 & 42,958 & 0 \\
\hline 205 & 9 & 257.500 & 0 & 3 & 0,1353 & 4 & 0,068 & 40,225 & 0 \\
\hline 206 & 9 & 175.000 & 1 & 10 & 0,1970 & 4 & 0,068 & 27,337 & 0 \\
\hline 207 & 9 & 262.500 & 0 & 7 & 0,1315 & 4 & 0,068 & 41,006 & 0 \\
\hline 208 & 9 & 275.000 & 0 & 12 & 0,1222 & 4 & 0,068 & 42,958 & 0 \\
\hline 209 & 9 & 325.000 & 1 & 8 & 0,0848 & 1 & 0,068 & 50,769 & 0 \\
\hline 210 & 9 & 250.000 & 0 & 0 & 0,1409 & 1 & 0,068 & 39,053 & 0 \\
\hline 211 & 9 & 237.500 & 0 & 1 & 0,1502 & 4 & 0,068 & 37,100 & 0 \\
\hline 212 & 9 & 195.000 & 0 & 1 & 0,1820 & 4 & 0,068 & 30,461 & 0 \\
\hline 213 & 9 & 237.500 & 0 & 0 & 0,1502 & 4 & 0,068 & 37,100 & 0 \\
\hline
\end{tabular}




\section{Anexo 6. Variables Explicativas Modelos Logit y Probit.}

\begin{tabular}{|c|c|c|}
\hline & MODELO LOGIT & MODELO PROBIT \\
\hline VARIABLES EXPLICATIVAS & $\begin{array}{c}\text { EFECTO MARGINAL } \\
\text { (RATIO ODDS) }\end{array}$ & EFECTO MARGINAL \\
\hline Sindicato & $0.041^{* *}$ & $0.031^{* *}$ \\
\hline Insentivos & 0.780 & 0.868 \\
\hline Tasa activa de ganancia & $0.030^{* *}$ & $0.015^{* *}$ \\
\hline Abandono de tareas & 0.560 & 0.612 \\
\hline Eludiendo el trabajo & $0.000^{* * *}$ & $0.000^{* * *}$ \\
\hline
\end{tabular}

Fuente: Elaboración propia a partir de las encuestas realizadas. Datos Obtenidos al correr el modelo en Stata. ${ }^{*} p<0.1{ }^{* *} p<0.05^{* *} p<0.01$ 


\section{Anexo 7. Modelo Probit Propuesto (Efectos Marginales)}

\begin{tabular}{|c|c|c|}
\hline VARIABLES & $\begin{array}{c}\text { MODELO LOGIT } \\
\text { (EFECTOS } \\
\text { MARGINALES) }\end{array}$ & $\begin{array}{c}\text { MODELO PROBIT } \\
\text { (EFECTOS } \\
\text { MARGINALES) }\end{array}$ \\
\hline Existencia de convenciones Sindicalistas (S) & $0.065^{*}$ & $0.039^{* *}$ \\
\hline Tasa activa de ganancia ( $r)$ & $0.022^{* *}$ & $0.009^{* * *}$ \\
\hline Eludir el trabajo (q) & $0.000^{* * *}$ & $0.000^{* * *}$ \\
\hline Cambio de oficio (co) & $0.023^{* *}$ & $0.007^{* * *}$ \\
\hline Esfuerzo (e ) & $0.000^{* * *}$ & $0.000^{* * *}$ \\
\hline${ }^{*} \mathrm{p}<0.1 \quad{ }^{* *} \mathrm{p}<0.05^{* *} \mathrm{p}<0.01$ \\
\hline
\end{tabular}

Fuente:Elaboración propia a partir de las encuestas realizadas.

Datos Obtenidos al correr el modelo en Stata. 


\section{Anexo 8. Test Akaike (AIC) y Schwarz}

\begin{tabular}{|c|c|c|}
\hline MODELO & PRUEBA DE AKAIKE $(A I C)$ & PRUEBA DE SCHWARZ (BIC) \\
\hline LOGIT & 163.6993 & 183.8671 \\
\hline PROBIT & 162.8073 & 182.975 \\
\hline
\end{tabular}

Fuente:Elaboración propia a partir de las encuestas realizadas.

Datos Obtenidos al correr el modelo en Stata. 


\section{Anexo 9. Tabla de Bondad de Ajuste}

\begin{tabular}{|c|c|}
\hline MODELO PROBIT & SALARIOS DE EFICIENCIA \\
\hline No de observaciones & 213 \\
\hline LR chi2(5) & 141.04 \\
\hline Prob >chi2 & 0.0000 \\
\hline Log likelihood & -75.403628 \\
\hline Pseudo R2 & 0.4833 \\
\hline \multicolumn{2}{|c|}{ Capacidad de predicción } \\
\hline Chi2(5) Test de Wald \\
\hline Prob>chi2 & 77.57 \\
\hline
\end{tabular}

Fuente:Elaboración propia a partir de las encuestas realizadas. Datos Obtenidos al correr el modelo en Stata. 


\section{Anexo 10. Matriz de Clasificación}

\begin{tabular}{|c|c|c|}
\hline Sensitivity & $\operatorname{Pr}(+\mid D)$ & $84.17 \%$ \\
\hline Specificity & $\operatorname{Pr}(-\mid \sim D)$ & $78.49 \%$ \\
\hline Correctly classified & & $81.69 \%$ \\
\hline
\end{tabular}

Fuente:Elaboración propia a partir de las encuestas realizadas. Datos Obtenidos al correr el modelo en Stata. 


\section{Anexo 11. Curva ROC (Receiver Operating Characteristic)}

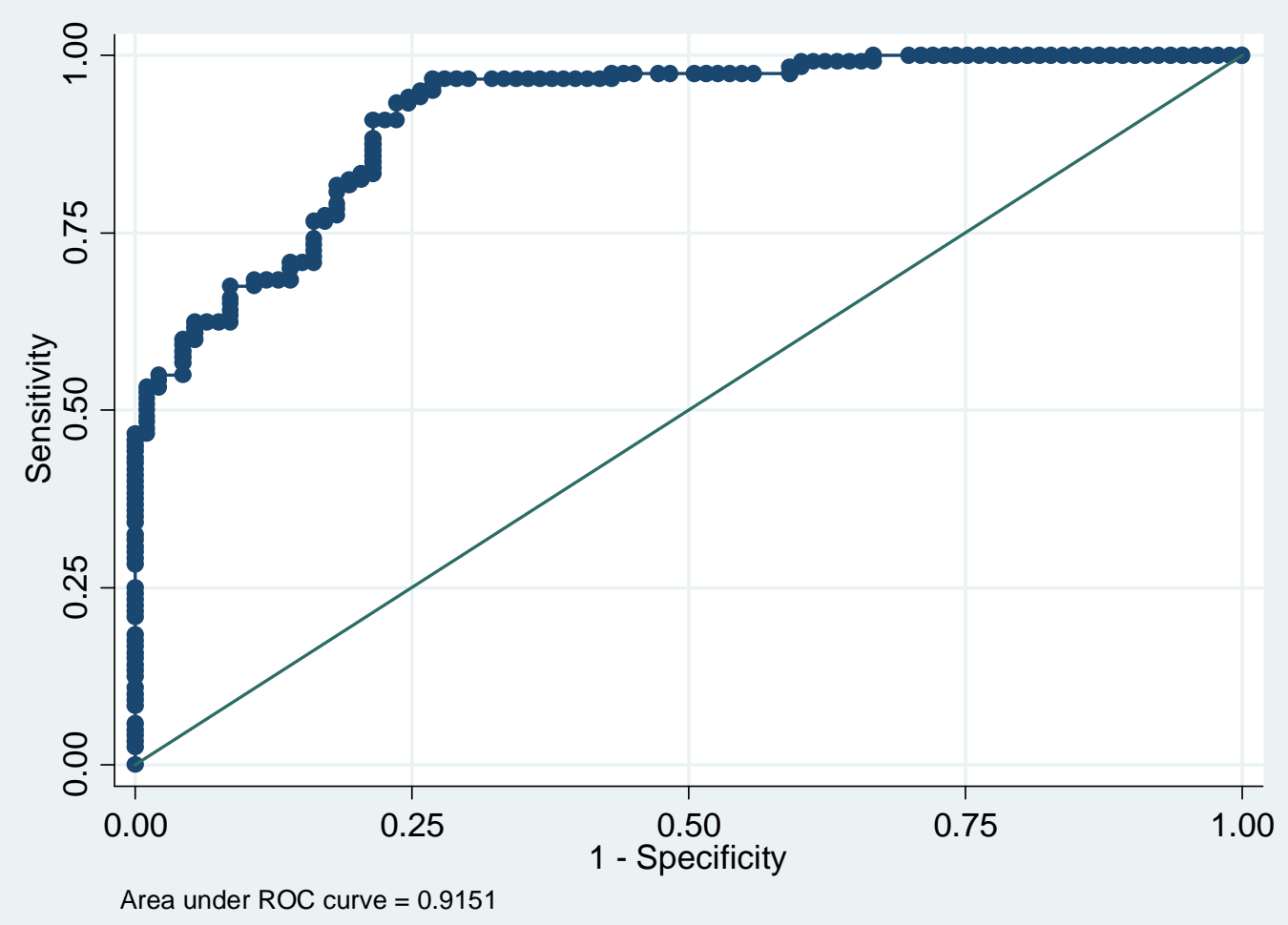

Fuente:Elaboración propia a partir de las encuestas realizadas.

Datos Obtenidos al correr el modelo en Stata. 


\section{Anexo 12. Efectos Marginales del Modelo}

Marginal effects after probit

$\mathrm{y}=\operatorname{Pr}(\mathrm{se})$ (predict)

$=0.74090805$

\begin{tabular}{|c|c|c|c|c|c|c|}
\hline Variable & e $d y / d x$ & Std. Err. & z & $P>|z|$ & [ 95\% C.I. ] & $x$ \\
\hline S & | . .0210089 & .01019 & 2.06 & 0.039 & $.001035 \quad .040983$ & 3.89437 \\
\hline | & | 4.344397 & 1.67344 & 2.60 & 0.009 & 1.064527 .62427 & .032527 \\
\hline$q$ & | -8.534685 & 2.01918 & -4.23 & 0.000 & $-12.4922 \quad-4.57716$ & .044836 \\
\hline co* $^{*}$ & | - -.3534178 & .13106 & -2.70 & 0.007 & $-.61029 \quad-.096545$ & .234742 \\
\hline e & | . .0663948 & .00652 & 10.19 & 0.000 & .053621 .079168 & 41.2575 \\
\hline
\end{tabular}

$\left.{ }^{*}\right) \mathrm{dy} / \mathrm{dx}$ is for discrete change of dummy variable from 0 to 1

Fuente: Stata 


\section{BIBLIOGRAFIA}

Akerlof, George A. \& Yellen, Janet L. (1990). The Fair Wage-Effort Hypothesis and Unemployment. The Quarterly Journal of Economics, Vol. 105, No. 2, pp. 255283.

Aktiva. (2015). El Desempeño Del Sector Bananero Colombiano. Estudios sectoriales. Recuperado de http://aktiva.com.co/app/webroot/blog/ Estudios\%20sectoriales/2015/sector\%20bananero_colombiano_mayo_2015 .pdf.

Albán, Álvaro. (2011). Reforma y Contrarreforma Agraria en Colombia.Revista de Economía Institucional, vol. 13, n.ำ 24, pp. 327-356.

Arango, Luis Eduardo; Herrera, Paula \& Posada, Carlos Esteban. (2007). El salario mínimo: aspectos generales sobre los casos de Colombia y otros países. Borradores de Economía No.436. Banco de la República.

Arango, Luis Eduardo \& Posada, Carlos Esteban. (2002). La participación laboral en Colombia. Borrador de Economía 217. Banco de la República. Agosto.

Augura. (1987). Información Laboral.

Augura. (1993). Negociación Colectiva de Trabajo 1993 - 1995.

Augura. (1998). Acuerdos Suscritos Entre Productores Bananeros de la Zona de Urabá y Sintrainagro en el Proceso de Negociación Colectiva de Trabajo $1998-2000$.

Augura. (2015). Acuerdos Generales 2015 - 2017. 
Augura. (2015). Coyuntura Bananera 2014. Recuperado de http://spiderdigital marketing.com/augura/wp-content/uploads/2015/08/coyuntura_2014.pdf.

Augura, Sac \& Sena. (2000). Acuerdos Generales Suscritos Entre Productores Bananeros de la Zona de Urabá y Sintrainagro en el Proceso de Negociación Colectiva de Trabajo 2000-2002.

Augura \& Sintrainagro. (2002). Proceso de Negociación Colectiva de Trabajo Acuerdos Generales Suscritos Entre Productores Bananeros de la Zona de Urabá y Sintrainagro 2002 - 2004.

Augura \& Sintrainagro. (2004). Negociación Colectiva. Recopilación Acuerdos Generales 2004 - 2009

Augura \& Sintrainagro. (2009). Negociación Colectiva Vigencia 2009-2011.

Augura \& Sintrainagro. (2011). Negociación Colectiva Vigencia 2011-2013.

Augura \& Sintrainagro. (2013). Negociación Colectiva Vigencia 2013-2015.

Benavides, Elcira Solano \& Navarro, Gabriel. (2012). Remuneración salarial eficiente en la educación superior en Colombia. Economía, XXXVII, 33, pp. 43-63.

Bose, Gautam (1996). Agrarian efficiency wages in a dual economy. Journal of Development Economics Vol. 49, pp. 371-386.

Bulkley,George \&Myles, Gareth D. (1996). Trade Unions, Efficiency Wages, and Shirking. Oxford Economic Papers, New Series, Vol. 48, No.1 (Jan., 1996), pp. 75-88. 
Burkhauser, Richard V.\& Sabia, Joseph J. (2007) The Effectiveness Of Minimum Wage Increases In Reducing Poverty: Past, Present, And Future. Contemporary Economic Policy, Volume 25, Issue 2, pp. 262-281, April.

Calvo, Guillermo A. (1979).Fiscal policy, welfare, and employment with perfect foresight. Journal of Macroeconomics, Elsevier, vol. 1(2), pp. 149-166.

Calvo, Guillermo A \& Wellisz, Stanislaw. (1979). Hierarchy, Ability, and Income Distribution. Journal of Political Economy, University of Chicago Press, vol. 87(5), pp. 991-1010, October.

Camargo, Astrid. (2014). Estudio de la Economía Informal en Villavicencio con Enfoque Neoestructural. Tesis de Maestría, Universidad santo Tomás, Bogotá Colombia, pp. 77-78.

Caraballo Pou, Ma Ángeles. (1996). Salarios, productividad y empleo: la hipótesis de los salarios de eficiencia.Cuadernos de Estudios Empresariales, No. 06. Servicio de Publicaciones UCM, Madrid.

CEPAL. (1988). Agroindustria y pequeña agricultura: vínculos, potencialidades y oportunidades comerciales. Oficina Regional para América Latina y el Caribe de la FAO y Sociedad Alemana de Cooperación Técnica (GTZ) (1998). № de venta S.98.II.G.4 (LC/G.2007-P). Naciones Unidas, Santiago de Chile.

Desormeaux R, Nicolás. (2010).Salarios de Eficiencia y Productividad. Universidad Técnica Federico Santa María. Recuperado de http://www.ceas.usm.cl/docu mentos/Estudios/Desempleo/Documento\%20de\%20Trabajo\%20-\%20Salari os\%20de\%20Eficiencia\%20y\%20Productividad.pdf. 
Eaton, B Curtis \& White, William D. (1982). Agent Compensation and the Limits of Bonding. Economic Inquiry, Western Economic Association International, vol. 20 (3), pp. 330-43, July.

Enchautegui, María E. (2015). Módulo de estudio sobre Modelos Probit y Logit, Departamento de Economía, Universidad de Puerto Rico, Recinto de Río Piedras. Recuperado de http://economia.uprrp.edu/notas\%20de\%20clase\% 207.pdf.

González García, Carlos Enrique. (2008). Los salarios de eficiencia, una vía paraaccionar positivamente sobre la productividad del trabajo en Cuba. Tesis en opción al Grado de Master en Economía. Facultad de Economía, Universidad de La Habana.

Gujarati, Damodar n. \& Porter, Dawn C. (2010). Econometría. Editorial McGraw Hill; 5ta edición.

Hernández Díaz, Gustavo (2008).Salario mínimo, mercado laboral y política económica. Universidad Santo Tomás, Revista Cife No 13, pp. 335-352.

Hernández Sampieri, Roberto;Fernández Collado, Carlos \& Baptista Lucio, Pilar. (2006).Metodología de la investigación. Cuarta edición. Editorial McGraw Hill.

Iregui, Ana María; Melo, Ligia Alba \& Ramírez, María Teresa. (2010). Incrementos y rigideces de los salarios en Colombia: Un estudio a partir de una encuesta a nivel de firma. Revista de Economía del Rosario. Vol.13, No.2, pp. 279-311.

Jouvin, Jean-Jacques. (1966). La Agricultura en el Reciente Desarrollo de América Latina. Desarrollo Económico, Vol. 5, No. 20, pp. 449-492. 
Keynes, John Maynard (1936). Teoria General de la Ocupación, el Interés y el Dinero. Fondo de Cultura Económica.

Leibenstein, Harvey. (1957). Economic Backwardness and Economic Growth. The American Economic Review Vol. 48, No. 5 (Dec., 1958), pp. 1020-1023.

López Hugo. (2001), Mercado laboral colombiano: funcionamiento y barreras institucionales, Informe de consultoría elaborado para el Banco Mundial, mayo.

López Macías, Francisco Javier \& Castrillón, Pepe. (2007). La Agroindustria en Colombia. Teoría económica y algunas experiencias latinoamericanas relativas a la agroindustria. Recuperado dewww.eumed.net/libros/ 2007b/304/.

Marjit, Sugata; Kar, Saibal \&Acharyya, Rajat. (2007). Agricultural prospects and informal wage in general equilibrium. Economic Modelling 24 2007,pp.3803850.

Moretti, Enrico \& Perloff, Jeffrey M. (2002). Efficiency Wages, Deferred Payments, and Direct Incentives in Agriculture. American Journal of Agricultural Economics, Vol. 84, No. 4, pp. 1144-1155.

Ortíz, Carlos Humberto; Uribe, José Ignacio \&García, Gustavo Adolfo. (2007). Informalidad Y Subempleo: Un Modelo Probit Bivariado Aplicado Al Valle Del Cauca. Recuperado de sociedadyeconomia.univalle.edu.co/index.php/sye/ article/.../145/153.

Pulido San Roman, Antonio \& Pérez García, Julián. (2001). Modelos Econométricos. Ediciones Pirámide. 
Posso,Christian (2010). Incrementos del salario mínimo legal: un análisis de los costos y beneficios sobre los hogares colombianos en el año 2006. Borradores de economía 595. Banco de la República.

Ramírez, Margarita \& Henao, Ricardo. (1987).Economía Bananera Y Movimiento Sindical En Colombia. Recuperado de: http://www.flacsoandes.edu.ec/ biblio/catalog/resGet.php?resld=25180

Ricardo, David (1817). Principios de Economía Política y Tributación. Fondo de Cultura Económica.

Riveros, Luis A. (1991). El enfoque de Salarios de Eficiencia y el Ajuste Económico en Países en Desarrollo. Revista Desarrollo y Sociedad. pp.25-46.

Rodríguez, Mauricio. (2009). Salarios de Eficiencia en un Modelo de Crecimiento Económico. Serie Documentos de TrabajoNo.62.

Romer, David (2006). Macroeconomía Avanzada. Tercera Edición. Editorial McGraw Hill.

Rosales Alvarez, Ramon Antonio; Perdomo Calvo, Jorge Andres; Morales Torrado, Carlos Andres \& Urrego Mondragón, Jaime Alejandro. (2010). Fundamentos de Econometría Intermedia: Teoría y Aplicaciones. Apuntes de Clase Cede. Universidad de los Andes.

Salas Durazo, Iván Alejandro \& Murillo García, Favio. (2009). Salarios de eficiencia y el desempleo en México. Observatorio de la Economía Latinoamericana № 123. 
Shapiro, Carl \& Stiglitz, Joseph E. (1984).Equilibrium Unemployment as a Worker Discipline Device. The American Economic Review, Vol. 74, No. 3, pp. 433444.

Sena. (2003). Caracterización Subsector Bananero en Colombia.

Solow, Robert M. (1979). Another possible source of wage stickiness.Journal of Macroeconomics, Elsevier, vol. 1, pp. 79-82.

Torres, Jose Fernando \& Guarnizo, Carlos Jose. (2004). En la Búsqueda del Mejoramiento de las Relaciones Laborales. Proyecto OIT/USDOLpp. 27-38.

Villar, Leonardo; Ramírez, Juan Mauricio \& Malagón, Jonathan. (2013). Editorial: Las Diferencias Salariales Entre Sectores Económicos En Colombia. Informe Mensual del Mercado Laboral. Fedesarrollo.

Viloria De la Hoz, Joaquín. (2009). Historia Empresarial Del Guineo: Empresas y empresarios bananeros en el departamento del Magdalena, 1870-1930. Cuadernos de Historia Económica y Empresarial. Banco de la República, Sucursal Cartagena.No.23.

Wooldridge, Jeffrey M. (2010). Introducción a la econometría, Un enfoque moderno. Cengage Learning Editores, S.A. 